\title{
Physiological role of cytoplasmic fatty acid-binding protein for the cardiac myocyte
}

Citation for published version (APA):

Schaap, F. G. (1999). Physiological role of cytoplasmic fatty acid-binding protein for the cardiac myocyte. [Doctoral Thesis, Maastricht University]. Universiteit Maastricht. https://doi.org/10.26481/dis.19990701fs

Document status and date:

Published: 01/01/1999

DOI:

10.26481/dis.19990701fs

Document Version:

Publisher's PDF, also known as Version of record

\section{Please check the document version of this publication:}

- A submitted manuscript is the version of the article upon submission and before peer-review. There can be important differences between the submitted version and the official published version of record.

People interested in the research are advised to contact the author for the final version of the publication, or visit the DOI to the publisher's website.

- The final author version and the galley proof are versions of the publication after peer review.

- The final published version features the final layout of the paper including the volume, issue and page numbers.

Link to publication

\footnotetext{
General rights rights.

- You may freely distribute the URL identifying the publication in the public portal. please follow below link for the End User Agreement:

www.umlib.nl/taverne-license

Take down policy

If you believe that this document breaches copyright please contact us at:

repository@maastrichtuniversity.nl

providing details and we will investigate your claim.
}

Copyright and moral rights for the publications made accessible in the public portal are retained by the authors and/or other copyright owners and it is a condition of accessing publications that users recognise and abide by the legal requirements associated with these

- Users may download and print one copy of any publication from the public portal for the purpose of private study or research.

- You may not further distribute the material or use it for any profit-making activity or commercial gain

If the publication is distributed under the terms of Article $25 \mathrm{fa}$ of the Dutch Copyright Act, indicated by the "Taverne" license above, 


\title{
PHYSIOLOGICAL ROLE OF CYTOPLASMIC FATTY ACID-BINDING PROTEIN FOR THE CARDIAC MYOCYTE
}

\author{
DE FYSIOLOGISCHE ROL VAN CYTOPLASMATISCH \\ VETZUURBINDEND EIWIT VOOR DE CARDIOMYOCYT
}

\section{PROEFSCHRIFT}

ter verkrijging van de graad van doctor aan de Universiteit Maastricht, op gezag van de Rector Magnificus, Prof. dr. A.C. Nieuwenhuijzen Kruseman, volgens het besluit van het College van Decanen, in het openbaar te verdedigen op donderdag 1 juli 1999 om 12.00 uur

door

Franciscus Gerardus Schaap geboren op 11 juni 1968 te Zaandam 


\section{Promotor:}

Prof. dr. G.J. van der Vusse

\section{Co-promotor:}

Dr. J.F.C. Glatz

\section{Beoordelingscommissie:}

Prof. dr. F.C.S. Ramaekers (voorzitter)

Prof. dr. A. Bonen (Universiteit van Waterloo, Canada)

Prof. dr. R.S. Reneman

Prof. dr. F. Spener (Universiteit van Münster, Duitsland)

Prof. dr. R.F.A. Zwaal

Financial support by the Netherlands Heart Foundation for the publication of this thesis is gratefully acknowledged.

ISBN 90-9012786-0

(C) F.G. Schaap, Maastricht 1999 
"Anyone whose disposition leads him to attach more weight to unexplained difficulties than to the explanation of a certain number of facts will certainly reject the theory."

Charles Darwin, THE ORIGIN OF SPECIES by Means of natural selection

"Vreemde regelingen en grappige oplossingen zijn het bewijs van de evolutie; paden die een verstandige God nooit zou betreden, maar die een natuurlijk, door de geschiedenis beteugeld proces noodgedwongen volgt."

Stephen Jay Gould, DE dUIM VAN DE PANDA OVER EVOLUTIE \& ONTWIKKELING 


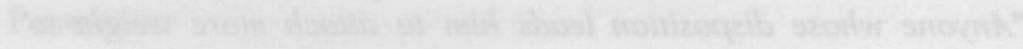

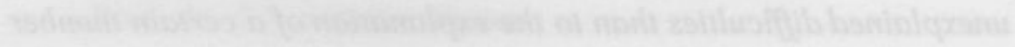

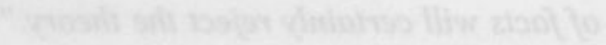

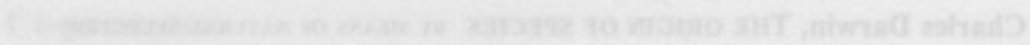

a

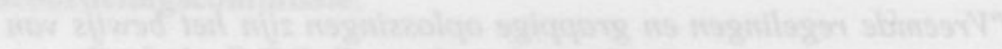

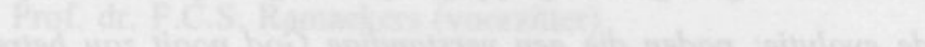

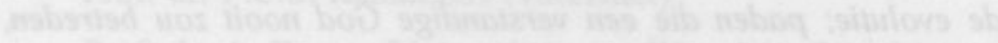

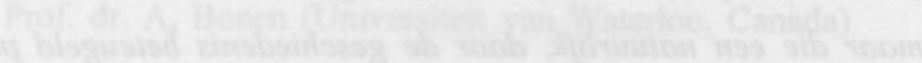

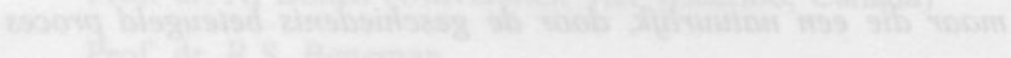

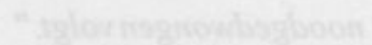

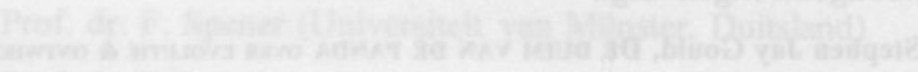

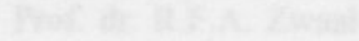

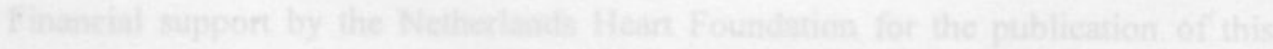

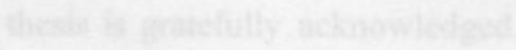

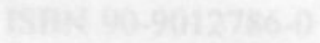

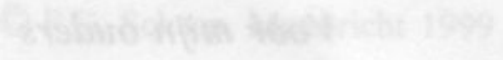




\section{CHAPTER 1}

General introduction $\ldots \ldots \ldots \ldots \ldots \ldots \ldots \ldots, \ldots \ldots \ldots$

\section{CHAPTER 2}

Fatty acid-binding proteins in the heart $\ldots \ldots \ldots \ldots \ldots \ldots \ldots \ldots \ldots \ldots \ldots$

\section{CHAPTER 3}

Evolution of the family of intracellular lipid binding proteins in vertebrates

\section{CHAPTER 4}

New methodologies

One-step purification of rat heart-type fatty acid-

binding protein expressed in Escherichia coli

A method for isolating adult mouse cardiac myocytes

\section{CHAPTER 5}

Molecular cloning of fatty acid-transport protein cDNA from rat

\section{CHAPTER 6}

Impaired long-chain fatty acid utilization by cardiac myocytes

from mice lacking the heart-type fatty acid-binding protein gene

\section{CHAPTER 7}

General discussion

Summary

Samenvatting

Publications

Curriculum vitae

Dankwoord 


\section{AbBreviations}

aa

amino acid(s)

ABP albumin binding protein

ACBP acyl-CoA binding protein

ACS acyl-CoA synthetase

bp

base pair(s)

BSA bovine serum albumin

CoA coenzyme A

CRABP cellular retinoic acid-binding protein

CRBP cellular retinol-binding protein

ELISA enzyme-linked immunosorbent assay

FA fatty acid

FABP fatty acid-binding protein

$\mathrm{FABP}_{\mathrm{pm}} \quad$ plasmalemmal FABP

FAT fatty acid translocase

FATP fatty acid-transport protein

IEF isoelectric focusing

iLBP intracellular lipid binding protein

IPTG isopropyl- $B$-D-thiogalactoside

$K_{\mathrm{a}} \quad$ nonsynonymous substitution rate

$\mathrm{kb} \quad$ kilo base pairs

$K_{\mathrm{d}}$

$K_{\text {s }}$

apparent dissociation constant

synonymous substitution rate

LCFA long-chain fatty acid

$\mathrm{M}_{\mathrm{r}} \quad$ relative mass

mya millions of years ago

nt nucleotide(s)

PAGE polyacrylamide gel electrophoresis

PBS phosphate-buffered saline

PCR polymerase chain reaction

RT reverse transcription

SDS sodium dodecylsulphate 


\section{Chapter 1}

GENERAL INTRODUCTION 


\section{General and metabolic aspects of the heart}

The flow of blood in the circulation supplies organs with oxygen and nutrients, and removes metabolic waist products and heat produced by these organs ${ }^{8}$. The movement of blood through the vasculature is accomplished by the pumping action of the heart. Given its pivotal role in supplying organs -including itself- with blood, adequate functioning of the heart is of vital importance. Cardiac tissue is composed of a variety of different cell types ${ }^{11}$. Endothelial cells make up the blood vessels, nerve cells are involved in generation and conduction of electric stimuli in the heart, and fibroblasts provide a collagenous framework keeping cardiac substructures in place. However, the main cell type in the heart, which accounts for more than half of the heart's weight, are muscle cells. Cardiac myocytes provide the mechanical force to sustain the circulatory flow ${ }^{8,11}$.

The energy required for this process is obtained by oxidation of substrates which are extracted from the coronary vasculature. In this respect, cardiac myocytes are omnivorous as they are able to utilize several substrates for their energy production ${ }^{16}$. Under conditions when the workload of the heart is normal, i.e. when the body is in rest or undergoes non-exhaustive physical exercise, long-chain fatty acids (LCFAs) are the preferred energy substrate accounting for up to $70 \%$ of the ATP produced ${ }^{10,16}$. During strenuous exercise, the contribution of LCFAs to energy production diminishes and other substrates, such as lactate and (endogenous) glycogen, are being consumed ${ }^{7,16}$.

Because of their hydrophobic nature, LCFAs have limited solubility in aqueous environments. This property could compromise efficient utilization of these compounds by tissues had not proteins capable of binding LCFAs evolved. For instance, bulk movement of LCFAs in extracellular surroundings like blood and the interstitial fluid is accomplished by albumin. This abundant plasma protein reversibly binds LCFAs and thus takes care of their delivery to tissues ${ }^{16}$.

Uptake and metabolism of LCFAs by cardiac myocytes is a complex process which is incompletely understood (Figure 1.1). Albumin transports LCFAs in the vascular compartment. By an unresolved mechanism, LCFAs dissociate from albumin and pass the capillary vessel wall (endothelium) to enter the interstitial space for reassociation with albumin ${ }^{16,17}$. Subsequent uptake of LCFAs by cardiac myocytes is thought to be facilitated by both membrane-associated and intracellular fatty acidbinding proteins (FABPs) $)^{1,4,6,14,15}$.

Once translocated across the sarcolemma, metabolism of LCFAs takes place at subcellular sites like the mitochondria and sarcoplasmic reticulum. Cytoplasmic hearttype FABP (H-FABP) is thought to transport LCFAs to these organelles ${ }^{6}$. Under normal workload conditions, mitochondrial oxidation of LCFAs provides the majority of energy required for myofibrillar contractions and other cellular processes ${ }^{10,16}$. LCFAs delivered to the sarcoplasmic reticulum are esterified and subsequently incorporated into triacylglycerols and phospholipids ${ }^{16}$. 


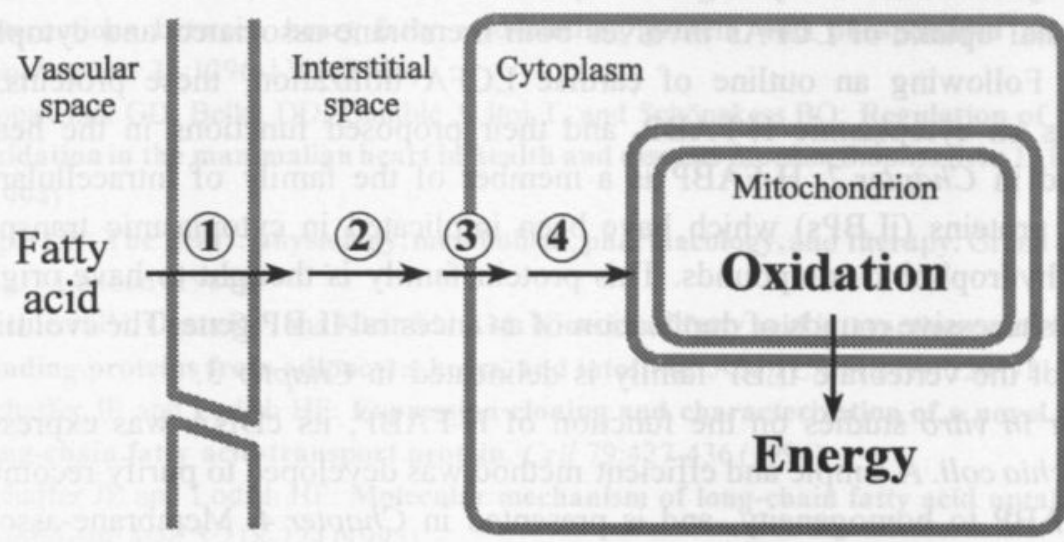

Endothelium

Cardiac myocyte

Figure 1.1 Simplified scheme for myocardial utilization of long-chain fatty acids (LCFAs) which requires passage of LCFAs over the capillary wall (1), movement of LCFAs through the interstitial fluid (2), translocation of LCFAs across the plasma membrane of the cardiac myocyte (3), and cytoplasmic transport of LCFAs to sites of metabolic conversion (4). Soluble and membraneassociated proteins are likely to be involved in each of these steps.

H-FABP is abundantly expressed in cardiac myocytes and is generally assumed to facilitate cellular uptake and cytoplasmic trafficking of LCFAs $s^{6,18}$. In addition, H-FABP might protect cardiac myocytes from adverse effects of LCFAs under conditions when their cellular oxidation is impaired. Such buffering function may be meaningful in ischemic myocardium where intracellular accumulation of LCFAs and their CoA esters has been associated with inhibition of certain enzymes and loss of membrane integrity ${ }^{16}$.

\section{Aim of the study}

$\mathrm{H}-\mathrm{FABP}$ has been intensively studied in the past twenty years, resulting in a wealth of information on for instance protein structure ${ }^{2}$, mechanism and kinetics of binding and release of ligands ${ }^{2,9,12}$, and factors affecting H-FABP gene expression ${ }^{3,5,6,19}$. The combined findings from biochemical characterization, in vitro experiments, and theoretical considerations, suggest an important role for $\mathrm{H}-\mathrm{FABP}$ in cellular utilization of LCFAs. However, direct evidence for involvement of H-FABP in cytoplasmic transport of LCFAs has not been obtained yet. The studies described in this thesis aimed at determining the physiological significance of H-FABP for the cardiac myocyte. 


\section{Outline of the thesis}

Myocardial uptake of LCFAs involves both membrane-associated and cytoplasmic FABPs. Following an outline of cardiac LCFA utilization, these proteins, with emphasis on cytoplasmic H-FABP, and their proposed functions in the heart are discussed in Chapter 2. H-FABP is a member of the family of intracellular lipid binding proteins (iLBPs) which have been implicated in cytoplasmic transport of various hydrophobic compounds. This protein family is thought to have originated through successive rounds of duplication of an ancestral ILBP gene. The evolutionary history of the vertebrate iLBP family is delineated in Chapter 3.

For in vitro studies on the function of H-FABP, its cDNA was expressed in Escherichia coli. A simple and efficient method was developed to purify recombinant rat H-FABP to homogeneity, and is presented in Chapter 4. Membrane-associated proteins, such as fatty acid-transport protein (FATP) ${ }^{13}$, and cytoplasmic H-FABP may cooperate in myocardial uptake of LCFAs. Rat FATP cDNA was cloned in order to enable studies on its role in cardiac LCFA uptake and its possible interaction with H-FABP (Chapter 5). The physiological role of H-FABP in myocardial LCFA utilization was studied using H-FABP knock-out mice. For these studies, a method was developed for isolating myocytes from adult mice hearts (Chapter 4). Isolated cardiac myocytes were then used to determine cellular uptake and oxidation of fatty acids by quiescent and contracting cells as detailed in Chapter 6 . A general discussion communicating new findings, and recommendations for future research are given in Chapter 7. A brief summary concludes this thesis.

\section{References}

1) Abumrad NA, Harmon C, and Ibrahimi A: Membrane transport of long-chain fatty acids. Evidence for a facilitated process. J Lipid Res 39:2309-2318(1998)

2) Banaszak L, Winter N, Xu Z, Bernlohr DA, Cowan S, and Jones TA: Lipid binding proteins: a family of fatty acid and retinoid transport proteins. Adv Protein Chem 45:89-151 (1994)

3) Bernlohr DA, Simpson MA, Hertzel AV, and Banaszak LJ: Intracellular lipid binding proteins and their genes. Anmu Rev Nutr 17:277-303 (1997)

4) Bonen A, Luiken JJFP, Liu S, Dyck DJ, Kiens B, Kristiansen S, Turcotte LP, van der Vusse GJ, and Glatz JFC: Palmitate transport and fatty acid transporters in red and white muscles. Am J Physiol 275:E471-478 (1998)

5) Börchers T and Spener F: Fatty acid-binding proteins. Curr Top Membr 40:261-294 (1994)

6) Glatz JFC and van der Vusse GJ: Cellular fatty acid-binding proteins: their function and physiological significance. Prog Lipid Res 35:243-282 (1996)

7) Goodwin GW, Ahmad F, Doenst T, and Taegtmeyer H: Energy provision from glycogen, glucose, and fatty acids on adrenergic stimulation of isolated working rat hearts. $\mathrm{Am} \mathrm{J}$ Physiol 274:H1239-1247(1998)

8) Guyton AC: Textbook of Medical Physiology. ( $7^{\text {th }}$ edition). WB Saunders Company Philadelphia (1991) 
9) Herr FM, Aronson J, and Storch J: Role of portal region lysine residues in electrostatic interactions between heart fatty acid-binding protein and phospholipid membranes. Biochemistry 35:1296-1303(1996)

10) Lopaschuk GD, Belke DD, Gamble J, Itoi T, and Schönekess BO: Regulation of fatty acid oxidation in the mammalian heart in health and disease. Biochim Biophys Acta 1213:263-276 (1994)

11) Opie LH: The heart: physiology, metabolism, pharmacology, and therapy. Grune \& Stratton Inc. - London (1984)

12) Richieri GV, Ogata RT, and Kleinfeld AM: Kinetics of fatty acid interactions with fatty acidbinding proteins from adipocyte, heart, and intestine. J Biol Chem 271:11291-11300(1996)

13) Schaffer JE and Lodish HF: Expression cloning and characterization of a novel adipocyte long-chain fatty acid-transport protein. Cell 79:427-436(1994)

14) Schaffer JE and Lodish HF: Molecular mechanism of long-chain fatty acid uptake. Trends Cardiovasc Med 5:218-224 (1995)

15) Stremmel W: Fatty acid uptake by isolated rat heart myocytes represents a carrier-mediated transport process. J Clin Invest 81:844-852 (1988)

16) van der Vusse GJ, Glatz JFC, Stam HC, and Reneman RS: Fatty acid homeostasis in the normoxic and ischemic heart. Physiol Rev 72:881-940 (1992)

17) van der Vusse GJ, Glatz JFC, van Nieuwenhoven FA, Reneman RS, and Bassingthwaighte JB: Transport of long-chain fatty acids across the muscular endothelium. Adv Exp Med Biol 441:181-191 (1998)

18) Veerkamp JH: Fatty acid transport and fatty acid-binding proteins. Proc Nutr Soc 54:23-37 (1995)

19) Veerkamp JH and Maatman RG: Cytoplasmic fatty acid-binding proteins: their structure and genes. Prog Lipid Res 34:17-52 (1995) 


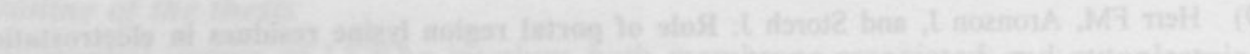

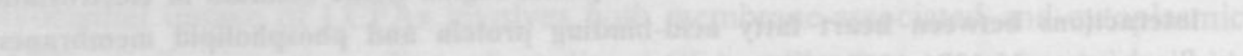
-

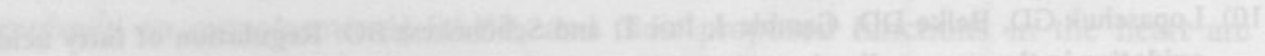

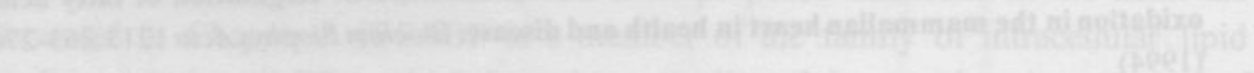
2.

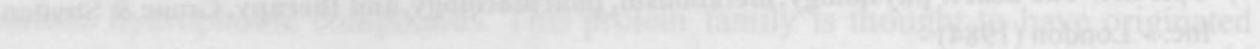

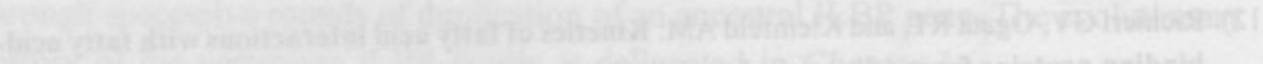

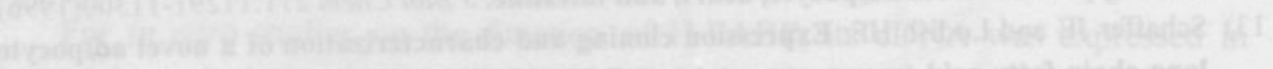

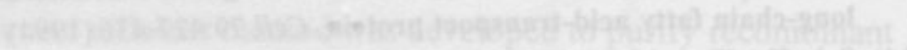

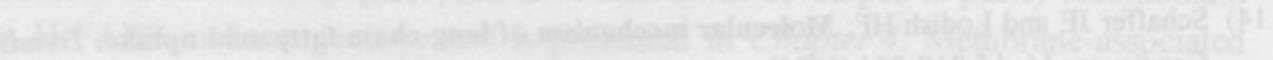

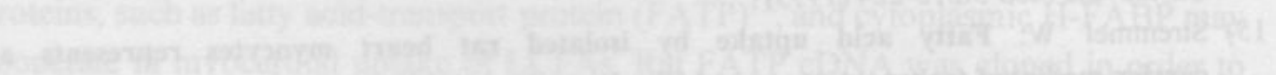
-

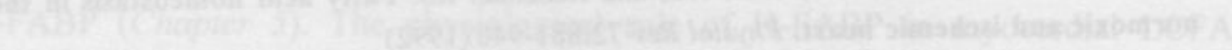

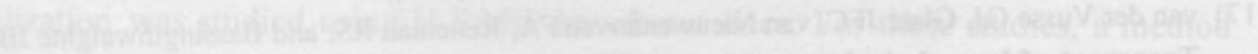

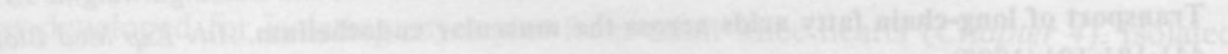

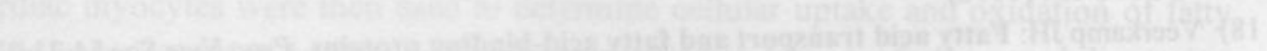
ant 


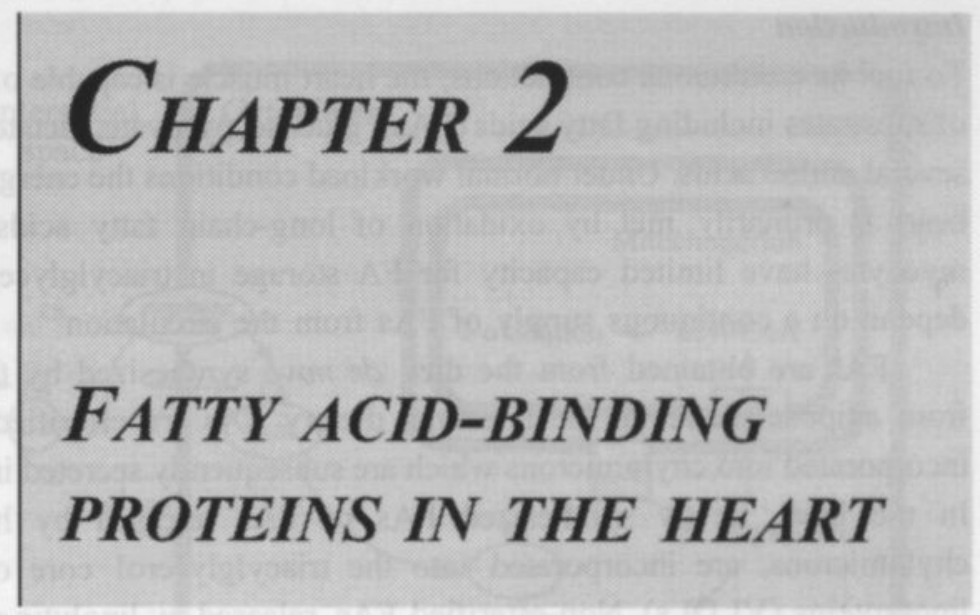

Adapted from:

Schaap FG, van der Vusse GJ, and Glatz JFC: Mol Cell Biochem 180:43-51 (1998) 
Long-chain fatty acids (LCFAs) are important fuel molecules for the heart, their oxidation in mitochondria providing the bulk of energy required for cardiac functioning. The low solubility of LCFAs in aqueous solutions impairs their cellular transport. However, cardiac tissue contains several proteins capable of binding LCFAs non-covalently. These fatty acid-binding proteins (FABPs) are thought to facilitate both cellular uptake and intracellular transport of LCFAs. Myocardial uptake of LCFAs involves both passive diffusion and carrier-mediated translocation mechanisms, the latter consisting of one or more membrane-associated FABPs. Intracellular transport of LCFAs towards sites of metabolic conversion is most likely accomplished by cytoplasmic FABPs. In this chapter, the roles of membraneassociated and cytoplasmic FABPs in cardiac fatty acid metabolism under (patho)physiological circumstances are discussed.

\section{Introduction}

To fuel its continuous contractions, the heart muscle is capable of oxidizing a variety of substrates including fatty acids (FAs), glucose, pyruvate, lactate, ketone bodies, and several amino acids. Under normal workload conditions the energy requirement of the heart is primarily met by oxidation of long-chain fatty acids (LCFAs). Cardiac myocytes have limited capacity for FA storage in triacylglycerols and, therefore, depend on a continuous supply of FAs from the circulation ${ }^{83}$.

FAs are obtained from the diet, de novo synthesized by the liver or released from adipose tissue. In the intestine, dietary FAs are esterified with glycerol and incorporated into chylomicrons which are subsequently secreted into the bloodstream. In the liver, newly synthesized FAs or FAs released by hepatic lipolysis of chylomicrons, are incorporated into the triacylglycerol core of very-low density lipoproteins (VLDLs). Non-esterified FAs, released by lipolytic processes in adipose tissue, are bound to albumin which has several high-affinity binding sites for LCFAs. From a physiological point of view these processes are of utmost importance because the low solubility of LCFAs in aqueous environments necessitates the presence of transport proteins (e.g. albumin) or transport vehicles (e.g. VLDLs) to allow their supply to tissues in sufficient quantities. LCFAs transported in the esterified form are made available to parenchymal cells after lipolytic action of lipoprotein lipase (LPL) on the triacylglycerol core of these transport vehicles. LPL is an enzyme associated with the glycocalyx on the luminal surface of the capillary endothelium, including that of the heart ${ }^{83}$.

Cardiac muscle is very efficient in extracting FAs from the vascular fluid, $50-70 \%$ of circulating FA can be taken up during a single capillary passage ${ }^{83}$. Similar extraction ratios are observed for lactate, whereas only a relatively minor proportion of glucose is taken up at first passage ${ }^{83}$. Current insight suggests that in addition to 
passive diffusion ${ }^{32}$, a number of (non-enzymatic) proteins participate in the uptake of LCFAs. Among these proteins are membrane-associated and cytoplasmic fatty acidbinding proteins (FABPs). In this chapter, the current knowledge on the functions of FABPs in myocardial LCFA uptake and metabolism is discussed.

\section{Uptake of long-chain fatty acids by the heart}

Cardiac uptake of LCFAs is a complex process requiring passage of several (cellular) barriers (Figure 2.1). The first obstacle met is the endothelial cell layer. The movement of albumin-bound LCFAs through endothelial clefts is impeded by the size of albumin and by tethering of the glycocalyx lining the endothelial clefts ${ }^{9,84}$. Apparently, transport of LCFAs from the vascular to the interstitial compartments takes place through the endothelial cells. This process is poorly understood and might involve albumin-binding proteins (ABPs) which have been identified on the surface of capillary endothelial cells ${ }^{5,69,78}$.

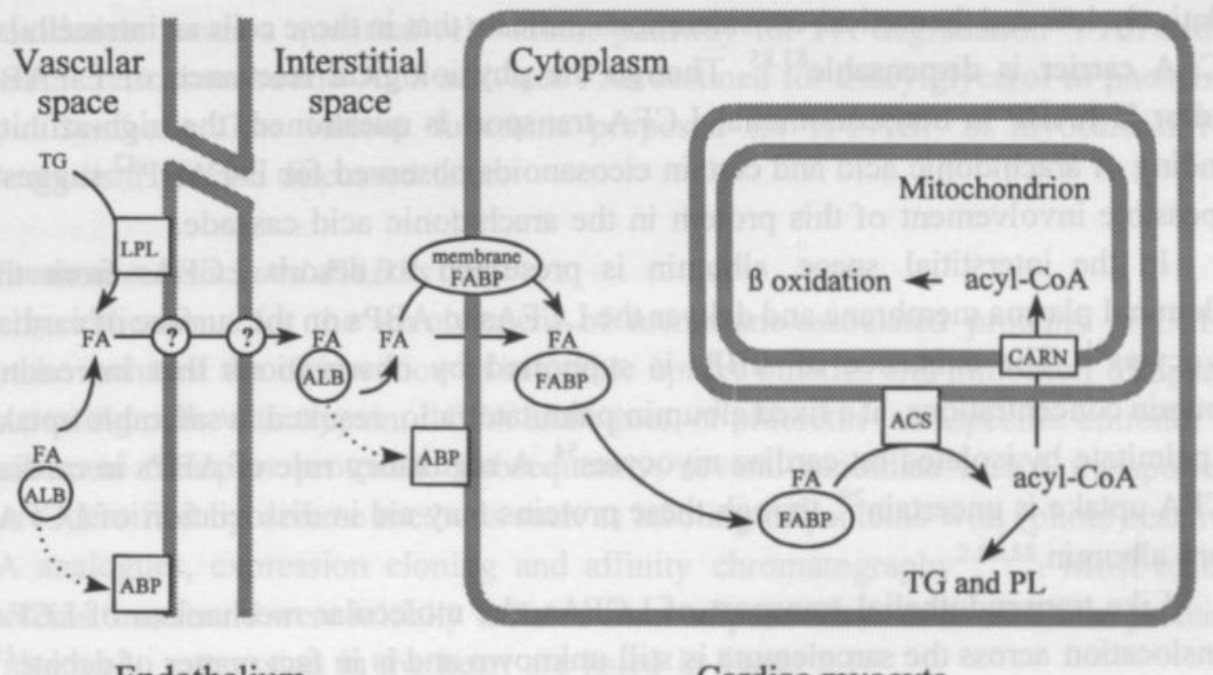

Endothelium

Cardiac myocyte

Figure 2.1 Model for myocardial uptake of LCFAs and subsequent intracellular metabolism. Abbreviations: $A L B=$ albumin, $A B P=$ albumin binding protein, $A C S=$ acyl-CoA synthetase, $C A R N$ $=$ carnitine shuttle, $F A=$ long-chain fatty acid, $F A B P=$ fatty acid-binding protein, $L P L=$ lipoprotein lipase, $P L=$ phospholipid, $T G=$ triacylglycerol. Question marks denote unresolved mechanisms for FA translocation.

ABPs might facilitate transendocytosis of albumin-bound LCFAs although such process appears too slow to explain observed LCFA transport rates ${ }^{84}$. Alternatively, ABPs might enhance the dissociation of LCFAs from albumin. In this respect, ABPs may resemble the membrane receptor mediating transfer of retinol from its carrier in 
plasma to its cytoplasmic recipient, cellular retinol-binding protein ${ }^{77}$. Non-proteinbound LCFAs may be translocated across the endothelial plasma membrane via movement of LCFAs from the outer to the inner membrane leaflet (flip-flop) or by a protein-mediated mechanism. Plasmalemmal $\mathrm{FABP}\left(\mathrm{FABP}_{\mathrm{pm}}\right)$, a peripheral membrane protein, has been implicated in the carrier-mediated transfer of LCFAs across the endothelial cell layer ${ }^{30}$. Passive diffusion of LCFAs via flip-flop was shown to be rapid in model membranes ${ }^{41,102}$, but it is unknown how well this proposed translocation mechanism of LCFAs translates to biological membranes ${ }^{36,68}$. Lateral diffusion of LCFAs within the plasmalemmal leaflets could theoretically transfer LCFAs from the luminal to the abluminal side of the endothelium, but this pathway has been argued to form a negligible transport route ${ }^{84}$.

Once internalized, cytoplasmic FABPs could be involved in shuttling LCFAs from the luminal to the abluminal plasma membrane of the endothelial cell. Two types of FABP are found in cardiac endothelial cells, namely epidermal-type FABP $(\mathrm{E}-\mathrm{FABP})^{55}$ and heart-type FABP (H-FABP) ${ }^{6}$. Expression levels of these proteins are relatively low and theoretical considerations indicate that in these cells an intracellular LCFA carrier is dispensable ${ }^{83,85}$. Though the physiological relevance of E-FABP and/or H-FABP in transendothelial LCFA transport is questioned, the high-affinity binding of arachidonic acid and certain eicosanoids observed for E-FABP ${ }^{42}$ suggests a possible involvement of this protein in the arachidonic acid cascade.

In the interstitial space, albumin is presumed to desorb LCFAs from the abluminal plasma membrane and deliver the LCFAs to ABPs on the surface of cardiac myocytes $^{61}$. The existence of ABPs is supported by observations that increasing albumin concentrations, at a fixed albumin:palmitate ratio, resulted in saturable uptake of palmitate by isolated rat cardiac myocytes ${ }^{54}$. A regulatory role of ABPs in cardiac LCFA uptake is uncertain ${ }^{29}$, though these proteins may aid in dissociation of LCFAs from albumin.

Like transendothelial transport of LCFAs, the molecular mechanism of LCFA translocation across the sarcolemma is still unknown and is in fact matter of debate ${ }^{11}$. Traditionally, it was assumed that LCFAs traverse the phospholipid bilayer by a simple, non-saturable diffusion mechanism ${ }^{32,100}$. The driving force for LCFA transport through the lipid phase of a cell membrane would be the concentration gradient across the cellular membrane and transport rates would, thus, depend on extracellular LCFA levels and intracellular metabolism. The rate-limiting step in this process would be the movement of LCFA from the plasmalemmal to the cytoplasmic leaflet of the bilayer which requires passage of the fatty acid's polar headgroup through the lipid phase. Studies using synthetic vesicles predicted flip-flop rates to be fast enough for protonated LCFAs to sustain high metabolic fluxes ${ }^{41,102}$. Recent studies oppose this view noting that measured flip-flop rates are affected by the diameter and composition of vesicles ${ }^{45,46}$, and that flip-flop rates of natural LCFAs determined in erythrocyte 
ghosts appear insufficient to account for metabolic rates in cells with prominent FA handling ${ }^{47}$.

Evidence is accumulating that myocardial LCFA uptake involves mainly a carrier-mediated, saturable uptake system ${ }^{29,54}$. In resting rat cardiac myocytes this protein-mediated component accounts for $80 \%$ of the palmitate uptake ${ }^{54}$. Several membrane proteins thought to be involved in cellular LCFA uptake have been identified in the heart ${ }^{28,68,88}$. These so-called membrane-associated FABPs will be discussed in more detail in the following section.

After translocation across the sarcolemma, LCFAs are presumably bound to $\mathrm{H}-\mathrm{FABP}$ and delivered to sites of metabolic conversion. Prior to further metabolism, FAs are activated by esterification with $\mathrm{CoA}$, a reaction catalyzed by acyl-CoA synthetase (ACS) which is associated with internal membranes. FAs destined for oxidation are activated by ACS on the mitochondrial outer membrane. The carnitine shuttle promotes subsequent entry of the acyl-moiety of acyl-CoA esters into the mitochondrial matrix where $B$-oxidation takes place. In the heart, peroxisomal $B$-oxidation forms a quantitatively minor pathway for FA degradation ${ }^{83}$. An endoplasmic reticulum-bound ACS activates FAs destined for triacylglycerol or phospholipid synthesis. The various functions proposed for H-FABP in myocardial FA metabolism will be discussed later.

\section{Membrane-associated FABPs}

Early indications for the involvement of membrane-associated proteins in LCFA uptake included the observation of saturable uptake kinetics and inhibition of uptake by treating cells with trypsin, LCFA analogues, or phloretin (an aspecific inhibitor of membrane transport proteins). Subsequently, several candidate LCFA transporters were identified by diverse methods such as labeling of proteins with (photo)reactive FA analogues, expression cloning and affinity chromatography ${ }^{2,68,88}$. Most of the proteins thus found were initially isolated from adipose tissue or liver. Those proteins with known expression in the heart are listed in Table 2.1.

(1) Plasmalemmal FABP $\left(\mathrm{FABP}_{\mathrm{pm}}\right)$, a 43-kDa peripheral membrane protein with possible identity to the mitochondrial isoform of aspartate aminotransferase $(\mathrm{mtAAT})^{76}$, has been identified in numerous cell types including hepatocytes, adipocytes and cardiac myocytes. Antibodies directed against this protein diminished oleate uptake by isolated rat cardiac myocytes with $40 \%$ while having no effect on glucose uptake $^{71}$. Moreover, $3 \mathrm{~T} 3$ fibroblasts transfected with mtAAT cDNA displayed saturable uptake of oleate which was severalfold higher than uptake in mocktransfected cells ${ }^{40}$.

(2) A 60-kDa protein isolated from rat heart sarcolemmal membranes was shown to bind palmitate with high affinity $\left(K_{d}=1.0 \mu \mathrm{M}\right)^{24}$. Unfortunately, no functional data on this protein, which was tentatively called FA receptor (FAR), are available. 
Mass (kDa) (Putative) Localization (Putative) Function

Reference

Extracellular

Albumin

68

circulation, interstitium

plasma LCFA transporter

83

Plasma membrane-associated

\begin{tabular}{|c|c|c|c|c|}
\hline ABP & $18,31,60$ & endothelium, cardiac myocyte & plasmalemmal albumin receptor & 61,78 \\
\hline $\mathrm{FABP}_{\mathrm{pm}}$ & 43 & endothelium, cardiac myocyte & plasmalemmal LCFA transport & 28,30 \\
\hline FAR & 60 & cardiac myocyte & sarcolemmal LCFA transport & 24 \\
\hline FAT & 88 & cardiac myocyte & sarcolemmal LCFA transport & 1 \\
\hline FATP $_{1}$ & 63 & cardiac myocyte & sarcolemmal LCFA transport & 67 \\
\hline $\mathrm{FATP}_{4}$ & 71 & ? & sarcolemmal LCFA transport & 22 \\
\hline
\end{tabular}

\title{
Intracellular
}

$\begin{array}{ll}\text { E-FABP } & 15 \\ \text { H-FABP } & 14.5 \\ \text { ACBP } & 10\end{array}$

vascular endothelium

endothelium, cardiac myocyte cardiac myocyte cytoplasmic LCFA transport

28

cytoplasmic LCFA transport

cytoplasmic acyl-CoA transport

\begin{abstract}
Abbreviations: $A B P=$ albumin binding protein, $F A B P_{p m}=$ plasmalemmal fatty acid-binding protein, $F A R=$ fatty acid receptor,$F A T=$ fatty acid translocase, $F A T P=$ fatty acid-transport protein, $F A B P$ $=$ fatty acid-binding protein, $A C B P=$ acyl-CoA binding protein .
\end{abstract}

(3) Incubation of rat adipocytes with a reactive FA derivative resulted in labeling of an $88-\mathrm{kDa}$ membrane protein and a concomitant $75 \%$ decrease in FA uptake ${ }^{1}$. A cDNA encoding this protein (Fatty Acid Translocase, FAT) showed high homology with mouse and human $\mathrm{CD} 36^{1}$. FAT/CD36 appears to be involved in various cellular processes $^{31}$ including cellular uptake of LCFAs ${ }^{39}$ and oxidized low-density lipoproteins $^{21}$, and uptake of cholesteryl esters from high-density lipoproteins ${ }^{19}$. Northern blot analysis ${ }^{86}$ and immunochemistry (F. van Nieuwenhoven et al., unpublished observations) revealed FAT expression in rat cardiac myocytes. Moreover, developmental regulation of FAT mRNA expression correlated well with the observed increase in cardiac FA oxidation capacity during development ${ }^{86}$. A newly-developed immunoassay allowed quantification of FAT protein levels and demonstrated a relationship between FAT content and oxidative capacity in different muscle types ${ }^{59}$.

Several findings imply a role of FAT/CD36 in cellular FA handling. For instance, LCFA uptake by sarcolemmal vesicles was inhibited by anti-FAT antibodies $^{13}$. Type-I FAT/CD36 deficiency, reported to occur in the Japanese population, has been associated with impaired cardiac FA uptake ${ }^{95}$. Recently, FAT/CD36 was identified as an insulin-resistance gene in spontaneously hypertensive rats. Adipocytes of these FAT/CD36 deficient animals showed reduced insulin- 
mediated glucose uptake and impaired release of FAs following B-adrenergic stimulation $^{3}$. Transgenic mice overexpressing FAT/CD36 in heart and skeletal muscle were reported to have lower plasma levels of triacylglycerols and of non-esterified $\mathrm{FAs}^{3}$.

(4) A murine 3T3-L1 adipocyte cDNA library was expressed in COS7 cells to identify cDNAs which could augment cellular uptake of a fluorescent FA analogue ${ }^{67}$. Using this functional approach a cDNA encoding a $63-\mathrm{kDa}$ integral membrane protein named fatty acid-transport protein (FATP) was identified. Recently, FATP was shown to belong to a larger family of FA transporters ${ }^{37}$. Northern blot analysis revealed expression of two FATP types $\left(\mathrm{FATP}_{1}\right.$ and $\left.\mathrm{FATP}_{4}\right)$ in cardiac tissue ${ }^{22,67}$. Current knowledge on FATP is discussed in more detail in Chapter 5.

The involvement of membrane proteins in cellular FA uptake is now well established. Recent studies showed that the $K_{\mathrm{m}}$ for uptake of non-protein-bound FAs by adipocytes ${ }^{2}$, cardiac myocytes ${ }^{54}$, and giant sarcolemmal vesicles derived from skeletal muscle ${ }^{13}$, is in the same range $(6-9 \mathrm{nM})$ as physiological plasma concentrations of non-protein-bound FA $(5-50 \mathrm{nM})^{65}$. Kinetic studies revealed that cardiac FA uptake consists of both passive diffusion and carrier-mediated components. The latter may constitute a high-affinity transport system prevalent at low FA concentrations, while low-affinity transport through passive diffusion might predominate at higher FA levels.

Despite growing evidence for their involvement in cellular FA uptake, little is known about tissue contents of the various membrane-associated FABPs, the contribution of each to myocardial FA uptake and whether these proteins interact and/or cooperate. It will be interesting to learn if an interaction occurs between membrane-associated FABPs and proteins that putatively facilitate the final part of the myocardial FA uptake chain, the cytoplasmic FABPs. In vitro experiments with FAT/CD36 and FABP isolated from bovine mammary gland, suggest that such an interaction indeed occurs ${ }^{73}$.

\section{Cytoplasmic FABPs}

Following their initial discovery in the early $70 \mathrm{~s}^{58}$, cytoplasmic FABPs are now known to comprise a family of proteins showing high-affinity binding of hydrophobic ligands $7,14,28,90$. This so-called intracellular lipid binding protein (iLBP) family is part of a larger family of ligand binding proteins which share a similar protein architecture and are named calycins ${ }^{23}$. This protein superfamily and the evolutionary relationships between vertebrate iLBPs are discussed in detail in Chapter 3.

In mammals, the iLBP family currently consists of one bile acid-binding protein, two retinol-binding proteins, two retinoic acid-binding proteins (CRABPs) and eight 'true' $\mathrm{FABPs}^{28}$. iLBPs consist of 126-137 amino acids $\left(\mathrm{M}_{\mathrm{r}} 14-16 \mathrm{kDa}\right)$ and in rodents amino acid identity between different iLBPs ranges between 16-72\%. 
iLBPs were named after the initial source of isolation, but expression is not necessarily restricted to that tissue. For example, H-FABP is expressed in among others cardiac and skeletal muscle, brain, and kidney. Several tissues or cell types express more than one iLBP type. In cardiac tissue, two types of FABP have been identified (Table 2.1), H-FABP is expressed mainly in cardiac myocytes whereas E-FABP is found in endothelial cells ${ }^{28,70}$.

\section{Structure of $H-F A B P$ and binding characteristics}

H-FABP, which appears to be identical to mammary-derived growth inhibitor (MDGI $^{72}$ and is also known as muscle-FABP, consists of 132 amino acid residues and has a molecular mass of $14.5 \mathrm{kDa}$. It has been characterized in detail in several mammalian species and apparently homologous FABPs have been identified in flight muscle of desert and migratory locusts ${ }^{33}$ and in skeletal muscle of the antarctic icefish $^{52,89}$. In bovine heart, two H-FABP isoforms (Asp98 and Asn98) are encoded by distinct $m R N A s^{8}$ which might result from transcription of different alleles.

$\mathrm{H}$-FABP is post-translationally modified by acetylation of its $\mathrm{N}$-terminus and is a stable protein with a half-life of 2.5 days, as measured in cultured neonatal cardiac myocytes ${ }^{66}$. A minute amount of the H-FABP pool in isolated rat cardiac myocytes was found to be phosphorylated on Tyr19 upon stimulation with near-physiological insulin levels ${ }^{57}$. The physiological significance of this finding is unknown, although it was speculated that phosphorylated H-FABP might modulate the insulin signal transduction pathway in the presence of $\mathrm{FAs}^{57}$.

Crystal structures have been determined for bovine H-FABP at intermediate resolution and for recombinant human $\mathrm{H}$-FABP complexed with various saturated and (poly)unsaturated fatty acids at high resolution (1.4-2.1 Ångstroms) $)^{7,99}$. The protein structure consists of 10 antiparallel B-strands arranged into two more or less orthogonal $\beta$-sheets and two short $\alpha$-helices (Figure 2.2). FA is bound in an internal binding cavity where its negatively charged carboxylate group forms a hydrogen-bond network with Arg106 (via a water molecule), Arg126 and Tyr128. Mutation of any of these residues is likely to affect FA binding affinity, e.g. an Arg126Gln substitution completely abolished FA binding activity ${ }^{62}$. A detailed description of the various structural aspects of H-FABP and other iLBPs can be found in reference 7.

Several methods have been employed in the past to determine kinetic parameters of the interaction between H-FABP and LCFAs ${ }^{28}$. Recent methodological improvements revealed equilibrium dissociation constants in the nanomolar range and a binding stoichiometry of one LCFA molecule per protein molecule ${ }^{64}$. Both saturated and (poly)unsaturated FAs are bound to H-FABP with high-affinity $\left(K_{\mathrm{d}}=2-60 \mathrm{nM}\right)$. As apparent from the interactions between the FA and residues in the binding cavity ${ }^{7}$, the binding of FAs to H-FABP is pH-dependent. In the neutral and basic $\mathrm{pH}$ range, FAs are bound whereas they dissociate at $\mathrm{pH}$ values below 4.5 , the $\mathrm{pK}$ of free FA. 
Acyl-CoA esters, acyl-carnitine esters and long-chain fatty alcohols do not bind to H-FABP. Acyl-CoA esters are bound with high affinity by acyl-CoA binding protein (ACBP), a protein expressed in most -if not all- cell types ${ }^{48}$.

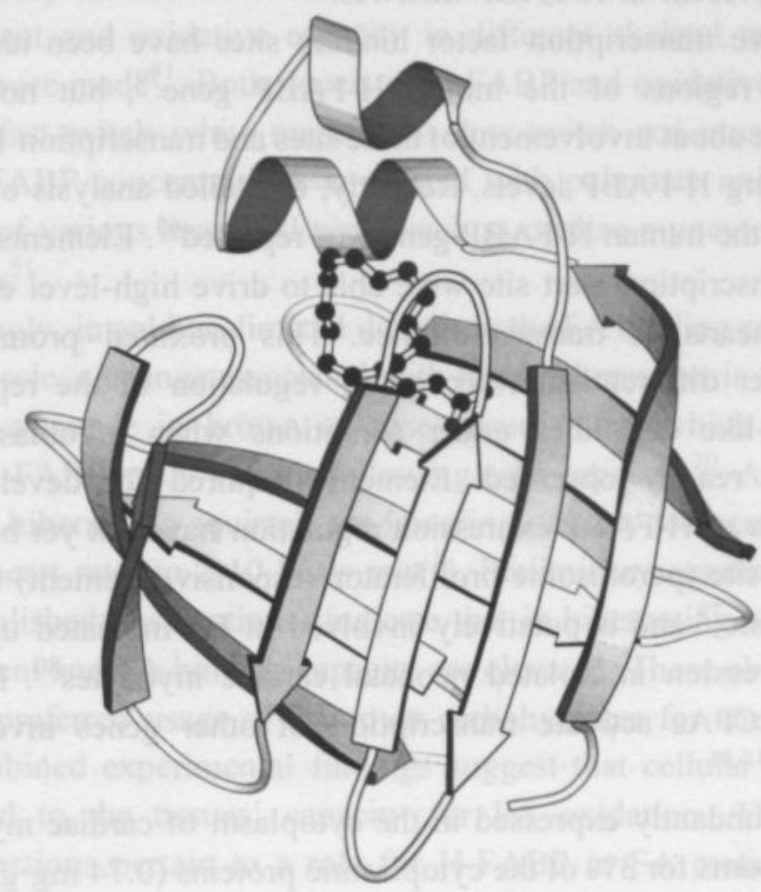

Figure 2.2 Ribbon diagram showing the tertiary structure of human cytoplasmic H-FABP complexed with oleate (black balls). A clam-like structure is formed by two orthogonal $\beta$ sheets and is capped by a flexible structure consisting of two $\alpha$-helices. The ligand is bound in a U-shaped conformation. The drawing was created with Molscript $r^{49}$.

\section{Regulation of $H-F A B P$ expression}

The gene encoding H-FABP consists of four exons and has been mapped to human chromosome $1 \mathrm{p} 32-\mathrm{p} 35^{60,90}$. Apart from the expressed H-FABP gene on chromosome 4 , several intronless pseudogenes located on different chromosomes have been identified in the mouse $\mathrm{e}^{79}$. The human H-FABP/MDGI gene is a candidate tumor suppressor gene, its locus lying in a region commonly found to be lost in sporadic breast cancers ${ }^{60}$. However, a detailed genetic analysis suggested that mutations in the $\mathrm{H}-\mathrm{FABP} / \mathrm{MDGI}$ coding region are uncommon in breast tumorigenesis ${ }^{60}$. These studies revealed a rare polymorphism in the H-FABP gene resulting in a Lys54 to Arg54 transition. 
Because H-FABP is a stable protein and the factors influencing H-FABP levels generally result in mild and gradual changes, H-FABP expression seems to be regulated primarily at the transcriptional level. Typical mRNA destabilizing elements, such as those commonly found in the 3' untranslated regions of growth factor mRNAs ${ }^{18}$, are not present in H-FABP mRNAs.

Several putative transcription factor binding sites have been identified in the promoter/enhancer regions of the mouse H-FABP gene ${ }^{79}$, but no experimental evidence is available about involvement of these sites and transcription factors binding to them in controlling H-FABP levels. Recently, a detailed analysis of the proximal promoter region of the human H-FABP gene was reported ${ }^{63}$. Elements within $1.2 \mathrm{~kb}$ upstream of the transcription start site were able to drive high-level expression of a reporter gene in hearts of transgenic mice. This proximal promoter appeared inadequate to confer differentiation-dependent regulation of the reporter gene in transfected muscle-like cell lines under conditions when myoblast to myotube differentiation was readily observed. Elements required for developmental and metabolic regulation of H-FABP expression regulation have not yet been identified. A consensus PPRE-site (peroxisome-proliferator responsive element) is found in the murine H-FABP gene ${ }^{79}$ and is putatively involved in FA-mediated upregulation of $\mathrm{H}-\mathrm{FABP}$ gene expression in isolated neonatal cardiac myocytes ${ }^{80}$. Recent studies demonstrate that LCFAs activate transcription of other genes involved in their metabolism as well ${ }^{15,81}$.

H-FABP is abundantly expressed in the cytoplasm of cardiac myocytes. In rat heart, H-FABP accounts for $3 \%$ of the cytoplasmic proteins $\left(0.74 \mathrm{mg} \cdot \mathrm{g}^{-1} \text { wet mass }\right)^{91}$. Using immunochemistry, small amounts of H-FABP have been detected inside the nucleus and in the mitochondrial matrix ${ }^{28}$. Moreover, H-FABP was found to be associated with myofibrils. Because H-FABP lacks nuclear localization signals and it is generally assumed that small proteins can pass nuclear pores unrestricted, the presence of H-FABP in the nucleus probably reflects equilibration with the cytoplasmic pool.

Apart from cardiac myocytes, the presence of H-FABP has been demonstrated in other cardiac cell types, albeit in far less abundance ${ }^{51}$. Heart capillary endothelium, cultured endothelial cells from bovine aortic tissue ${ }^{66}$, cardiac fibroblasts and vascular smooth muscle cells ${ }^{44}$ contain low levels of H-FABP. Outside the heart, relatively high-level expression of H-FABP has been detected in red skeletal muscles, renal cortex, testis, lung, and brain ${ }^{28,35}$.

Testosterone-treatment, endurance training ${ }^{82}$, circadian rhythm ${ }^{28}$, nutritional state, and pharmacological intervention ${ }^{25}$ were all shown to influence the myocardial H-FABP content. Moreover, H-FABP expression is altered in certain pathophysiological conditions. In general, metabolic situations that tend to increase fatty acid oxidation result in elevated H-FABP levels. 
Throughout prenatal development, H-FABP is present at constant levels in rat heart ${ }^{35}$. Around the time of birth there is a marked increase in H-FABP protein and mRNA levels which reach a maximum one month after birth ${ }^{35,86}$. A parallel increase in oxidative capacity of heart tissue is found during development. When comparing $\mathrm{H}-\mathrm{FABP}$ content and oxidative capacity in different skeletal muscle types similar observations were made ${ }^{91}$. Both, levels of H-FABP and oxidative capacity increased in the order: fast-twitch white muscle $<<$ slow-twitch red muscle $<$ heart muscle. Likewise, H-FABP concentrations correlated with palmitate oxidation measured in homogenates of various heart cell types such as cardiac myocytes, endothelial cells, and fibroblasts ${ }^{51}$.

Interestingly, in cold-acclimated ducklings the FA binding capacity was elevated in skeletal muscle, a change associated with higher thermogenic activity ${ }^{10}$. A similar observation was made in brown adipose tissue of rat which showed drastically upregulated H-FABP mRNA levels following cold-exposure ${ }^{20}$. Among physiological adaptations in hibernating squirrels are lowering of body temperature (to $2-7^{\circ} \mathrm{C}$ ) and reduction of heart rate (to $2-10$ beats $\cdot \mathrm{min}^{-1}$ ). Preliminary results (F. Schaap and M. Pelsers, unpublished observations) indicate that in hibernating squirrels, the cardiac H-FABP content and FA binding capacity are elevated. These observations appear in line with the preferred usage of FAs over carbohydrates for energy provision ${ }^{4}$.

The combined experimental findings suggest that cellular H-FABP levels are directly linked to the tissues' capacity for FA oxidation. Therefore, the major postulated functions pertain to a role for H-FABP in FA metabolism. H-FABP is thought to stimulate the cellular uptake of LCFAs and to facilitate their cytoplasmic transport. Protection against detergent-like effects of LCFAs ${ }^{28}$ and modulation of signal transduction pathways ${ }^{27}$ have been proposed as additional functions of H-FABP.

\section{Facilitation of cellular LCFA uptake by H-FABP}

By intracellular binding of LCFAs and, thus, maintaining a gradient between the extracellular and intracellular compartments, H-FABP might increase the cellular influx of LCFAs. For this, H-FABP may directly take up LCFAs from the cytoplasmic leaflet of the phospholipid bilayer or acquire ligand through interaction with membrane-associated FABPs. L1 cell fibroblasts transfected with liver- or intestinal-type FABP cDNA indeed showed increased uptake of LCFAs ${ }^{56}$. However, H-FABP cDNA expression in COS7 cells did not affect LCFA uptake ${ }^{67}$. In order to stimulate LCFA uptake in these cells, expression of H-FABP alone is apparently not sufficient and might require simultaneous expression of membrane-associated FABPs. 
In contrast to short-chain FAs, the physiologically important long-chain $\mathrm{FAs}\left(\mathrm{C}_{16}\right.$ and $\mathrm{C}_{18}$ ) are virtually insoluble in aqueous environments. While it seems obvious that $\mathrm{H}-\mathrm{FABP}$ increases the aqueous phase solubility of LCFAs and, accordingly, enhances the intracellular LCFA flux, experimental proof for such function in vivo is scarce. Inside the cardiac myocyte the majority of LCFAs are associated with phospholipid bilayers $^{93}$. Theoretical calculations indicated that H-FABP raises aqueous phase LCFA levels from about $3 \mathrm{nM}$ to $3 \mu \mathrm{M}$, thereby potentially stimulating their intracellular flux severalfold ${ }^{28,93}$.

In vitro, H-FABP was shown to transfer LCFAs between a variety of model membranes $^{28}$. The mechanism by which LCFAs are transferred from H-FABP to synthetic phospholipid membranes is believed to proceed through collisional transfer ${ }^{75,97}$. This process requires an interaction between FABP and the acceptor membrane. Computer simulations suggested that FABP can promote cytoplasmic FA transport provided that such interaction occurs between FABP and both donor and acceptor membranes, and that bound ligand is not released in the aqueous phase during actual shuttling between these membranes ${ }^{94}$. Using a fluorescence resonance energy transfer assay, it was shown that transfer of FA-derivatives from H-FABP to model membranes depends on the composition and structure of membrane phospholipids, and the ionic strength ${ }^{97}$. Acidic phospholipid bilayers were most efficient in accepting FAs from H-FABP, suggesting an interaction between positively charged residues on the surface of H-FABP and negatively charged phospholipids in the model membrane. The portal region of H-FABP, which is formed by the two $\alpha$-helices (Figure 2.2) and is presumed to form a flexible structure which caps the internal binding cavity ${ }^{7,101}$, contains several positively charged residues. Mutation of these residues, e.g. Lys22 to Ile22, did not affect FA binding affinity but did result in diminished transfer of FA-derivatives from H-FABP to model phospholipid membranes ${ }^{34}$.

These latter findings suggest that positively charged residues in the portal region are involved in the collisional transfer of LCFAs between H-FABP and membranes. Interestingly, the mitochondrial outer membrane contains considerable amounts of negatively charged phospholipids (e.g. cardiolipin) which could interact with these positively charged residues. Moreover, in the vicinity of actively respirating $\left(\mathrm{H}^{+}\right.$pumping) mitochondria the FA binding affinity of $\mathrm{H}-\mathrm{FABP}$, which is $\mathrm{pH}$ dependent, could be lowered. These speculations imply a possible mechanism for enhanced transfer of LCFAs from cytoplasmic H-FABP to mitochondrial membranes.

\section{Additional functions proposed for $H-F A B P$}

Several extracellular functions have been postulated for MDGI/H-FABP. This protein is thought to be involved in growth-regulation and differentiation of mammary 
epithelial cells ${ }^{12,98}$. MDGI was in fact shown to be a mixture of adipocyte lipid binding protein (ALBP) and $\mathrm{H}-\mathrm{FABP}$, with its anti-proliferative activity residing in $\mathrm{H}-\mathrm{FABP}^{72}$. For exerting an extracellular function, MDGI, which is synthesized by lactating mammary epithelial cells, is probably co-secreted with other constituents of milk fat droplets. Recently, H-FABP was shown to inhibit protein synthesis in a cellfree system ${ }^{103}$. It is unknown whether this activity is related to the growth-inhibiting effect of H-FABP on mammary epithelial cells.

A possible involvement of $\mathrm{H}-\mathrm{FABP}$ in development of cardiac hypertrophy has been reported ${ }^{16}$. In cultured neonatal cardiac myocytes, low extracellular concentrations of $\mathrm{H}-\mathrm{FABP}$ were found to induce expression of the proto-oncogene c-jun, and cause an increase in cellular protein synthesis and cellular surface area. However, Vork and coworkers were unable to reproduce this reported increase in cellular protein synthesis under similar experimental conditions (unpublished data). In addition, because H-FABP normally has an intracellular localization, the physiological relevance of the reported findings remains to be established.

\section{Pathophysiological disturbances of myocardial FA metabolism}

In the healthy heart oxidation of LCFAs supplies already up to $70 \%$ of the overall energy requirement. Under certain conditions, such as fasting and diabetes, the contribution of FA oxidation to total ATP production may even exceed $90 \%$. A number of pathophysiological conditions which affect the workload of the heart, such as chronic hypertension and hypertrophy, cause alterations in myocardial FA metabolism ${ }^{53,83}$. A possible involvement of H-FABP in metabolic adaptation under (patho)physiological conditions is discussed below.

\section{Diabetes and fasting}

Circulating FA levels are elevated in diabetes mellitus and during fasting. In diabetic hearts, the uptake and utilization of glucose is impaired and the heart becomes almost entirely dependent on FA oxidation to fulfil its energy needs ${ }^{74}$. The increased FA utilization by the diabetic heart may be accompanied by enhanced uptake and/or intracellular transport of LCFAs. Both, FAT and H-FABP protein contents were found to be increased in hearts from streptozotocin-induced diabetic rats ${ }^{26,59,88}$. In red skeletal muscle of rat, the mechanism by which H-FABP mRNA levels are raised appears to be on the transcriptional level in fasted animals, whereas an increased mRNA stability is implied in the streptozotocin-induced diabetic animals ${ }^{17}$. In energyrestricted obese women, skeletal muscle H-FABP content was found to be increased ${ }^{43}$. Increased LCFA utilization by skeletal and/or cardiac muscle in diabetes mellitus or during fasting are apparently accompanied by elevated H-FABP levels. 
It was shown that in rats exposed for 3 weeks to hypoxic conditions the myocardial FABP content had decreased by $20 \%{ }^{25}$. Moreover, hearts from these rats had somewhat reduced capacity to oxidize $\mathrm{FAs}^{25}$.

The reduced oxygen supply in ischemic heart severely impairs mitochondrial oxidation of $\mathrm{FAs}^{83}$. Under ischemic conditions, residual FAs extracted from the extracellular compartment are mainly incorporated into triacylglycerols ${ }^{83}$. Moreover, accumulation of acyl-CoA and acyl-carnitine esters is readily (within 5 minutes) observed in low-flow ischemic heart. Intracellular FA levels are significantly raised 20 to 45 minutes following onset of ischemia ${ }^{83}$. Due to their amphiphilic nature, LCFAs can have detergent-like effects on cell membranes and influence the activity of proteins. For instance, LCFAs were shown to be weak uncouplers of mitochondria ${ }^{96}$ and alter the activity of several enzymes and ion channels ${ }^{28}$. In the ischemic heart, tissue accumulation of FAs and their metabolites has been associated with arrhythmias, increased myocardial infarct size and depressed myocardial contractility ${ }^{83}$. Under ischemic conditions, H-FABP may be crucial to sequester accumulating LCFAs and thus prevent tissue damage.

Prolonged ischemic periods or severe coronary occlusion may result in myocardial infarction. Following myocardial infarction or skeletal muscle injury, $\mathrm{H}-\mathrm{FABP}$ is released into the bloodstream by damaged myocytes and is rapidly cleared from the blood by renal filtration. The development of rapid and sensitive assays for quantification of H-FABP in plasma, makes this protein an ideal marker for diagnosis of acute myocardial infarction. The ratio of blood myoglobin/H-FABP levels allows discrimination between skeletal muscle damage and acute myocardial infarction ${ }^{87}$.

\section{Hypertensive and hypertrophied heart}

The heart muscle adapts to prolonged periods of enhanced workload, e.g. chronic hypertension, by structural remodelling. The enlargement of ventricular size, which is observed in hypertrophied heart, forms a serious risk for development of congestive heart failure. Among the metabolic changes observed in hypertrophied heart, a decrease in FA oxidation is evident ${ }^{53}$. It is thought that the lowered FA oxidation capacity, which still accounts for $55 \%$ of the ATP produced, results from a decreased myocardial carnitine content. Oxidation of short-chain FAs, which do not rely on carnitine for entering the mitochondrial matrix, is not impaired in the hypertrophied heart $^{53}$. Alternatively, a reduced H-FABP content may account for the lowered FA oxidation rate. In spontaneously hypertensive rats, which develop mild ventricular hypertrophy, H-FABP levels tended to be lower than in normotensive rats ${ }^{92}$. 


\section{Future prospects}

Research in the field of cellular FA utilization is rapidly progressing as evidenced by the identification of several putative FA transporters in a short time-span. The growing number of proteins apparently involved in FA uptake raises several questions concerning their structural organization. Perhaps these proteins are assembled into a multimeric FA transport complex in which individual proteins participate in different steps of the translocation process, e.g. binding of FAs, transmembrane movement of FAs and transfer of FAs to cytoplasmic FABPs. The existence of a protein-mediated mechanism for FA uptake introduces regulatory points for adjusting the cellular FA flux to the metabolic need. Hence, post-translational modification such as (de)phosphorylation may modulate this process. In addition, dysfunction of proteins involved in sarcolemmal FA translocation might be related to certain pathologies.

Future research is required to learn about the functions of membrane-associated FABPs and their possible interaction. Moreover, the regulation of their expression/activity under diverse (patho)physiological conditions needs to be established. Use of sophisticated techniques, such as gene replacement (knock-in) and gene disruption (knock-out), which allows study of protein function in living animals, could help in resolving these issues.

Using the latter approach, we determined FA utilization by cardiac myocytes derived from mice with a disrupted H-FABP gene (Chapter 6). Previous studies employing mice with a targeted iLBP gene did not reveal obvious phenotypes. Mice lacking both ALBP alleles were shown to be developmentally and metabolically normal $^{38}$. In adipose tissue of these mice an elevated expression of E-FABP was observed and was suggested to compensate the deficiency in $\mathrm{ALBP}^{38}$. Mice with targeted inactivation of both the $\mathrm{CRABP}_{1}$ and $\mathrm{CRABP}_{2}$ genes were found to be essentially normal ${ }^{50}$. Presumably, alternative cellular binding sites exist for retinoic acid, a vitamin A derivative which is essential for embryonic development.

The eventual development of mice lacking membrane-associated FABPs, and crossing with the H-FABP nullizygous mice, could probably resolve several unanswered questions on the roles of these proteins in myocardial FA uptake and metabolism, and in cardiac pathophysiology.

\section{References}

1) Abumrad NA, el-Maghrabi MR, Amri EZ, Lopez E, and Grimaldi PA: Cloning of a rat adipocyte membrane protein implicated in binding or transport of long-chain fatty acids that is induced during pre-adipocyte differentiation. Homology with human CD36. J Biol Chem 268:17665-17668(1993)

2) Abumrad NA, Harmon C, and Ibrahimi A: Membrane transport of long-chain fatty acids. Evidence for a facilitated process. J Lipid Res 39:2309-2318(1998) 
3) Aitman TJ, Glazier AM, Wallace CA, Cooper LD, Norsworthy PJ, Wahid FN, Al-Majali KM, Trembling PM, Mann CJ, Shoulders CC, Graf D, St. Lezin E, Kurtz TW, Kren V, Pravenec M, Ibrahimi A, Abumrad NA, Stanton LW, and Scott J: Identification of CD36 (FAT) as an insulin-resistance gene causing defective fatty acid and glucose metabolism in hypertensive rats. Nat Genet 21:76-83 (1999)

4) Andrews MT, Squire TL, Bowen CM, and Rollins MB: Low-temperature carbon utilization is regulated by novel gene activity in the heart of a hibernating mammal. Proc Natl Acad Sci U S A 95:8392-8397(1998)

5) Antohe F, Dobrila L, Heltianu C, Simionescu N, and Simionescu M: Albumin binding proteins function in the receptor-mediated binding and transcytosis of albumin across cultured endothelial cells. Eur J Cell Biol 60:268-275 (1993)

6) Antohe F, Popov D, Radulescu L, Simionescu N, Börchers T, Spener F, and Simionescu M: Heart microvessels and aortic endothelial cells express the $15 \mathrm{kDa}$ heart-type fatty acid-binding protein. Eur J Cell Biol 76:102-109 (1998)

7) Banaszak L, Winter N, Xu Z, Bernlohr DA, Cowan S, and Jones TA: Lipid binding proteins: a family of fatty acid and retinoid transport proteins. Adv Protein Chem 45:89-151 (1994)

8) Bartetzko N, Lezius AG, and Spener F: Isoforms of fatty acid-binding protein in bovine heart are coded by distinct mRNA. Eur J Biochem 215:555-559(1993)

9) Bassingthwaighte JB, Noodleman L, van der Vusse GJ, and Glatz JFC: Modeling of palmitate transport in the heart. Mol Cell Biochem 88:51-58 (1989)

10) Benistant C, Duchamp C, Cohen-Adad F, Rouanet JL, and Barre H: Increased in vitro fatty acid supply and cellular transport capacities in cold-acclimated ducklings (Cairina moschata). Am J Physiol 275:R683-690(1998)

11) Berk PD: How do long-chain free fatty acids cross cell membranes? Proc Soc Exp Biol Med 212:1-4 (1996)

12) Böhmer FD, Kraft R, Otto A, Wernstedt C, Hellman U, Kurtz A, Müller T, Rohde K, Etzold G, Lehmann W, Langen P, Heldin $\mathrm{CH}$, and Grosse R: Identification of a polypeptide growth inhibitor from bovine mammary gland. Sequence homology to fatty acid- and retinoid-binding proteins. $J$ Biol Chem 262:15137-15143(1987)

13) Bonen A, Luiken JJFP, Liu S, Dyck DJ, Kiens B, Kristiansen S, Turcotte LP, van der Vusse GJ, and Glatz JFC: Palmitate transport and fatty acid transporters in red and white muscles. Am J Physiol 275:E471-478 (1998)

14) Börchers T and Spener F: Fatty acid-binding proteins. Curr Top Membr 40:261-294 (1994)

15) Brandt JM, Djouadi F, and Kelly DP: Fatty acids activate transcription of the muscle carnitine palmitoyltransferase $I$ gene in cardiac myocytes via the peroxisome proliferator-activated receptor ${ }_{\alpha^{*}} J$ Biol Chem 273:23786-23792(1998)

16) Burton PB, Hogben CE, Joannou CL, Clark AG, Hsuan JJ, Totty NF, Sorensen C, Evans RW, and Tynan MJ: Heart fatty acid-binding protein is a novel regulator of cardiac myocyte hypertrophy. Biochem Biophys Res Commun 205:1822-1828(1994)

17) Carey JO, Neufer PD, Farrar RP, Veerkamp JH, and Dohm GL: Transeriptional regulation of muscle fatty acid-binding protein. Biochem J 298:613-617(1994)

18) Chen $\mathrm{CY}$ and Shyu $\mathrm{AB}$ : AU-rich elements: characterization and importance in mRNA degradation. Trends Biochem Sci 20:465-470(1995)

19) Connelly MA, Klein SM, Azhar S, Abumrad NA, and Williams DL: Comparison of class B scavenger receptors, CD36 and scavenger receptor BI (SR-BI), shows that both receptors mediate high-density lipoprotein-cholesteryl ester selective uptake but SR-BI exhibits a unique enhancement of cholesteryl ester uptake. $J$ Biol Chem 274:41-47 (1999) 
20) Daikoku T, Shinohara Y, Shima A, Yamazaki N, and Terada H: Dramatic enhancement of the specific expression of the heart-type fatty acid-binding protein in rat brown adipose tissue by cold-exposure. FEBS Lett 410:383-386(1997)

21) Endemann G, Stanton LW, Madden KS, Bryant CM, White RT, and Protter AA: CD36 is a receptor for oxidized low-density lipoprotein. J Biol Chem 268:11811-11816(1993)

22) Fitscher BA, Riedel HD, Young KC, and Stremmel W: Tissue distribution and cDNA cloning of a human fatty acid-transport protein (hsFATP $)_{4}$. Biochim Biophys Acta 1443:381-385 (1998)

23) Flower DR: The lipocalin protein family: structure and function. Biochem J 318:1-14(1996)

24) Fujii $S$, Kawaguchi $H$, and $Y$ asuda $H$ : Purification of high-affinity fatty acid receptors in rat myocardial sarcolemmal membranes. Lipids 22:544-546(1987)

25) Garnier A, Poizat C, Keriel C, Cuchet P, Vork MM, de Jong YF, and Glatz JFC: Modulation of fatty acid-binding protein content of adult rat heart in response to chronic changes in plasma lipid levels. Mol Cell Biochem 123:107-112(1993)

26) Glatz JFC, van Breda E, Keizer HA, de Jong YF, Lakey JR, Rajotte RV, Thompson A, van der Vusse GJ, and Lopaschuk GD: Rat heart fatty acid-binding protein content is increased in experimental diabetes. Biochem Biophys Res Commun 199:639-646(1994)

27) Glatz JFC, Börchers T, Spener F, and van der Vusse GJ: Fatty acids in cell signalling: modulation by lipid binding proteins. Prostaglandins Leukot Essent Fatty Acids 52:121-127 (1995)

28) Glatz JFC and van der Vusse GJ: Cellular fatty acid-binding proteins: their function and physiological significance. Prog Lipid Res 35:243-282 (1996)

29) Glatz JFC, Luiken JJFP, van Nieuwenhoven FA, and van der Vusse GJ: Molecular mechanism of cellular uptake and intracellular translocation of fatty acids. Prostaglandins Leukot Essent Fatty Acids 57:3-9 (1997)

30) Goresky CA, Stremmel W, Rose CP, Guirguis S, Schwab AJ, Diede HE, and Ibrahim E: The capillary transport system for free fatty acids in the heart. Circ Res 74:1015-1026(1994)

31) Greenwalt DE, Lipsky RH, Ockenhouse CF, Ikeda H, Tandon NN, and Jamieson GA: Membrane glycoprotein CD36: a review of its roles in adherence, signal transduction, and transfusion medicine. Blood 80:1105-1115(1992)

32) Hamilton JA: Fatty acid transport: difficult or easy? J Lipid Res 39:467-481 (1998)

33) Haunerland NH: Fatty acid-binding protein in locust and mammalian muscle. Comparison of structure, function, and regulation. Comp Biochem Physiol B Biochem Mol Biol 109:199-208(1994)

34) Herr FM, Aronson J, and Storch J: Role of portal region lysine residues in electrostatic interactions between heart fatty acid-binding protein and phospholipid membranes. Biochemistry 35:1296-1303 (1996)

35) Heuckeroth RO, Birkenmeier EH, Levin MS, and Gordon JI: Analysis of the tissue-specific expression, developmental regulation, and linkage relationships of a rodent gene encoding heart fatty acid-binding protein. $J$ Biol Chem 262:9709-9717(1987)

36) Higgins CF: Flip-flop: the transmembrane translocation of lipids. Cell 79:393-395 (1994)

37) Hirsch D, Stahl A, and Lodish HF: A family of fatty acid transporters conserved from mycobacterium to man. Proc Natl Acad Sci US A 95:8625-8629(1998)

38) Hotamisligil GS, Johnson RS, Distel RJ, Ellis R, Papaioannou VE, and Spiegelman BM: Uncoupling of obesity from insulin resistance through a targeted mutation in aP2, the adipocyte fatty acid-binding protein. Science 274:1377-1379(1996) 
39) Ibrahimi A, Sfeir Z, Magharaie H, Amri EZ, Grimaldi P, and Abumrad NA: Expression of the CD36 homolog (FAT) in fibroblast cells: effects on fatty acid transport. Proc Natl Acad Sci USA 93:2646-2651 (1996)

40) Isola LM, Zhou SL, Kiang CL, Stump DD, Bradbury MW, and Berk PD: 3T3 fibroblasts transfected with a cDNA for mitochondrial aspartate aminotransferase express plasma membrane fatty acid-binding protein and saturable fatty acid uptake. Proc Natl Acad Sci U S A 92:9866-9870(1995)

41) Kamp F, Zakim D, Zhang F, Noy N, and Hamilton JA: Fatty acid flip-flop in phospholipid bilayers is extremely fast. Biochemistry 34:11928-11937(1995)

42) Kane CD, Coe NR, Vanlandingham B, Krieg P, and Bernlohr DA: Expression, purification, and ligand-binding analysis of recombinant keratinocyte lipid-binding protein (MAL-1), an intracellular lipid binding protein found overexpressed in neoplastic skin cells. Biochemistry 35:2894-2900(1996)

43) Kempen KP, Saris WH, Kuipers H, Glatz JFC, and van der Vusse GJ: Skeletal muscle metabolic characteristics before and after energy restriction in human obesity: fibre type, enzymatic B-oxidative capacity and fatty acid-binding protein content. Eur J Clin Invest 28:1030-1037(1998)

44) Kleine AH, Glatz JFC, Havenith MG, van Nieuwenhoven FA, van der Vusse GJ, and Bosman FT: Immunohistochemical detection of very recent myocardial infarctions in man with antibodies against heart-type fatty acid-binding protein. Cardiovasc Pathol 2:63-69 (1993)

45) Kleinfeld AM, Chu P, and Storch J: Flip-flop is slow and rate limiting for the movement of long-chain anthroyloxy fatty acids across lipid vesicles. Biochemistry 36:5702-5711 (1997)

46) Kleinfeld AM, Chu P, and Romero C: Transport of long-chain native fatty acids across lipid bilayer membranes indicates that transbilayer flip-flop is rate limiting. Biochemistry 36:14146-14158(1997)

47) Kleinfeld AM, Storms S, and Watts M: Transport of long-chain native fatty acids across human erythrocyte ghost membranes. Biochemistry 37:8011-8019(1998)

48) Knudsen J, Mandrup S, Rasmussen JT, Andreasen PH, Poulsen F, and Kristiansen K: The function of acyl-CoA binding protein (ACBP)/diazepam binding inhibitor (DBI). Mol Cell Biochem 123:129-138(1993)

49) Kraulis P: MOLSCRIPT: A program to produce both detailed and schematic plots of protein structures. $J$ Appl Cryst 24:946-950(1991)

50) Lampron C, Rochette-Egly C, Gorry P, Dollé P, Mark M, Lufkin T, LeMeur M, and Chambon P: Mice deficient in cellular retinoic acid binding protein II (CRABPII) or in both CRABPI and CRABPII are essentially normal. Development 121:539-548(1995)

51) Linssen MC, Vork MM, de Jong YF, Glatz JFC, and van der Vusse GJ: Fatty acid oxidation capacity and fatty acid-binding protein content of different cell types isolated from rat heart. Mol Cell Biochem 98:19-25 (1990)

52) Londraville RL and Sidell BD: Purification and characterization of fatty acid-binding protein from aerobic muscle of the Antarctic icefish Chaenocephalus aceratus. J Exp Zool 273:190-203(1995)

53) Lopaschuk GD, Belke DD, Gamble J, Itoi T, and Schönekess BO: Regulation of fatty acid oxidation in the mammalian heart in health and disease. Biochim Biophys Acta 1213:263-276 (1994)

54) Luiken JJFP, van NieuwenhovenFA, America G, van der Vusse GJ, and Glatz JFC: Uptake and metabolism of palmitate by isolated cardiac myocytes from adult rats: involvement of sarcolemmal proteins. J Lipid Res 38:745-758(1997) 
55) Masouyé I, Hagens G, van Kuppevelt TH, Madsen P, Saurat JH, Veerkamp JH, Pepper MS, and Siegenthaler G: Endothelial cells of the human microvasculature express epidermal fatty acid-binding protein. Circ Res 81:297-303 (1997)

56) Murphy EJ: L-FABP and I-FABP expression increase NBD-stearate uptake and cytoplasmic diffusion in L cells. Am J Physiol 275:G244-249 (1998)

57) Nielsen SU and Spener F: Fatty acid-binding protein from rat heart is phosphorylated on Tyr19 in response to insulin stimulation. $J$ Lipid Res 34:1355-1366(1993)

58) Ockner RK, Manning JA, Poppenhausen RB, and Ho WK: A binding protein for fatty acids in cytosol of intestinal mucosa, liver, myocardium, and other tissues. Science 177:56-58 (1972)

59) Pelsers MMAL, Lutgerink JT, van Nieuwenhoven FA, Tandon NN, van der Vusse GJ, Arends JW, Hoogenboom HR, and Glatz JFC: A sensitive immunoassay for rat fatty acid translocase (CD36) using phage antibodies selected on cell transfectants: abundant presence of fatty acid translocase/CD36 in cardiac and red skeletal muscle and upregulation in diabetes. Biochem J 337:407-414 (1999)

60) Phelan C, Larsson C, Baird S, Futreal P, Ruttledge M, Morgan K, Tonin P, Hung H, Korneluk R, Pollak M, and Narod S: The human mammary-derived growth inhibitor (MGDI) gene: genomic structure and mutation analysis in human breasts tumors. Genomics 34:63-68 (1996)

61) Popov D, Hasu M, Ghinea N, Simionescu N, and Simionescu M: Cardiomyocytes express albumin binding proteins. $J \mathrm{Mol}$ Cell Cardiol 24:989-1002 (1992)

62) Prinsen CFM and Veerkamp JH: Fatty acid binding and conformational stability of mutants of human muscle fatty acid-binding protein. Biochem $J$ 314:253-260(1996)

63) Qian Q, Kuo L, Yu YT, and Rottman JN: A concise promoter region of the heart fatty acid-binding protein gene dictates tissue-appropriate expression. Circ Res 84:276-289(1999)

64) Richieri GV, Ogata RT, and Kleinfeld AM: Equilibrium constants for the binding of fatty acids with fatty acid-binding proteins from adipocyte, intestine, heart, and liver measured with the fluorescent probe ADIFAB. $J$ Biol Chem 269:23918-23930(1994)

65) Richieri GV and Kleinfeld AM: Unbound free fatty acid levels in human serum. $J$ Lipid Res 36:229-240(1995)

66) Robers M, Loddenkötter B, Kresse H, and Spener F: Effect of clofibric acid on the turnover of the fatty acid-binding protein identified in cultured endothelial cells from bovine aorta. Lipids 28:483-486 (1993)

67) Schaffer JE and Lodish HF: Expression cloning and characterization of a novel adipocyte long-chain fatty acid-transport protein. Cell 79:427-436(1994)

68) Schaffer JE and Lodish HF: Molecular mechanism of long-chain fatty acid uptake. Trends Cardiovasc Med 5:218-224 (1995)

69) Schnitzer JE and Oh P: Albondin-mediated capillary permeability to albumin. Differential role of receptors in endothelial transcytosis and endocytosis of native and modified albumins. J Biol Chem 269:6072-6082(1994)

70) Siegenthaler G, Hotz R, Chatellard-Gruaz D, Didierjean L, Hellman U, and Saurat JH: Purification and characterization of the human epidermal fatty acid-binding protein: localization during epidermal cell differentiation in vivo and in vitro. Biochem J302:363-371 (1994) 
71) Sorrentino D, Stump D, Potter BJ, Robinson RB, White R, Kiang CL, and Berk PD: Oleate uptake by cardiac myocytes is carrier-mediated and involves a 40-kDa plasma membrane fatty acid-binding protein similar to that in liver, adipose tissue, and gut. $J$ Clin Invest 82:928-935 (1988)

72) Specht B, Bartetzko N, Hohoff C, Kuhl H, Franke R, Börchers T, and Spener F: Mammaryderived growth inhibitor is not a distinct protein but a mix of heart-type and adipocyte-type fatty acid-binding protein. J Biol Chem 271:19943-19949(1996)

73) Spitsberg VL, Matitashvili E, and Gorewit RC: Association and co-expression of fatty acid-binding protein and glycoprotein CD36 in the bovine mammary gland. Eur J Biochem 230:872-878(1995)

74) Stanley WC, Lopaschuk GD, and McCormack JG: Regulation of energy substrate metabolism in the diabetic heart. Cardiovasc Res 34:25-33 (1997)

75) Storch J, Herr FM, Kuo TH, Hye KK, Heng LL, and Smith ER: The role of membranes and intracellular binding proteins in cytoplasmic transport of hydrophobic molecules: fatty acid-binding proteins. Comp Biochem Physiol B Bioch Mol Biol 115:333-339 (1996)

76) Stump DD, Zhou SL, and Berk PD: Comparison of plasma membrane FABP and mitochondrial isoform of aspartate aminotransferase from rat liver. Am J Physiol 265:G894-902 (1993)

77) Sundaram M, Sivaprasadarao A, DeSousa MM, and Findlay JB: The transfer of retinol from serum retinol-binding protein to cellular retinol-binding protein is mediated by a membrane receptor. J Biol Chem 273:3336-3342(1998)

78) Tiruppathi $C$, Finnegan $A$, and Malik AB: Isolation and characterization of a cell surface albumin binding protein from vascular endothelial cells. Proc Natl Acad Sci $U S A$ 93:250-254 (1996)

79) Treuner M, Kozak CA, Gallahan D, Grosse R, and Müller T: Cloning and characterization of the mouse gene encoding mammary-derived growth inhibitor/heart fatty acid-binding protein. Gene 147:237-242(1994)

80) van Bilsen M, de Vries JE, and van der Vusse GJ: Long-term effects of fatty acids on cell viability and gene expression of neonatal cardiac myocytes. Prostaglandins Leukot Essent Fatty Acids 57:39-45 (1997)

81) van Bilsen M, van der Vusse GJ, and Reneman RS: Transcriptional regulation of metabolic processes: implications for cardiac metabolism. Pflügers Arch-Eur JPhysiol 437:2-14(1998)

82) van Breda E, Keizer HA, Vork MM, Surtel DA, de Jong YF, van der Vusse GJ, and Glatz JFC: Modulation of fatty acid-binding protein content of rat heart and skeletal muscle by endurance training and testosterone treatment. Pflügers Arch - Eur J Physiol 421:274-279 (1992)

83) van der Vusse GJ, Glatz JFC, Stam HC, and Reneman RS: Fatty acid homeostasis in the normoxic and ischemic heart. Physiol Rev 72:881-940(1992)

84) van der Vusse GJ, Glatz JFC, van Nieuwenhoven FA, Reneman RS, and Bassingthwaighte JB: Transport of long-chain fatty acids across the muscular endothelium. Adv Exp Med Biol 441:181-191 (1998)

85) van Nieuwenhoven FA, Verstijnen CP, van Eys GJ, van Breda E, de Jong YF, van der Vusse GJ, and Glatz JFC: Fatty acid transfer across the myocardial capillary wall: no evidence of a substantial role for cytoplasmic fatty acid-binding protein. $J \mathrm{Mol}$ Cell Cardiol 26:1635-1647(1994) 
86) van NieuwenhovenFA, Verstijnen CP, Abumrad NA, Willemsen PH, van Eys GJ, van der Vusse GJ, and Glatz JFC: Putative membrane fatty acid translocase and cytoplasmic fatty acid-binding protein are co-expressed in rat heart and skeletal muscles. Biochem Biophys Res Commun 207:747-752 (1995)

87) van Nieuwenhoven FA, Kleine AH, Wodzig WH, Hermens WT, Kragten HA, Maessen JG, Punt $\mathrm{CD}$, van Dieijen MP, van der Vusse GJ, and Glatz JFC: Discrimination between myocardial and skeletal muscle injury by assessment of the plasma ratio of myoglobin over fatty acid-binding protein. Circulation 92:2848-2854(1995)

88) van Nieuwenhoven FA, van der Vusse GJ, and Glatz JFC: Membrane-associated and cytoplasmic fatty acid-binding proteins. Lipids 31:S223-227(1996)

89) Vayda ME, Londraville RL, Cashon RE, Costello L, and Sidell BD: Two distinct types of fatty acid-binding protein are expressed in heart ventricle of Antarctic teleost fishes. Biochem J 330:375-382(1998)

90) Veerkamp JH and Maatman RGHJ: Cytoplasmic fatty acid-binding proteins: their structure and genes. Prog Lipid Res 34:17-52 (1995)

91) Vork MM, Glatz JFC, Surtel DA, Knubben HJ, and van der Vusse GJ: A sandwich enzyme linked immunosorbent assay for the determination of rat heart fatty acid-binding protein using the streptavidin-biotin system. Application to tissue and effluent samples from normoxic rat heart perfusion. Biochim Biophys Acta 1075:199-205(1991)

92) Vork MM, Trigault N, Snoeckx LHEH, Glatz JFC, and van der Vusse GJ: Heterogeneous distribution of fatty acid-binding protein in the hearts of Wistar Kyoto and spontaneously hypertensive rats. $J$ Mol Cell Cardiol 24:317-321 (1992)

93) Vork MM, Glatz JFC, and van der Vusse GJ: On the mechanism of long-chain fatty acid transport in cardiomyocytesas facilitated by cytoplasmic fatty acid-binding protein. $J$ Theor Biol 160:207-222(1993)

94) Vork MM, Glatz JFC, and van der Vusse GJ: Modeling intracellular fatty acid transport: possible mechanistic role of cytoplasmic fatty acid-binding protein. Prostaglandins Leukot Essent Fatty Acids 57:11-16 (1997)

95) Watanabe K, Ohta Y, Toba K, Ogawa Y, Hanawa H, Hirokawa Y, Kodama M, Tanabe N, Hirono S, Ohkura Y, Nakamura Y, Kato K, Aizawa Y, Fuse I, Miyajima S, Kusano Y, Nagamoto T, Hasegawa G, and Naito M: Myocardial CD36 expression and fatty acid accumulation in patients with type I and II CD36 deficiency. Ann Nucl Med 12:261-266 (1998)

96) Wojtczak L and Schönfeld P: Effect of fatty acids on energy coupling processes in mitochondria. Biochim Biophys Acta 1183:41-57(1993)

97) Wootan MG and Storch J: Regulation of fluorescent fatty acid transfer from adipocyte and heart fatty acid-binding proteins by acceptor membrane lipid composition and structure. J Biol Chem 269:10517-10523(1994)

98) Yang Y, Spitzer E, Kenney N, Zschiesche W, Li M, Kromminga A, Müller T, Spener F, Lezius A, Veerkamp JH, Smith GH, Salomon DS, and Grosse R: Members of the fatty acid-binding protein family are đifferentiation factors for the mammary gland. J Cell Biol 127:1097-1109 (1994)

99) Young AC, Scapin G, Kromminga A, Patel SB, Veerkamp JH, and Sacchettini JC: Structural studies on human muscle fatty acid-binding protein at $1.4 \AA$ resolution: binding interactions with three $\mathbf{C}_{18}$ fatty acids. Structure 2:523-534 (1994)

100) Zakim D: Fatty acids enter cells by simple diffusion. Proc Soc Exp Biol Med 212:5-14 (1996) 
101) Zanotti G, Feltre L, and Spadon P: A possible route for the release of fatty acid from fatty acid-binding protein. Biochem J 301:459-463 (1994)

102) Zhang F, Kamp F, and Hamilton JA: Dissociation of long- and very long-chain fatty acids from phospholipid bilayers. Biochemistry 35:16055-16060(1996)

103) Zimmerman $\mathrm{AW}$ and Veerkamp JH: Members of the fatty acid-binding protein family inhibit cell-free protein synthesis. FEBS Lett 437:183-186(1998)

34 | Chapter 2 


\section{ChAPTER 3}

EVOLUTION OF THE FAMILY OF INTRACELLULAR LIPID

\section{BINDING PROTEINS IN}

\section{VERTEBRATES}

Schaap FG, van der Vusse GJ, and Glatz JFC: submitted for publication 
In the animal kingdom, members of the intracellular lipid binding protein (iLBP) family are thought to be involved in cytoplasmic transport of hydrophobic ligands, such as long-chain fatty acids and retinoids. iLBPs are low molecular mass proteins (14-16 kDa) with a characteristic structural fold known as the B-barrel. The iLBP family likely arose through duplication and diversification of an ancestral iLBP gene. Phylogenetic methods were used to determine the evolutionary relationships between vertebrate iLBPs and to estimate the time points that gene duplications occurred.

The ancestral iLBP gene presumably arose after divergence of higher eukaryotes from lower eukaryotes and plants. The first gene duplication was dated around 950 million years ago, and subsequent duplications in the succeeding 600 millions of years gave rise to the fourteen iLBP types currently recognized in vertebrates. Four groups of proteins, each binding a characteristic range of ligands, are apparent from the phylogenetic tree. Evolution of different binding properties probably allowed cytoplasmic trafficking of distinct ligands. It is speculated that recruitment of an iLBP during evolution of higher eukaryotes enabled the mitochondrial oxidation of longchain fatty acids.

\section{Introduction}

Efficient transport of hydrophobic molecules in aqueous solutions is supposedly accomplished by specialized binding proteins. The calycins constitute a superfamily of such lipophilic ligand binding proteins and are widely expressed throughout the animal kingdom ${ }^{13}$. Moreover, genomic sequencing revealed the existence of putative homologues in prokaryotes and yeast as well $^{12}$. The calycins share a similar characteristic structural fold known as the B-barrel and are subdivided into three subfamilies: the avidins, the lipocalins, and the intracellular lipid binding proteins (iLBPs) $^{13}$.

The avidins are biotin binding proteins expressed in certain oviparous vertebrates. Biotin is a vitamin cofactor found in for instance acetyl-CoA carboxylase and is bound with very high affinity by avidin $\left(\mathrm{M}_{\mathrm{r}} 16.4 \mathrm{kDa}\right)$. A prokaryotic equivalent (streptavidin, $\mathrm{M}_{\mathrm{r}} 14.5 \mathrm{kDa}$ ) is found in certain Streptomyces strains ${ }^{11}$. The lipocalins form a large subfamily of proteins $\left(\mathrm{M}_{\mathrm{r}} 18-45 \mathrm{kDa}\right)$ with great structural and functional diversity ${ }^{13}$. They are usually secreted proteins and are recognized by specific receptors on the cell surface. Lipocalins have been implicated in diverse biological processes, such as pheromone transport, olfaction, and cryptic coloration ${ }^{13}$. Expression is apparently not confined to members of the animal kingdom, as bacterial lipocalins were recently described ${ }^{12}$. $\operatorname{iLBPs}_{\left(\mathrm{M}_{\mathrm{r}}\right.}$ 14-16 kDa) make up the third calycin subfamily. These cytoplasmic proteins are thought to be involved in cellular uptake and intracellular transport of various hydrophobic compounds, such as long-chain fatty acids (LCFAs) and retinoids ${ }^{9,14}$. Thus far, iLBP expression seems to be restricted to 
species of the animal kingdom. Note that iLBPs are unrelated to plant lipid transfer proteins $\left(M_{\mathrm{r}} 8-9 \mathrm{kDa}\right)$ which bind LCFAs and their CoA esters as well, and have been implicated in the transfer of phospholipids between organelles ${ }^{48}$.

\section{Intracellular lipid binding proteins}

Within the animal kingdom, iLBPs have been identified in both vertebrates and invertebrates although these proteins have been studied most intensively in vertebrates. The evolutionary relationships between vertebrate iLBPs are discussed in this chapter. A short introduction to molecular evolution preludes the description of vertebrate and invertebrate iLBPs.

\section{Evolution of multigene families}

Evolutionary biology is founded on the concept that all species descended from a common ancestor. Likewise, members of a protein family are thought to originate from a common ancestral gene. Duplication of such primordial gene gave rise to two (initially identical) genes which evolved independently through time, and eventually encoded distinct -but related- proteins. Protein families are thus formed from a single ancestral gene through successive rounds of gene duplication and diversification.

Orthologous sequences ('species homologues') are the products of speciation (i.e. the gene was present before speciation occurred) and can thus be used to study the evolution of species. Paralogous sequences result from gene duplications (i.e. the gene arose after speciation) and can thus be used to study the evolutionary relationships between gene species.

Evolution is brought about by transmission of alterations (substitutions) in the genetic material. Substitutions in protein-coding regions of genes can be classified as synonymous (silent) or nonsynonymous ${ }^{36}$. For example, due to degeneracy of the genetic code substitutions at the third position of the Gly codon are synonymous, while substitutions at the other positions of the Gly codon are nonsynonymous as they alter the encoded amino acid (e.g. GGG [Gly] $\rightarrow$ AGG [Arg]).

By comparing orthologous sequences, the evolutionary rate of a sequence pair can be calculated. For this the evolutionary distance (number of substitutions per site) between a pair of sequences is divided by the total time (twice the species divergence time) elapsed since the divergence of the compared species from their common ancestor $^{36}$. For example, the amino acid distance between rat and human H-FABP is 0.126 amino acid substitutions per amino acid site. Rat and human diverged 112 millions of years ago (mya) from their common ancestor ${ }^{27}$. Hence, the total time passed since their divergence is 224 millions of years, yielding an evolutionary rate of $0.56 \cdot 10^{-9}$ amino acid substitutions per amino acid site per year. When comparing two sequences, the observed number of substitutions is corrected for undetected substitutions such as multiple substitutions at a single site. Correction for so-called multiple hits becomes unreliable when the compared sequences are too divergent ${ }^{36}$. 
Evolutionary rates can be used to determine the time of divergence of paralogous sequences as explained further on.

Phylogenetic methods can be employed to study the evolutionary relationships between members of a protein family ${ }^{15,23,36}$. For this, an aligned set of sequences serves as input data.

\section{Vertebrate iLBPs}

A cytoplasmic protein hypothesized to be involved in intracellular transport of LCFAs in mammalian tissues, was first described some thirty years ago ${ }^{30}$ and was later termed fatty acid-binding protein (FABP) ${ }^{37}$. Initially, a single protein was thought to be present in hepatic, intestinal, adipose, and cardiac tissue. Nowadays it is known that the mentioned tissues each express a distinct FABP type, namely liver-type FABP $\left(\mathrm{L}-\mathrm{FABP}_{1}{ }^{\circ}\right.$ ), intestinal-type FABP (I-FABP), adipocyte lipid binding protein (ALBP), and heart-type $\mathrm{FABP}(\mathrm{H}-\mathrm{FABP})^{2,3,14,56}$. Together with the cellular retinol- and retinoic acid-binding proteins $\left(\mathrm{CRBP}_{1 / 2}, \mathrm{CRABP}_{1 / 2}\right)^{9}$ these proteins constitute the iLBP family.

iLBPs are low molecular mass proteins (14-16 kDa) and they share a threedimensional structure consisting of two orthogonal B-sheets and a helical cap ${ }^{1}$ (see Figure 2.2). This structural feature provides an internal cavity which serves as binding site for hydrophobic ligands. The various iLBPs have distinct ligand binding properties. For instance, H-FABP shows high-affinity binding of LCFAs in a 1:1 stoichiometry, whereas $\mathrm{L}-\mathrm{FABP}{ }_{1}$ has been reported to bind a wider variety of ligands including cholesterol, acyl-CoA esters, and LCFAs. A larger cavity volume presumably enables L-FABP, to bind these bulkier ligands, and to accommodate up to two LCFA molecules per protein molecule ${ }^{52}$.

iLBPs have been identified in fishes, amphibians, reptiles and birds, and mammals $^{31}$. Most of our knowledge on iLBP characteristics, however, derives from the study of mammalian iLBPs. Table 3.1 lists some features of the 13 mammalian iLBP types currently known. In rodents, amino acid identity and similarity (BLOSUM62 matrix) between the different iLBPs range between 16-72\% and $36-85 \%$, respectively. Initially, iLBPs were named after their tissue of first isolation. However, several iLBPs have a widespread tissue distribution ${ }^{14}$. For instance, H-FABP is expressed in cardiac and skeletal muscle, brain, kidney, testis, and stomach $^{14}$. Several tissues contain more than one iLBP type, for example expression of brain-type FABP (B-FABP), epidermal-type FABP (E-FABP), and H-FABP was detected in the brain ${ }^{40}$. Note the terminology used to distinguish between iLBPs binding a single class of ligands (FABPs, CRBPs, and CRABPs) and those displaying affinity for a wider range of ligands (LBPs).

\footnotetext{
- Recently, two distinct L-FABPs were identified in liver of the axolotl ${ }^{8}$. L-FABP refers to the protein originally isolated from rat liver ${ }^{37}$, whereas $\mathrm{L}-\mathrm{FABP}{ }_{2}$ denotes the protein initially identified in chicken liver ${ }^{5}$. Note that $\mathrm{L}-\mathrm{FABP}_{2}$ has not yet been identified in mammals.
} 


\begin{tabular}{|c|c|c|c|}
\hline \multicolumn{2}{|c|}{ Gene Symbol } & \multirow{2}{*}{$\begin{array}{l}\text { Main occurrence } \\
\text { Cardiac \& skeletal myocytes }\end{array}$} & \multirow{2}{*}{$\begin{array}{l}\text { Ligands } \\
\text { FA }\end{array}$} \\
\hline Heart-FABP (H-FABP) & FABP3 & & \\
\hline Brain-FABP (B-FABP) & FABP7 & Brain astrocytes & FA \\
\hline Adipocyte LBP (ALBP) & FABP4 & Adipocytes & FA, retinoic acid \\
\hline Myelin P2 (MLBP) & PMP2 & Myelinating Schwann cells & FA, retinoids \\
\hline Testicular LBP (TLBP) & FABP9 & Spermatozoa & $?$ \\
\hline Epidermal-FABP (E-FABP) & FABP5 & Skin & FA, eicosanoids \\
\hline Cellular RBP $\left(\mathrm{CRBP}_{1}\right)$ & RBP1 & Liver & retinol \\
\hline Cellular $\mathrm{RBP}_{2}\left(\mathrm{CRBP}_{2}\right)$ & $\mathrm{RBP} 2$ & Intestine & retinol,retinaldehyde \\
\hline Cellular $\mathrm{RABP}_{1}\left(\mathrm{CRABP}_{1}\right)$ & CRABP1 & Testis & retinoic acid \\
\hline Cellular $\mathrm{RABP}_{2}\left(\mathrm{CRABP}_{2}\right)$ & CRABP2 & Skin & retinoic acid \\
\hline Intestinal-FABP (I-FABP) & FABP2 & Intestinal epithelium & FA \\
\hline Ileal LBP (ILBP) & FABP6 & Ileal enterocytes & FA, bile salts \\
\hline Liver-FABP (L-FABP $\left.{ }_{1}\right)$ & FABP1 & Liver & FA, cholesterol, heme \\
\hline
\end{tabular}

Characteristics of the mammalian iLBPs. Gene nomenclatureaccording to Human Genome Database conventions. The major tissue or cell type expressing a particular iLBP is indicated. Data compiled from references 2,3,9,14, and 56. Abbreviations: $L B P=$ lipid binding protein, $F A B P=$ fatty acidbinding protein, $R B P=$ retinol binding protein, $R A B P=$ retinoic acid-binding protein, $F A=$ longchain fatty acid.

All vertebrate iLBP genes characterized thus far consist of four exons with a similar intron phase (Table 3.2). This common gene organization suggests that duplication and diversification of a common ancestral iLBP gene, gave rise to the present-day iLBP types. In humans, most iLBP genes reside on different chromosomes. Only the genes encoding ALBP/MLBP and $\mathrm{CRBP}_{1} / \mathrm{CRBP}_{2}$ seem tightly linked and may have arisen through direct gene duplication. In addition to transcribed genes, several nonfunctional pseudogenes have been identified in mammalian genomes. For example, an intronless H-FABP pseudogene is found at human chromosomal region $13 \mathrm{q} 13-\mathrm{q} 14^{41}$.

\section{Invertebrate iLBPs}

An invertebrate iLBP (Muscle-FABP $=$ M-FABP) was first isolated from flight muscle of the desert locust Schistocerca gregaria some 10 years $\mathrm{ago}^{20}$. During migratory flight, fatty acids are mobilized from triacylglycerol stores in fat bodies and form the preferred substrate for muscle energy production. Expression of M-FABP 


\begin{tabular}{|c|c|c|c|c|c|c|}
\hline \multirow[b]{2}{*}{ Gene } & \multicolumn{5}{|c|}{ Exon Size (nucleotides) } & \multirow[b]{2}{*}{$\begin{array}{l}\text { Protein } \\
\text { Length }\end{array}$} \\
\hline & -5. UTR & exonl & exon2 & exon3 & exon4 & \\
\hline FABP3 & $1 p 32-p 33$ & 73 & 173 & 102 & 54 & 132 \\
\hline FABP7 & $6 q 22-q 23$ & 73 & 173 & 102 & 51 & 131 \\
\hline FABP4 & $8 q 21-q 22$ & 73 & 173 & 102 & 51 & 131 \\
\hline PMP2 & $8 \mathrm{q} 21.3-\mathrm{q} 22.1$ & 73 & 173 & 102 & 51 & 131 \\
\hline FABP9 & $?$ & 73 & 173 & 102 & 51 & 131 \\
\hline FABP5 & 8 or 17 & 79 & 173 & 102 & 54 & 134 \\
\hline RBP1 & $3 q 21-q 22$ & 73 & 179 & 102 & 54 & 134 \\
\hline RBP2 & 3q21-qter & 73 & 179 & 102 & 51 & 133 \\
\hline CRABPI & $15 q 24$ & 70 & 179 & 114 & 51 & athether \\
\hline CRABP2 & $1 \mathrm{q} 21.3$ & 70 & 179 & 117 & 51 & $37 x+9014$ \\
\hline FABP2 & $4 q 28-q 31$ & 67 & 173 & 108 & 51 & 131 \\
\hline FABP6 & $5 q 23-q 35$ & 67 & 176 & 90 & 54 & 127 \\
\hline FABP1 & $2 \mathrm{pll}$ & 67 & 173 & 93 & 51 & 126 \\
\hline
\end{tabular}

Characteristics of mammalian iLBP genes. The chromosomal location refers to the gene locus in the human genome. Exon sizes are given in nucleotides, the length of the mature protein is given in amino acids. Abbreviations: UTR = untranslated region. Data compiled from Human Genome and OMIM databases, and the following GenBankentries: FABP1 (M13051), FABP2 (M65033), FABP3 (U02884), FABP4 (M13385), FABP5 (AJ223066), FABP6 (U00938), FABP7 (U04827), PMP2/FABP8 (D16179-81), FABP9 (U66878), RBP1 (X07437-8), RBP2 (M16400-2), CRABPI (X51715-7), CRABP2 (M87538-9).

in flight muscle of the migratory locust Locusta migratora amounts up to $18 \%$ of the cytoplasmic protein pool and has been implicated in sustaining prolonged flight periods during migration ${ }^{22}$. Elucidation of the three dimensional structure of flight muscle FABP revealed conservation of the characteristic B-barrel structure ${ }^{21}$. iLBPs have also been identified in other Arthropoda, such as the tobacco hawkmoth Manduca sexta ${ }^{34,47}$ and the mite Blomia tropicalis ${ }^{4}$.

Other invertebrate phyla known to express iLBPs are Nematoda and Platyhelminthes. The completed genomic sequence of the nematode Caenorhabditiselegans revealed the presence of at least four gene products (136-171 amino acids) with $25-45 \%$ amino acid identity with vertebrate iLBPs. In C. elegans the corresponding genes consist of 2-3 exons, while vertebrate iLBP genes are made up of 4 exons interrupted by similarly positioned introns. 
Intravascular parasitic helminths, such as the trematodes Schistosoma japonica and Fasciola hepatica, are unable to synthesize fatty acids and must obtain these compounds from their host's circulation. iLBPs have been implicated in this process and were identified in these, as well as in other, platyhelminths ${ }^{35,43,51}$. The mentioned parasites infect man and cattle, and cause chronic diseases such as fascioliasis. Vaccines have been raised against platyhelminthic iLBPs and these proved useful in protecting against parasitic infections ${ }^{51}$.

Invertebrate and vertebrate iLBPs are clearly related as evidenced by sequence homology (25-47\% amino acid identity) and conservation of structural features. Recently an invertebrate iLBP gene, encoding a protein with presumed retinoic acidbinding properties, was shown to have the same gene organization as vertebrate $\mathrm{iLBPs}^{34}$. These notions suggest that a common ancestral iLBP gene was present before the vertebrate/invertebrate split which occurred 700-600 mya. Reconstruction of vertebrate iLBP evolution may resolve this issue.

\section{Aim of the study}

A previous study by Schleicher and coworkers established the basic evolutionary pattern of the iLBP family ${ }^{46}$. Their phylogenetic tree, which was constructed using the neighbour-joining method ${ }^{15}$, showed several regions where the branching order was unresolved. Hence, the relationships between individual iLBPs could not be clearly defined. In the present study a powerful methodology, i.e. maximumlikelihood analysis, was used to delineate the evolutionary relations between vertebrate iLBPs.

\section{Materials and Methods}

Vertebrate iLBPs for which the entire sequence had been determined (see Appendix-I), were taken from the GenBank (release 110) and SwissProt (release 35) databases. The cloning of a cDNA encoding the equine H-FABP orthologue is reported in AppendixII. For phylogenetic analysis, amino acid and protein-coding nucleotide sequences were aligned using ClustalW ${ }^{53}$. For this, an initial protein alignment was based on the structural information available for ten distinct iLBPs ${ }^{44}$. The remaining iLBP types were subsequently added, and the ensuing alignment was used to guide the alignment of nucleotide sequences. Von Ebner's gland protein (VEGP), which belongs to the lipocalin subfamily of calycins and has a size (159 amino acids) comparable with iLBPs, was used as an outgroup. No additional gaps were introduced by including VEGP in the alignment. Positions showing gaps were excluded from the alignment resulting in an aligned sequence length of 125 amino acids or 375 nucleotides.

Phylogenetic trees were constructed using maximum-likelihood methods implemented in the PUZZLE program ${ }^{50}$ and in programs of the PHYLIP package ${ }^{10}$. For inferring ancestral amino acid sequences the method of Zhang and $\mathrm{Nei}^{58}$, as implemented in ANCESTOR, was used. Maximum-likelihood amino acid distances 
were calculated for orthologous sequence pairs using the PUZZLE program ${ }^{50}$. For determination of (non)synonymous substitution distances between pairs of nucleotide sequences, the method described by Comeron ${ }^{6}$ as implemented in K-estimator, was employed. Species divergence times used for calculating substitution rates were taken from reference 27 (rodents/other mammals: 112 mya, reptiles/aves: 276 mya).
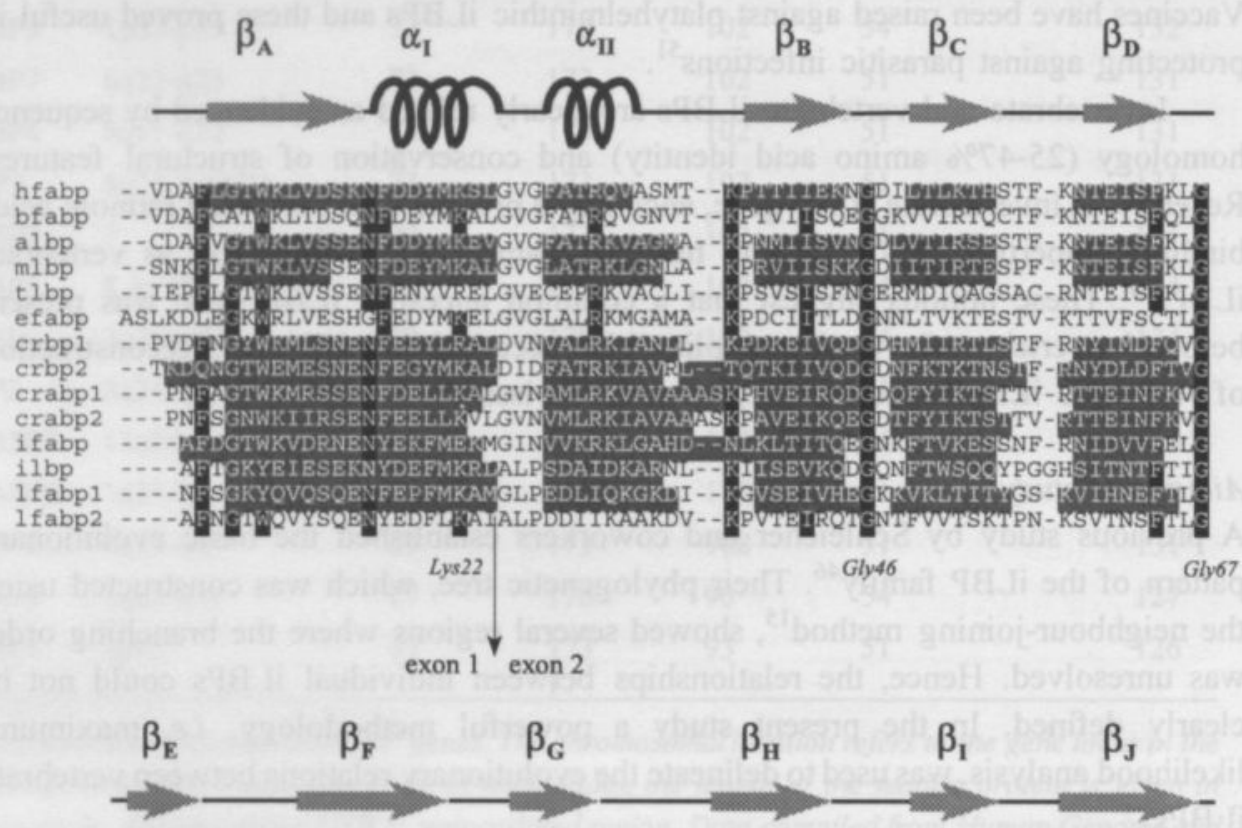

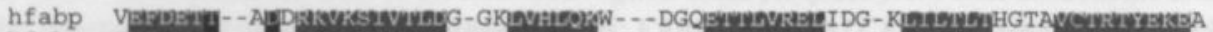

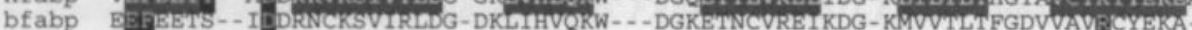

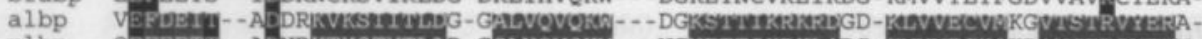

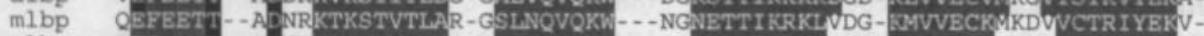

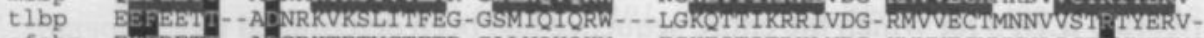

efabp EKSPET - - AD GRKTETVCTFTD-GALVQHQKW - - EGKESTITRKLNDG-KMVVECVMNNAICT PVYEKVQ

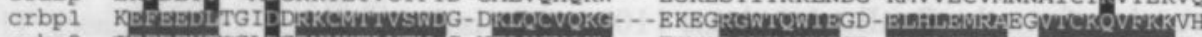

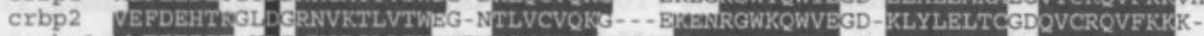

crabp1 EGFBBET--VDGFIKCRSLPTWBNENK IHCTOTELEGDGPKTYWTRELAND-EL I LTFGADDVVCTR IYVRE-

crabp2 ERFBEQT--VDGRPCKSLVKWBSEN|IMV CEQKL LKGEGPKTSWTRELTNDGBLILTMTADDVVCTRVYVRE-

if abp DDFAYSL--ADETBLTGTWTMEG-NKLVGKERR-VDNGKELIAVREISGN-BLIQTYTYEGVEAKR I FKRA-

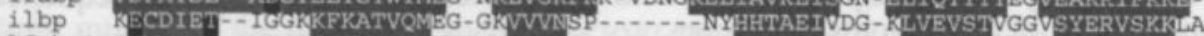

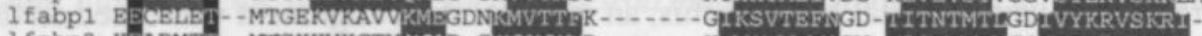

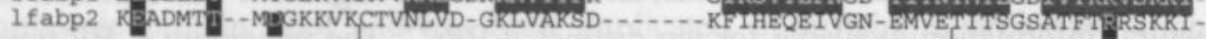

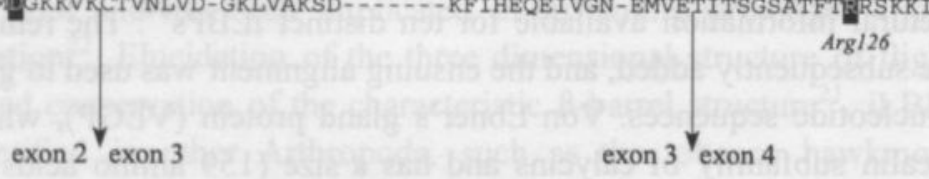

Figure $3.1 \quad$ Alignment of vertebrate iLBP protein sequences based on structural information. The location of secondarystructure elements ( $\alpha$-helices and $\beta$-strands) is shaded in grey and was derived from the following Protein Data Bank entries: H-FABP (IHMR), ALBP (IADL), MLBP (IPMP), $C R B P_{1}$ (ICRB), CRBP ${ }_{2}$ (IOPB), CRABP (ICBI), CRABP ${ }_{2}$ (ICBS), I-FABP (IIFC), ILBP (IEAL), $L-F A B P_{1}(I L F O)$. Residues identical in at least 11 iLBP types are shaded in black. The indicated amino acid residues are explained elsewhere in the text. The exon boundaries of the corresponding genes are indicated. 
Phylogenetic relationships between vertebrate iLBPs

The alignment of vertebrate iLBP protein sequences is shown in Figure 3.1. Several residues are strongly conserved and these have been implicated in ligand binding (e.g. Arg126), collisional interaction with membranes (e.g. Lys22), and protein folding (e.g. Gly46 and Gly67) ${ }^{1}$. A data set consisting of aligned amino acid (60 species) or protein-coding nucleotide sequences ( 54 species) was used for phylogenetic analysis.

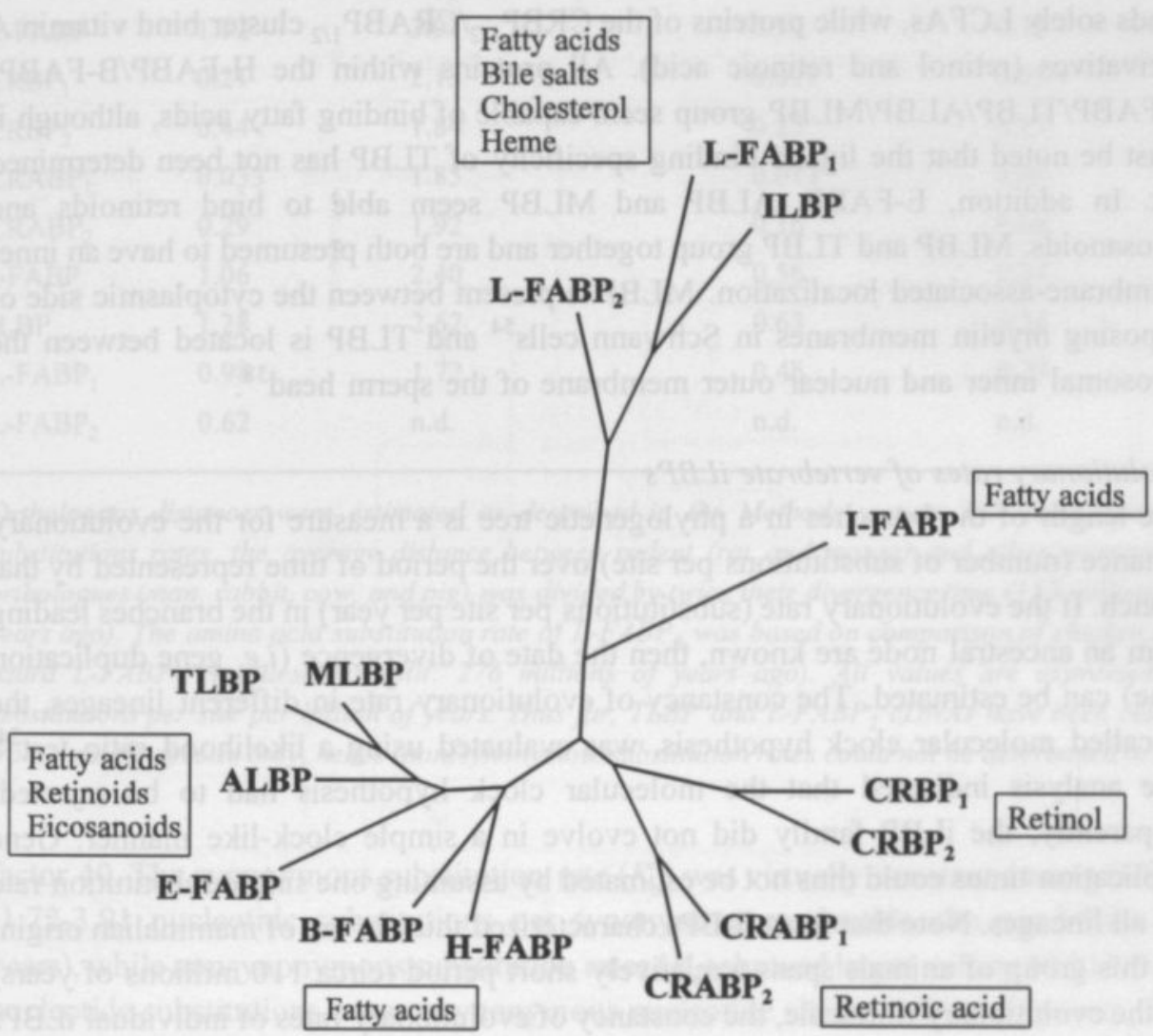

Figure 3.2 Unrooted phylogenetictree showing the evolutionaryrelationships between vertebrate iLBPs. The ligand-bindingspecificity of the various iLBP types is indicated. The tree was constructed by maximum-likelihoodanalysis of a set of 54-60 aligned iLBP sequences. Note that for clarity, the terminal branching pattern has been omitted.

Among phylogenetic methods, maximum-likelihood analysis offers several advantages including the ability to statistically compare different tree topologies using 
a likelihood ratio test ${ }^{24}$. Especially when evolutionary rates differ among lineages, this methodology most likely infers the correct evolutionary relationships between (gene) species $^{19}$. A maximum-likelihood tree depicting the evolution of the iLBP family is shown in Figure 3.2. The tree topology was completely resolved although it must be noted that a short branch connected TLBP/MLBP with ALBP. Some uncertainty in the branching order of MLBP, TLBP, and ALBP may thus exist.

Four different groups of proteins, each apparently binding a distinct range of ligands, are evident from the analysis. Within the ILBP/L-FABP 1 /L-FABP ${ }_{2}$ cluster rather bulky ligands, such as heme, bile salts and cholesterol, are bound. I-FABP binds solely LCFAs, while proteins of the CRBP ${ }_{1 / 2} / \mathrm{CRABP}_{1 / 2}$ cluster bind vitamin $\mathrm{A}$ derivatives (retinol and retinoic acid). All proteins within the H-FABP/B-FABP/ E-FABP/TLBP/ALBP/MLBP group seem capable of binding fatty acids, although it must be noted that the ligand binding specificity of TLBP has not been determined yet. In addition, E-FABP, ALBP and MLBP seem able to bind retinoids and eicosanoids. MLBP and TLBP group together and are both presumed to have an inner membrane-associated localization. MLBP is present between the cytoplasmic side of opposing myelin membranes in Schwann cells ${ }^{54}$ and TLBP is located between the acrosomal inner and nuclear outer membrane of the sperm head ${ }^{38}$.

\section{Evolutionary rates of vertebrate iLBPS}

The length of the branches in a phylogenetic tree is a measure for the evolutionary distance (number of substitutions per site) over the period of time represented by that branch. If the evolutionary rate (substitutions per site per year) in the branches leading from an ancestral node are known, then the date of divergence (i.e. gene duplication time) can be estimated. The constancy of evolutionary rate in different lineages, the so-called molecular clock hypothesis, was evaluated using a likelihood ratio test ${ }^{24}$. The analysis indicated that the molecular clock hypothesis had to be rejected. Apparently, the iLBP family did not evolve in a simple clock-like manner. Gene duplication times could thus not be estimated by assuming one single substitution rate for all lineages. Note that most iLBPs characterized thus far are of mammalian origin. As this group of animals spans a relatively short period (circa 110 millions of years) on the evolutionary timescale, the constancy of evolutionary rates of individual iLBPs in time could not be inspected.

Rate heterogeneity was further assessed by calculating evolutionary rates for individual iLBPs. For this, the amino acid or nucleotide distance between orthologous sequence pairs was computed and divided by twice the species divergence time (Table 3.3). Substitutions in protein-coding genes were divided in silent changes (synonymous substitutions) and changes that altered the encoded amino acid (non-synonymous substitutions). This analysis indicated that the amino acid substitution rate differed widely (0.033-1.28 amino acid substitutions per amino acid site per billion of years) between iLBPs, with the slowest $\left(\mathrm{CRABP}_{1}\right)$ and fastest rate (ILBP) differing by a 
Table 3.3 Substitution rates of vertebrate iLBPs

\begin{tabular}{lllll}
\hline & amino acid & synonymous $\left(K_{s}\right)$ & nonsynonymous $\left(K_{\mathrm{a}}\right)$ & $K_{\mathrm{a}} / K_{\mathrm{s}}$ ratio \\
\hline H-FABP & 0.66 & 2.57 & 0.35 & 0.14 \\
B-FABP & 0.60 & 2.28 & 0.32 & 0.14 \\
ALBP & 0.67 & 2.85 & 0.33 & 0.12 \\
MLBP & 0.65 & 2.38 & 0.28 & 0.12 \\
TLBP & n.d. & n.d. & n.d. & n.d. \\
E-FABP & 1.12 & 3.91 & 0.54 & 0.14 \\
CRBP $_{1}$ & 0.21 & 2.13 & 0.097 & 0.05 \\
CRBP $_{2}$ & 0.44 & 1.84 & 0.25 & 0.13 \\
CRABP $_{1}$ & 0.033 & 1.85 & 0.013 & 0.01 \\
CRABP $_{2}$ & 0.29 & 1.92 & 0.16 & 0.08 \\
I-FABP & 1.06 & 2.40 & 0.56 & 0.23 \\
ILBP & 1.28 & 2.62 & 0.63 & 0.24 \\
L-FABP $_{1}$ & 0.98 & 1.72 & 0.46 & 0.27 \\
L-FABP $_{2}$ & 0.62 & n.d. & n.d. & n.d. \\
\hline
\end{tabular}

Orthologous distances were estimated as described in the Methods section. For calculation of substitutions rates, the average distance between rodent (rat and mouse) and other-mammalian orthologues (man, rabbit, cow, and pig) was divided by twice their divergence time (112 millions of years ago). The amino acid substitution rate of $L-F A B P_{2}$ was based on comparison of chicken and lizard L-FABP ${ }_{2}$ (reptiles/aves split: 276 millions of years ago). All values are expressed as substitutions per site per billion of years. Thus far, TLBP and L-FABP,$c D N A$ s have been cloned from a single species only, hence (non) synonymoussubstitution rates could not be determined (n.d.).

factor 40 . The synonymous substitution rate $\left(K_{\mathrm{s}}\right)$ was virtually constant among iLBPs (1.72-3.91 nucleotide substitutions per synonymous nucleotide site per billion of years), while nonsynonymous substitution rates $\left(K_{\mathrm{a}}\right)$ showed larger variety $(0.013-0.63$ nucleotide substitutions per nonsynonymous nucleotide site per billion of years). The average (non)synonymous substitution rate of iLBPs $\left(K_{\mathrm{s}}=2.37\right.$ and $K_{\mathrm{a}}=0.33$ (non)synonymous substitutions per (non)synonymous site per billion of years) were comparable with values obtained for other mammalian genes $\left(K_{\mathrm{s}}=2.07\right.$ and $K_{\mathrm{a}}=0.38$ (non)synonymous substitutions per (non)synonymous site per billion of years) ${ }^{32}$.

When normalized against $K_{\mathrm{s}}$, the ratio of $K_{\mathrm{a}} / K_{\mathrm{s}}$ provides an index of the evolutionary conservation of a protein. From a large comparative study of rodent and human genes, an average ratio of 0.16 can be calculated ${ }^{32}$. In general, the retinoid binding proteins seemed to be most strongly conserved (e.g. bovine and mouse $\mathrm{CRABP}_{1}$ are fully conserved). Retinoids play an important role in controlling cellular 
growth and differentiation 9 . For exerting their biological function, retinoids interact with nuclear receptors. The cellular retinoid binding proteins presumably have a modulatory role in this process by controlling cellular retinoid levels. Strong conservation of retinoid binding proteins may thus be related to their confined ligand binding properties, or because they need to interact with other proteins. For example, holo-CRBP ${ }_{1}$ is the substrate for the enzyme retinol dehydrogenase ${ }^{39}$. Surprisingly, mice lacking both CRABP genes appeared developmentally normal ${ }^{29}$ suggesting that there is redundancy in cellular binding sites for retinoic acid.

Table 3.4 (Non)synonymous distances between vertebrate iLBPs

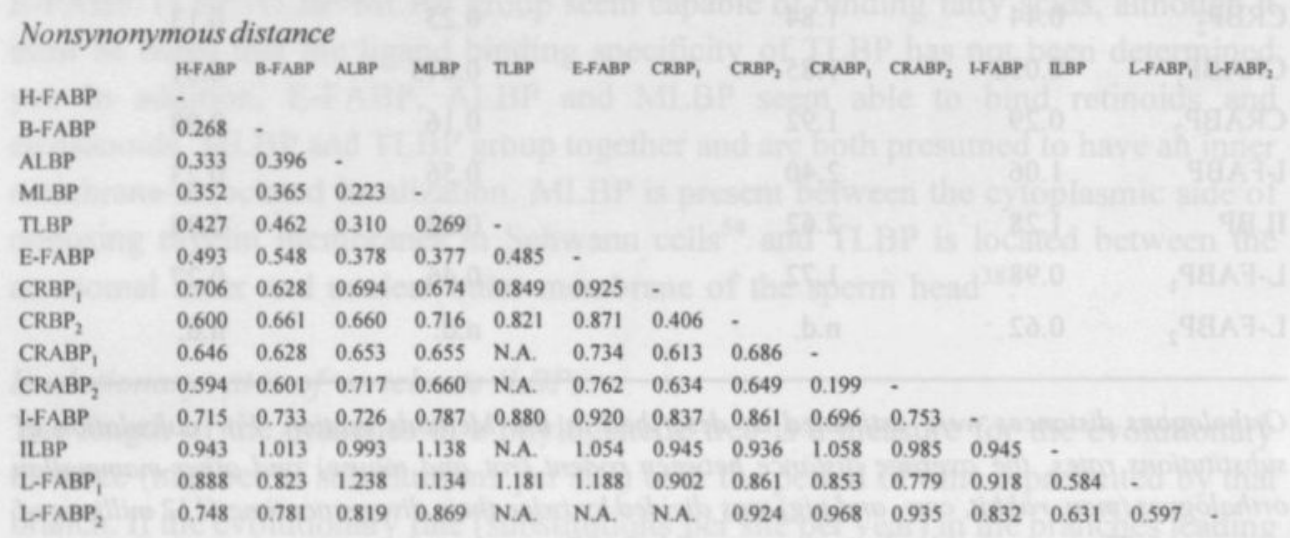

Synonymous distance

\begin{tabular}{lllll} 
& CRBP, & CRBP $_{2}$ & CRABP, \\
CRBP, $_{1}$ & - & & & \\
CRBP $_{2}$ & 1.913 & - & \\
CRABP $_{1}$ & 1.946 & 2.217 & - \\
CRABP $_{2}$ & 2.406 & 2.311 & 1.438 &. \\
\hline
\end{tabular}

Average (non)synonymous distances between paralogous iLBPs were calculated using the method described by Comeron ${ }^{6}$. Values are expressedas (non)synonymoussubstitutions per (non)synonymous mucleotide site. All available orthologues (see Appendix-I) were included in the analysis. N.A. means that Kimura-correction for multiple hits was not applicable and rates could thus not be calculated.

\section{Dating of gene duplication times}

For determining the time points that gene duplications occurred in the iLBP family, synonymous distances between paralogous sequence pairs would be most suitable as the synonymous substitution rate is fairly constant for all iLBPs. However, in most cases these values could not be reliably calculated. For estimating gene duplication times in the $\mathrm{CRABP}_{1 / 2} / \mathrm{CRBP}_{1 / 2}$ cluster, synonymous distances were used (Table 3.4) as nonsynonymous substitution rates varied too widely in this group (Table 3.3). For 
the other estimates of gene duplication times, nonsynonymous distances (Table 3.4) were employed.

For example, to calculate the divergence date of H-FABP and B-FABP, their nonsynonymous distance $(0.268)$ is divided by twice their average nonsynonymous substitution rate $(0.353$ and 0.320 substitutions per site per billion of years, respectively) yielding a value of 399 mya. To date the divergence of the $\mathrm{CRBP}_{1} /$ $\mathrm{CRBP}_{2}$ and $\mathrm{CRABP}_{1} / \mathrm{CRABP}_{2}$ lineages from their last common ancestor, the average synonymous distance between the two groups (average of 1.95, 2.22, 2.41, 2.31) was divided by twice the average synonymous substitution rate in each lineage (1.98 and 1.89 substitutions per site per billion of years) yielding an estimate of 575 mya.

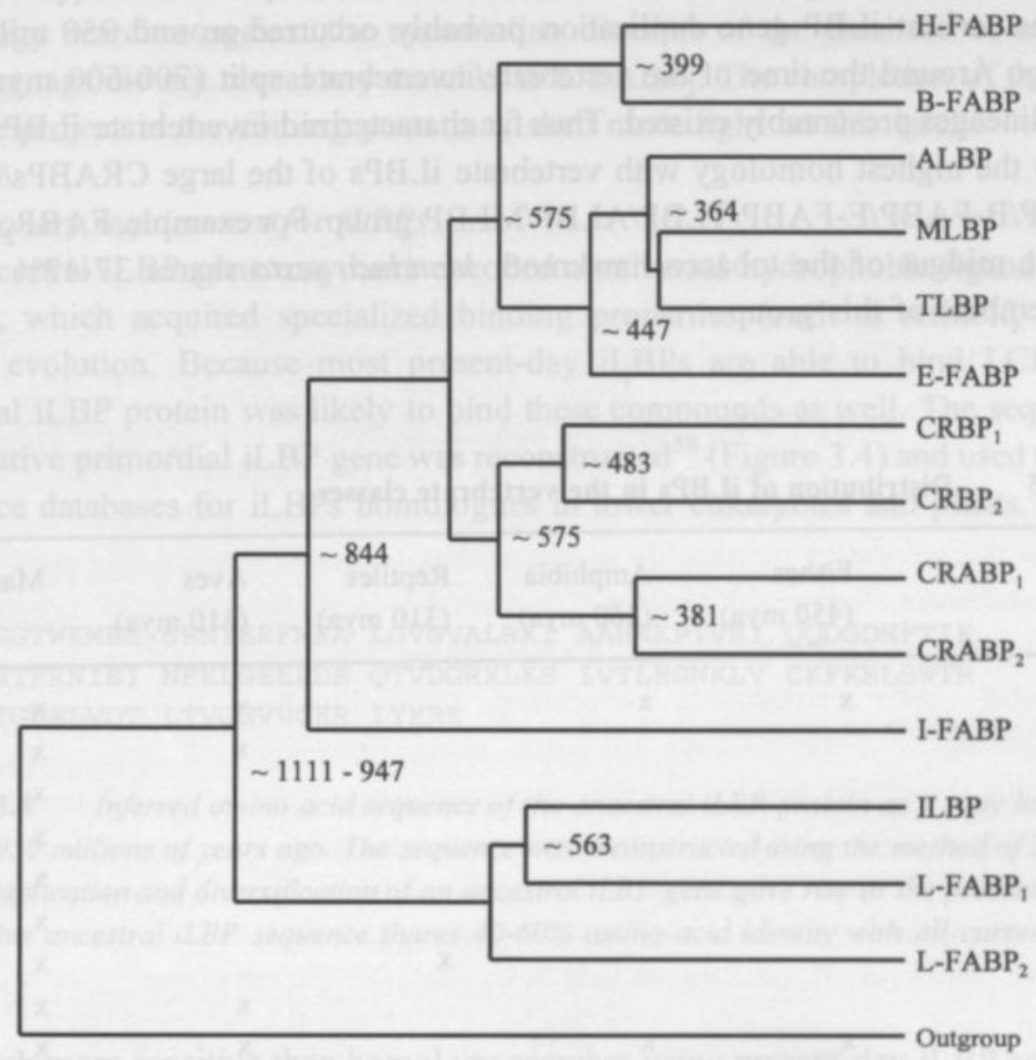

Figure 3.3 Scheme for the evolution of the vertebrate iLBP family. The tree was rooted by including an outgroup (Von Ebner's gland protein) in the phylogenetic analysis. Gene duplication times are shown in millions of years ago and were estimated as described in the text.

The combined results are presented in the tree shown in Figure 3.3. The tree was rooted, that is the location of the deepest branch (i.e. duplication of the primordial iLBP gene) was determined by including an unrelated sequence (outgroup) during tree 
reconstruction. Note that not all branching dates could be determined, either because substitution rates varied too much between the two lineages (e.g. between the $\mathrm{CRABP}_{1 / 2} / \mathrm{CRBP}_{1 / 2}$ and H-FABP/B-FABP/E-FABP/TLBP/MLBP/ALBP groups), or because individual substitution rates could not be calculated (TLBP and L-FABP ${ }_{2}$ ). A time range is given for divergence of the deepest branch. The upper value (1111 mya) was based on the average distance and substitution rate between the ILBP/L-FABP , and I-FABP/H-FABP/B-FABP/E-FABP/ALBP/MLBP groups. Due to variation in the individual substitution rates this value is likely to overestimate the divergence time. The lower value ( $947 \mathrm{mya}$ ) was calculated by using average distance and substitution rate between ILBP/L-FABP 1 and I-FABP/E-FABP as substitution rates of these iLBPs varied less.

The earliest iLBP gene duplication probably occurred around 950 millions of years ago Around the time of the vertebrate/invertebrate split (700-600 mya), three or four lineages presumably existed. Thus far characterized invertebrate iLBPs appear to show the highest homology with vertebrate iLBPs of the large CRABPs/CRBPs/ $\mathrm{H}-\mathrm{FABP} / \mathrm{B}-\mathrm{FABP} / \mathrm{E}-\mathrm{FABP} / \mathrm{TLBP} / \mathrm{ALBP} / \mathrm{MLBP}$ group. For example, $\mathrm{FABP}_{2}$ isolated from the midgut of the tobacco hawkmoth Manduca sexta shares $37-47 \%$ identity with members of this group.

Table 3.5 Distribution of iLBPs in the vertebrate classes

\begin{tabular}{|c|c|c|c|c|c|}
\hline & $\begin{array}{l}\text { Fishes } \\
(450 \text { mya) }\end{array}$ & $\begin{array}{l}\text { Amphibia } \\
\text { (360 mya) }\end{array}$ & $\begin{array}{l}\text { Reptiles } \\
\text { (310 mya) }\end{array}$ & $\begin{array}{l}\text { Aves } \\
\text { (310 mya) }\end{array}$ & Mammals \\
\hline H-FABP & $\mathbf{x}$ & $\mathrm{x}$ & & $\mathrm{x}$ & $\mathrm{x}$ \\
\hline B-FABP & $\sqrt{1}+2$ & & & $\mathrm{x}$ & $\mathrm{x}$ \\
\hline ALBP & & & & & $\mathrm{x}$ \\
\hline MLBP & & & & & $\mathrm{x}$ \\
\hline TLBP & & & & & $\mathrm{x}$ \\
\hline E-FABP & & & & & $\mathrm{x}$ \\
\hline $\mathrm{CRBP}_{1}$ & te & & $\mathrm{x}$ & & $\mathrm{x}$ \\
\hline $\mathrm{CRBP}_{2}$ & & & & $\mathrm{x}$ & $\mathrm{x}$ \\
\hline $\mathrm{CRABP}_{1}$ & $\mathrm{x}$ & $\mathbf{x}$ & & $x$ & $\mathrm{x}$ \\
\hline $\mathrm{CRABP}_{2}$ & & $\mathrm{x}$ & & $\mathrm{x}$ & $\mathrm{x}$ \\
\hline I-FABP & 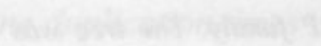 & $\mathrm{x}$ & 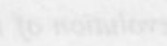 & 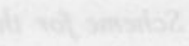 & $\mathrm{x}$ \\
\hline ILBP & 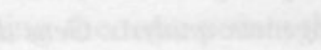 & 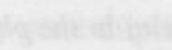 & 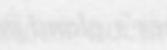 & 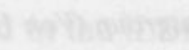 & $\mathrm{x}$ \\
\hline L-FABP 1 & 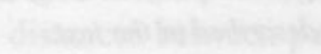 & $\mathrm{x}$ & 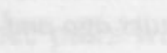 & $x=$ & $x$ \\
\hline $\mathrm{L}-\mathrm{FABP}_{2}$ & $\mathbf{x}$ & $\mathrm{x}$ & $\mathrm{x}$ & $x$ & \\
\hline
\end{tabular}

The presence of the various iLBP types in one of the major vertebrate groups is indicated by an ' $x$ '. The time of divergence of these groups from the mammalian lineage is given in parentheses ${ }^{27}$. Data was compiled from SwissProt, PIR and GenBank databases (see also Appendix-I). 
The phylogenetic distribution of iLBPs in vertebrates seems to correspond well with the estimated times of gene duplications (Table 3.5), although the time of the $\mathrm{CRABP}_{1} / \mathrm{CRABP}_{2}$ split may have been underestimated as a $\mathrm{CRABP}_{1}$ orthologue was found to be present in the pufferfish which diverged 450 mya from the mammalian lineage ${ }^{25}$. In liver of the axolotl Ambystoma mexicanum two iLBPs were recently identified ${ }^{8}$. The first represents the mammalian L-FABP 1 homologue, while L-FABP is closely related to the basic (pI 9.0) L-FABP initially identified in chicken liver 5 . $\mathrm{L}-\mathrm{FABP}_{2}$ diverged from the $\mathrm{L}-\mathrm{FABP}_{1} / \mathrm{ILBP}$ group at least 623 mya, and is therefore likely to be present in all vertebrates. Thus far, this iLBP type has been recognized only in fishes, amphibians, reptiles and birds. It will be interesting to learn whether this iLBP type is also expressed in mammals or whether its gene has been silenced. Homology searches against the mammalian division of the database of expressed sequence tags did not reveal any matches to $\mathrm{L}-\mathrm{FABP}_{2}$. The completion of the human genome project in the coming years may shed more light on this issue.

\section{Evolutionary requirement for iLBPs}

The ancestral iLBP gene may have encoded a universal hydrophobic ligand binding protein, which acquired specialized binding properties (such as retinoid binding) during evolution. Because most present-day iLBPs are able to bind LCFAs, the ancestral iLBP protein was likely to bind these compounds as well. The sequence of the putative primordial iLBP gene was reconstructed ${ }^{58}$ (Figure 3.4) and used to search sequence databases for iLBPs homologues in lower eukaryotes and plants.

\section{AFSGTWKMES SENYEBFMKA LGVNVALRKI AAHAKPTVEI QQDGDNFTIK 50 TSSTFRNIEI NFKLGEEFDE QTVDGRKLKS IVTLEGNKLV CKFKELSWTR 100 EITGDELVQT LTVGGVVCKR IYKRE

Figure 3.4 Inferred amino acid sequence of the ancestral iLBP protein as it may have existed around 950 millions of years ago. The sequence was reconstructed using the method of Zhang and $N e i^{58}$. Duplication and diversification of an ancestral iLBP gene gave rise to the present-day iLBP types. This ancestral iLBP sequence shares 40-60\% amino acid identity with all currently known iLBPs.

Although more sensitive than homology searches using present-day iLBP sequences, no significant matches were found when searches were performed against plant sequences or against the completed genome of the yeast Saccharomyces cerevisiae. Note that a 15-kDa protein with fatty acid-binding properties -but apparently unrelated to vertebrate iLBPs- has been reported for the yeast Yarrowia lipolytica ${ }^{7}$. Apparently, the ancestral iLBP gene arose after divergence of the higher eukaryotes from lower eukaryotes and plants (1200-1000 mya). Expression of iLBPs seems thus confined to members of the animal kingdom. 
iLBPs are thought to promote intracellular trafficking of hydrophobic molecules. Diverse iLBPs may have evolved to enable cytoplasmic transport of distinct ligands. For example, simultaneous expression of $\mathrm{L}^{-F A B P}{ }_{1}$, ILBP, I-FABP, $\mathrm{CRBP}_{2}$ and $\mathrm{CRABP}_{1}$ found in intestinal tissue may provide soluble carrier proteins for cholesterol and bile salts, and dietary LCFAs, retinol, and retinoic acid, respectively. The need for multiple iLBPs with apparently identical ligand binding properties (e.g. H-FABP and $\mathrm{B}-\mathrm{FABP}$ ) is however less obvious.

Recently, we demonstrated for the first time a physiological role of H-FABP in cellular utilization of fatty acids (Chapter 6). Using H-FABP knock-out mice, we showed that uptake and oxidation of palmitate was impaired -albeit not completely abolished- in cardiac myocytes isolated from $\mathrm{H}-\mathrm{FABP}^{-/}$mice. Apparently, intracellular trafficking of LCFAs towards mitochondria was affected in $\mathrm{H}-\mathrm{FABP}^{-/}$ cardiac myocytes. From an evolutionary perspective, the emerging of a cytoplasmic carrier of water-insoluble LCFAs may be related to the development of mitochondrial oxidation of LCFAs.

Most organisms are capable of catabolizing fatty acids to some extent. For example, the yeast Saccharomycescerevisiae is able to grow on LCFAs as sole carbon source, while during germination fatty acid oxidation occurs in fat-storing plants seeds $^{18}$. In prokaryotes, fatty acids are oxidized in the cytoplasm and ensuing oxidative phosphorylation occurs at the inner cell membrane. In lower eukaryotes and plants, oxidation of fatty acids proceeds solely in peroxisonnes ${ }^{28}$, whine oxidative phosphorylation occurs in the mitochondria. Peroxisomal supply of LCFAs in the form of acyl-CoA esters is probably accomplished by acyl-CoA binding protein ${ }^{26}$. In higher eukaryotes, fatty acid oxidation and oxidative phosphorylation occur in the same compartment (mitochondrion), a situation reminiscent to prokaryotes.

During early eukaryotic evolution, mitochondria were acquired as endosymbionts $^{16,17}$. For LCFAs to reach these newly-gained organelles, these hydrophobic molecules needed to cross the cytoplasmic fluid in an efficient manner. The emergence of an iLBP in higher eukaryotes may have been the evolutionary solution to this problem. Mitochondrial oxidation of fatty acids has the advantage of directly linking the $B$-oxidation and oxidative phosphorylation pathways, and is more efficient in terms of energy yield than peroxisomal fatty acid oxidation. Both iLBP expression and mitochondrial B-oxidation are apparently restricted to higher eukaryotes. This possible correlation is supported by the observation that certain marine invertebrates (echinoderms, molluscs and crustaceans) seem to lack iLBPs. Although these animals possess functional mitochondria, they appear to oxidize LCFAs in peroxisomes ${ }^{49}$. In these groups of species, mitochondria may be involved in oxidation of chain-shortened fatty acids. From our own experiments on LCFA utilization by $\mathrm{H}-\mathrm{FABP}^{\%}$ cardiac myocytes (Chapter 6 ) it appears that H-FABP is facilitative -but not obligatory- for mitochondrial oxidation of LCFAs. In the absence of H-FABP, LCFAs are probably oxidized in mitochondria located within short 
diffusion distance of the sarcolemma. Hence, H-FABP can be seen as an evolutionary adaptation to achieve high rates of LCFA utilization in cells where the diffusion distance between the site of uptake and the site of metabolic conversion is relatively large.

In conclusion, a scheme for the evolution of the vertebrate iLBP family is presented. An ancestral iLBP gene probably arose after divergence of higher eukaryotes from lower eukaryotes and plants. The first iLBP gene duplication was estimated to have occurred around 950 millions of years ago. Subsequent duplications gave rise to the 14 iLBP types currently known in vertebrates. The appearance of an iLBP during evolution of higher eukaryotes may have substantially enhanced the capacity of mitochondria and other organelles to metabolize LCFAs by facilitating transport of these hydrophobic substances from the cell membrane to the intracellular site of metabolic conversion.

\section{References}

1) Banaszak L, Winter N, Xu Z, Bernlohr DA, Cowan S, and Jones TA: Lipid binding proteins: a family of fatty acid and retinoid transport proteins. Adv Protein Chem 45:89-151 (1994)

2) Bernlohr DA, Simpson MA, Hertzel AV, and Banaszak LJ: Intracellular lipid binding proteins and their genes. Annu Rev Nutr 17:277-303(1997)

3) Börchers T and Spener F: Fatty acid-binding proteins. Curr Top Membr 40:261-294 (1994)

4) Caraballo L, Puerta L, Jimenez S, Martinez B, Mercado D, Avjiouglu A, and Marsh D: Cloning and IgE binding of a recombinant allergen from the mite Blomia tropicalis, homologous with fatty acid-binding proteins. Int Arch Allergy Immunol 112:341-347 (1997)

5) Ceciliani F, Monaco HL, Ronchi S, Faotto L, and Spadon P: The primary structure of a basic (pI 9.0) fatty acid-binding protein from liver of Gallus domesticus. Comp Biochem Physiol B Biochem Mol Biol 109:261-271 (1994)

6) Comeron JM: A method for estimating the numbers of synonymous and nonsynonymous substitutions per site. J Mol Evol 41:1152-1159(1995)

7) Dell'Angelica EC, Ermácora MR, and Santomé JA: Purification and partial characterization of a fatty acid-binding protein from the yeast, Yarrowia lipolytica. Biochem Mol Biol Int 39:439-445 (1996)

8) Di Pietro SM, Veerkamp JH, and Santomé JA: Isolation, amino acid sequence determination and binding properties of two fatty acid-binding proteins from axolotl (Ambistoma mexicanum) liver. Eur J Biochem 259:127-134(1999)

9) Donovan M, Olofsson B, Gustafson AL, Dencker L, and Eriksson U: The cellular retinoic acidbinding proteins. J Steroid Biochem Mol Biol 53:459-465 (1995)

10) Felsenstein J: PHYLIP (Version 3.57). Distributed by the author, University of Washington, Seattle (1993)

11) Flower DR: Structural relationship of streptavidin to the calycin protein superfamily. FEBS Lett 333:99-102 (1993)

12) Flower DR, Sansom CE, Beck ME, and Attwood TK: The first prokaryotic lipocalins. Trends Biochem Sci 20:498-499 (1995)

13) Flower DR: The lipocalin protein family: structure and function. Biochem J318:1-14(1996) 
14) Glatz JFC and van der Vusse GJ: Cellular fatty acid-binding proteins: their function and physiological significance. Prog Lipid Res 35:243-282 (1996)

15) Goldman N: in DNA and protein sequence analysis - a practical approach (Chapter 15). Eds. Bishop MJ and Rawlings CJ. IRL Press - Oxford (1997)

16) Gray MW: Origin and evolution of organelle genomes. Curr Opin Genet Dev 3:884-890 (1993)

17) Gray MW, Burger G, and Lang BF: Mitochondrial Evolution. Science 283:1476-1481(1999)

18) Harwood J: Fatty acid metabolism. Ann Rev Plant Physiol Plant Mol Biol 39:101-138(1988)

19) Hasegawa M, Kishino $H$, and Saitou N: On the maximum-likelihood method in molecular phylogenetics. $J$ Mol Evol 32:443-445 (1991)

20) Haunerland NH and Chisholm JM: Fatty acid-binding protein in flight muscle of the locust, Schistocerca gregaria. Biochim Biophys Acta 1047:233-238(1990)

21) Haunerland NH, Jacobson BL, Wesenberg G, Rayment I, and Holden HM: Three-dimensional structure of the muscle fatty acid-binding protein isolated from the desert locust Schistocerca gregaria. Biochemistry 33:12378-12385(1994)

22) Haunerland NH: Fatty acid-binding protein in locust and mammalian muscle. Comparison of structure, function and regulation. Comp Biochem Physiol B Biochem Mol Biol 109:199-208 (1994)

23) Hillis DM, Allard MW, and Miyamoto MM: Analysis of DNA sequence data: phylogenetic inference. Methods Enzymol 224:456-487 (1993)

24) Huelsenbeck JP and Rannala B: Phylogenetic methods come of age: testing hypotheses in an evolutionary context. Science 276:227-232(1997)

25) Kleinjan DA, Dekker S, Guy JA, and Grosveld FG: Cloning and sequencing of the CRABP1 locus from chicken and pufferfish: analysis of the promoter regions in transgenic mice. Transgenic Res 7:85-94 (1998)

26) Knudsen J, Færgeman NJ, Skott H, Hummel R, Borsting C, Rose TM, Andersen JS, Højrup P, Roepstorff $\mathrm{P}$, and Kristiansen K: Yeast acyl-CoA binding protein: acyl-CoA binding affinity and effect on intracellular acyl-CoA pool size. Biochem $J$ 302:479-485 (1994)

27) Kumar S and Hedges SB: A molecular timescale for vertebrate evolution. Nature 392:917-920 (1998)

28) Kunau WH, Bühne S, de la Garza M, Kionka C, Mateblowski M, Schultz-Borchard U, and Thieringer R: Comparative enzymology of B-oxidation. Biochem Soc Trans 16:418-420(1987)

29) Lampron C, Rochette-Egly C, Gorry P, Dollé P, Mark M, Lufkin T, LeMeur M, and Chambon P: Mice deficient in cellular retinoic acid-binding protein II (CRABPII) or in both CRABPI and CRABPII are essentially normal. Development 121:539-548(1995)

30) Levi AJ, Gatmaitan Z, and Arias IM: Two hepatic cytoplasmic protein fractions, Y and Z, and their possible role in the hepatic uptake of bilirubin, sulfobromophthalein, and other anions. J Clin Invest 48:2156-2167(1969)

31) Londraville RL: Intracellular fatty acid-binding proteins: putting lower vertebrates in perspective. Braz J Med Biol Res 29:707-720(1996)

32) Makalowski W and Boguski MS: Evolutionary parameters of the transeribed mammalian genome: an analysis of $\mathbf{2 , 8 2 0}$ orthologous rodent and human sequences. Proc Natl Acad Sci U S A 95:9407-9412(1998)

33) Malpeli G, Stoppini M, Zapponi MC, Folli C, and Berni R: Interactions with retinol and retinoids of bovine cellular retinol-binding protein. Eur J Biochem 229:486-493(1995) 
34) Mansfield SG, Cammer S, Alexander SC, Muehleisen DP, Gray RS, Tropsha A, and Bollenbacher WE: Molecular cloning and characterization of an invertebrate cellular retinoic acid-binding protein. Proc Natl Acad Sci U S A 95:6825-6830(1998)

35) Moser D, Tendler M, Griffiths G, and Klinkert MQ: A 14-kDa Schistosoma mansoni polypeptide is homologous to a gene family of fatty acid-binding proteins. $J$ Biol Chem 266:8447-8454(1991)

36) Nei M: Molecular evolutionary genetics. Columbia University Press - New York (1987)

37) Ockner RK, Manning JA, Poppenhausen RB, and Ho WK: A binding protein for fatty acids in cytosol of intestinal mucosa, liver, myocardium, and other tissues. Science 177:56-58 (1972)

38) Oko R and Morales CR: A novel testicular protein, with sequence similarities to a family of lipid binding proteins, is a major component of the rat sperm perinuclear theca. Dev Biol 166:235-245(1994)

39) Ottonello S, Scita G, Mantovani G, Cavazzini D, and Rossi GL: Retinol bound to cellular retinol-binding protein is a substrate for cytosolic retinoic acid synthesis. $J$ Biol Chem 268:27133-27142(1993)

40) Owada Y, Yoshimoto $T$, and Kondo H: Spatio-temporally differential expression of genes for three members of fatty acid binding proteins in developing and mature rat brains. $J \mathrm{Chem}$ Neuroanat 12:113-122(1996)

41) Prinsen CFM, Weghuis DO, Kessel AG, and Veerkamp JH: Identification of a human heart FABP pseudogene located on chromosome 13. Gene 193:245-251 (1997)

42) Rajan N, Kidd GL, Talmage DA, Blaner WS, Suhara A, and Goodman DS: Cellular retinoic acid-binding protein messenger RNA: levels in rat tissues and localization in rat testis. $J$ Lipid Res 32:1195-1204(1991)

43) Rodríguez-Pérez J, Rodríguez-Medina JR, García-Blanco MA, and Hillyer GV: Fasciola hepatica: molecular cloning, nucleotide sequence, and expression of a gene encoding a polypeptide homologous to a Schistosoma mansoni fatty acid-binding protein. Exp Parasitol 74:400-407 (1992)

44) Sander C: The FSSP database: fold classification based on structure-structure alignment of proteins. Nucleic Acids Res 24:206-209 (1996)

45) Schaap FG, Specht B, van der Vusse GJ, Börchers T, and Glatz JFC: One-step purification of rat heart-type fatty acid-binding protein expressed in Escherichia coli. $J$ Chromatogr $B$ Biomed Appl 679:61-67 (1996)

46) Schleicher CH, Córdoba OL, Santomé JA, and Dell'Angelica EC: Molecular evolution of the multigene family of intracellular lipid binding proteins. Biochem Mol Biol Int 36:1117-1125 (1995)

47) Smith AF, Tsuchida K, Hanneman E, Suzuki TC, and Wells MA: Isolation, characterization, and cDNA sequence of two fatty acid-binding proteins from the midgut of Manduca sexta larvae. J Biol Chem 267:380-384(1992)

48) Spener $F$ and Mukherjea M: Nonenzymatic proteins mediating intracellular lipid transport and metabolism. Current status and emerging trends. Subcell Biochem 16:1-19 (1990)

49) Stewart JM, Carlin RC, MacDonald JA, and Iderstine Sv: Fatty acid-binding proteins and fatty acid catabolism in marine invertebrates: peroxisomal B-oxidation. Invert Reprod Devel 25:73-82 (1994)

50) Strimmer K and von Haeseler A: Quartet puzzling: a quartet maximum-likelihood method for reconstructing tree topologies. Mol Biol Evol 13:964-969(1996) 
51) Tendler M, Brito CA, Vilar MM, Serra-Freire N, Diogo CM, Almeida MS, Delbem AC, Da Silva JF, Savino W, Garratt RC, Katz N, and Simpson AS: A Schistosoma mansoni fatty acid-binding protein, $\mathrm{Sm14}$, is the potential basis of a dual-purpose anti-helminth vaccine. Proc Natl Acad Sci US A 93:269-273 (1996)

52) Thompson J, Winter N, Terwey D, Bratt J, and Banaszak L: The crystal structure of the liver fatty acid-binding protein. A complex with two bound oleates. J Biol Chem 272:7140-7150 (1997)

53) Thompson JD, Higgins DG, and Gibson TJ: CLUSTAL W: improving the sensitivity of progressive multiple sequence alignment through sequence weighting, position-specific gap penalties and weight matrix choice. Nucleic Acids Res 22:4673-4680(1994)

54) Trapp BD, Dubois-Dalcq M, and Quarles RH: Ultrastructural localization of P2 protein in actively myelinating rat Schwann cells. $J$ Neurochem 43:944-948 (1984)

55) Tweedie $\mathrm{S}$ and Edwards $\mathrm{Y}$ : cDNA sequence for mouse heart fatty acid-binding protein, H-FABP. Nucleic Acids Res 17:4374 (1989)

56) Veerkamp JH and Maatman RG: Cytoplasmic fatty acid-binding proteins: their structure and genes. Prog Lipid Res 34:17-52 (1995)

57) Wahle $\mathrm{E}$ and Keller W: The biochemistry of poly-adenylation. Trends Biochem Sci 21:247-250 (1996)

58) Zhang $\mathrm{J}$ and Nei $\mathrm{M}$ : Accuracies of ancestral amino acid sequences inferred by the parsimony, likelihood, and distance methods. J Mol Evol 44S1:139-146(1997) 
The following iLBP sequences were employed in this study. Accession numbers refer to entries in the SwissProt (italicized) or GenBank databases. Species abbreviations are as follows: Am (Ambystoma mexicamum, axolotl), Ap (Anolis pulchellus, lizard), Bt (Bos taurus, cow), $\mathrm{Fr}$ (Fugu rubripes, puffer fish) Gg (Gallus gallus, chicken), Hs (Homo sapiens, man), Mm (Mus musculus, mouse), Oc (Oryctolaguscuniculus, rabbit), Om (Oncorhynchusmykiss, trout), Rn (Rattus norvegicus, rat), Rs (Rhamdia sapo, catfish), Ss (Sus scrofa, pig), XI (Xenopus laevis, African clawed frog)

H-FABP: $\quad$ Bt (X12710), Hs (X56549), Mm (U02883), Om (U95296), Rn (J02773), Ss (X98558)

B-FABP: $\quad$ Gg (X65459), Hs (AJ002962), Mm (S69799), Rn (U02096)

ALBP: $\quad$ Bt (X89244), Hs (J02874), Mm (K02109), Rn (U75581), Ss (AF102872)

MLBP: $\quad$ Bt (P02690), Hs (X62167), Oc (J03744), Mm (S39508)

TLBP: $\quad$ Rn (U09022)

E-FABP: $\quad$ Bt (U55188), Hs (M94856), Mm (X70100), Rn (S83247)

CRBP $_{1}$ : $\quad$ Bt (reference 33), Hs (M11433), Mm (X60367), Rn (M16459)

CRBP $_{2}$ : $\quad$ Hs (U13831), Mm (X74154), Rn (M13949), Ss (X77639,41)

CRABP $_{1}$ : Bt (X07436), Fr (Y12240), Hs(S74445), Mm (X51715-7), Rn (reference 42)

CRABP $_{2}$ : Hs (M68867), Mm (M87538-9), Rn (U23407), XI (S74933)

I-FABP: $\quad$ Hs (M18079), Mm (M65034), Rn (M35992), XI (L19946)

ILBP: $\quad$ Hs (U19869), Mm (U00938), Oc (Z54345), Rn (S52878), Ss (J05136)

L-FABP ${ }_{1}$ : $\quad$ Bt (X86904), Hs (M10617), Mm (Y14660), Rn (M35991), Ss (X77640)

L-FABP $_{2}: \quad$ Am $(P 81400)$, Ap (U28756), Gg (P80226), Rs (P80856)

\section{Universal resource locators for access to databases}

Human Genome Database: http://www.hgmp.mrc.ac.uk/gdb/

GenBank Database: http://www.ncbi.nlm.nih.gov/Entrez/

OMIM Database: $\quad$ http://www3.ncbi.nlm.nih.gov/Omim/

Protein Data Bank: $\quad$ http://www2.ebi.ac.uk/pdb/index.shtml

PIR/SwissProt Database: http://www.expasy.ch/srs5/ 


\section{Materials and Methods}

Reverse transcriptase and DNA ligase were from Life Technologies(Breda, The Netherlands). Oligonucleotides were as follows: FABP1 (5'CCATATGGCGGACGCCTTTGTCGGTA) is homologous to $n$ t $1-22$ of the coding region of mouse $\mathrm{H}-\mathrm{FABP} \mathrm{cDNA}^{55}$ and introduced an Ndel site for eventually cloning the cDNA into the pET3a expression vector ${ }^{45}$, the oligo-T primer (5'GCTAGTTATTGCTCAGCGGTTTTTTTTTTTTTTTTTTV) contains a poly-T stretch anchored to T7 (5'GCTAGTTATTGCTCAGCGG). Oligonucleotideswere purchased from Pharmacia Biotech (Roosendaal, The Netherlands).

\section{Cloning of equine $H-F A B P$ cDNA}

RNA was isolated from horse heart, which was obtained from a local abattoir, using Trizol ${ }^{\mathrm{TM}}$ reagent (Life Technologies). First strand cDNA was obtained by oligo-T primed reverse transcription of 5 $\mu \mathrm{g}$ total heart RNA. Reaction products were amplified by PCR $\left(25\right.$ cycles of $1 \mathrm{~min} 94^{\circ} \mathrm{C}, 1 \mathrm{~min}$ $50^{\circ} \mathrm{C}$, and $1 \mathrm{~min} 72^{\circ} \mathrm{C}$ ) employing Taq polymerase (Pharmacia Biotech) and primers FABP1 and T7. A single fragment of circa $700 \mathrm{bp}$ was visible following separation of PCR products on an agarose gel. The fragment was purified from gel using Qiaex (Qiagen Inc., USA) and ligated into the $\mathrm{pCR}_{\|}$ vector (Invitrogen BV, Leek, The Netherlands). Both strands of the insert were sequenced using fluorescent dye technology (Perkin Elmer, USA).

\section{Results}

The sequence of equine H-FABP cDNA is shown below (Genbank accession number AF143950). The coding region is shown in uppercase, and the 3' untranslated region is depicted in lower case. Note that the 5' untranslated region has not been cloned, and that nt 1-22 of the coding region (shown in bold) are de facto derived from the mouse H-FABP cDNA sequence. A canonical poly-adenylation site (underlined) is found $14 \mathrm{nt}$ upstream of the poly-A tail ${ }^{57}$. The inferred amino acid sequence of horse H-FABP is shown at the bottom of this page. Equine H-FABP is most homologous with porcine $\mathrm{H}-\mathrm{FABP}$ ( 117 out of 125 identical residues). Isolation of $\mathrm{H}-\mathrm{FABP}$ protein from horse heart, and $\mathrm{N}$-terminal sequence analysis is required to uncover the amino acids (indicated by $\mathrm{x}$ ) not deducable using the employed cloning procedure.

\section{Nucleotide sequence of equine $H-F A B P$ cDNA}

ATGGCgQA CGCCTTTOTCGGTACCTGGAMGCTAGTGGACAGCAAGATTTCGATGACTACATGAAGTCAATCGGTGTGGGTTTTGCTACCAGGCAGGTAG CCAACATGACCAAGCCTACCACAATCATCGAAGTAAATGGGGACACTATCACCATAAAACACACAGCACCTTCAAGAACACGGAGATCAGCTTCAAGCT GGGGGTGGAGTTTGATGAGACAMCAGCAGATGACAGGAAGGTCAAGTCCCTTGTGACACTGGATGGAGGCAAACTTGTCCATGTGCAGGAGTGGAATGGG CAAGAGACNACACTCGTGCGGGAGCTAATTGATGGAAAACTCATCCTGACACTCACCCATGGCAGCGCAGTGAGCACTCGTACTTACGAGAAAGAGGCCT GAcetactggetecttcactgactgegectetgccaagtggetgectgtggactcagcaccagattgectcatttttectetggcattttgtataaacC cagettggttggggaagttcttetgggetcagggggcaccagectggatctagttccagtteccattgtgtatgtgtgttttttaactgcatgcagagtg tgetctgaagtcaataaagcagagctaagaccaaaaaaaaaaaaaaaaa

\section{Deduced amino acid sequence of equine H-FABP}

xxxxxxocxW LVDSKNFDDY MKSIGVGFAT ROVANATKPT TIIEVNGDTI TIKTHSTFKN TEISFKLGVE FDETTADDRK VKSLVTLDGG KLVHVOEWNG OETTLVRELI DGKLILTLTH GSAVSTRTYE KEA 


\section{Chapter 4 \\ NEW METHODOLOGIES}

\section{Adapted from:}

Schaap FG, Specht B, van der Vusse GJ, Börchers T, and Glatz JFC: J Chromatogr B Biomed Apl 679:61-67 (1996)

Schaap FG, Binas B, Danneberg H, van der Vusse GJ, and Glatz JFC: Circ Res, under revision 


\section{Outline of this chapter}

For studying the function of heart-type fatty acid-binding protein (H-FABP) in vitro, the availability of pure protein is a prerequisite. Previously a method had been developed to purify H-FABP from rat heart. Although relatively rich in H-FABP, a single rat heart contains only circa $0.74 \mathrm{mg} \mathrm{H}-\mathrm{FABP}$. When bulk amounts of H-FABP are needed, a large number of hearts is required. Alternatively, making use of recombinant expression of $\mathrm{H}-\mathrm{FABP}$, large amounts of pure protein are readily obtained. In the first part of this chapter a method is described for efficient purification of recombinant H-FABP.

Recently, mice with a targeted disruption of the H-FABP gene were created. These knock-out mice allowed us to study the functions of H-FABP in a more physiological context, i.e. isolated cardiac myocytes. Since a method was lacking to efficiently isolate cardiac myocytes from the mouse heart, we developed a technique for this purpose (see second part of this chapter). Its application in studying the role of H-FABP in myocardial fatty acid utilization is described in Chapter 6.

\section{PART 1:}

\section{ONE-STEP PURIFICATION OF RAT H-FABP EXPRESSED IN ESCHERICHIA COLI}

\section{Abstract}

H-FABP is a member of a family of $14-16 \mathrm{kDa}$ lipid binding proteins which are believed to enhance intracellular transport of lipids by facilitating their cytoplasmic diffusion. To obtain sufficient amounts of protein for in vitro studies, we expressed rat $\mathrm{H}-\mathrm{FABP}$ in Escherichia coli and compared its biochemical properties with the protein isolated from rat heart. An effective method was developed to purify recombinant rat H-FABP from cell lysates in a single step using anion-exchange chromatography. Besides, this method proved to be applicable for purifying heterologously expressed human H-FABP. Recombinant rat H-FABP, which made up approximately $25 \%$ of the soluble proteins in E. coli, was obtained in a yield of $30-40$ $\mathrm{mg} \cdot \mathrm{l}^{-1}$ culture. Characterization showed that recombinant rat H-FABP was indistinguishable from the protein isolated from rat heart regarding molecular mass and oleate binding. Some heterogeneity upon isoelectric focusing was observed, presumably due to differences in $\mathrm{N}$-terminal processing of the recombinant protein. In conclusion, a method is presented for efficient high-yield production of recombinant rat $\mathrm{H}-\mathrm{FABP}$.

\section{Introduction}

Since 1971 , cytoplasmic proteins exhibiting high-affinity binding of fatty acids have been isolated from several tissues ${ }^{27}$. These low molecular mass proteins (14-16 kDa), 
currently known as fatty acid-binding proteins (FABPs), are abundantly present in the cytoplasm of tissues with high fatty acid handling capacity, such as intestine, liver and heart ${ }^{6,44}$. FABPs belong to a family of lipid binding proteins which also encompasses the cellular retinoid- binding proteins ${ }^{1}$.

$\mathrm{H}-\mathrm{FABP}$, initially identified in heart and subsequently shown to be present in several other tissues such as skeletal muscle, kidney and brain ${ }^{44}$, is implicated in the intracellular delivery of long-chain fatty acids to sites of metabolic conversion ${ }^{41,47}$. Moreover, roles in modulating fatty acid-mediated signal transduction pathways ${ }^{15}$ and in protecting cells against detrimental effects of long-chain fatty acids have been proposed $^{2}$. In addition to these intracellular actions, H-FABP was shown to function as an external growth regulator participating in reversible inhibition of bovine mammary carcinoma cell proliferation ${ }^{4}$, differentiation of mouse mammary epithelial cells ${ }^{51}$, and perhaps in the induction of cardiac myocyte hypertrophy in the rat ${ }^{8}$.

In vitro studies of FABP function require large amounts of protein, therefore FABPs from several species have been cloned and expressed in Escherichia coli. Among these are bovine heart $\mathrm{FABP}^{28}$, rat intestinal $\mathrm{FABP}^{36}$ and murine adipocyte $\mathrm{FABP}^{50}$. While this study was in progress, several other FABPs, including rat H-FABP, were expressed by Richieri et al. ${ }^{33}$. In all of these studies, procedures to purify recombinant FABPs from cell lysates were elaborate and time-consuming. In most cases, purification strategies consisted of ammonium sulphate precipitation followed by dialysis, ion-exchange chromatography and gel permeation chromatography (see e.g. reference 36 ).

In this study we obtained high-level expression of rat H-FABP in E. coli and developed a one-step purification method, employing anion-exchange chromatography, to purify the recombinant protein. Purification of heterologously expressed human $\mathrm{H}-\mathrm{FABP}$ was tested using the same procedure. The biochemical properties of recombinant rat $\mathrm{H}-\mathrm{FABP}$ and $\mathrm{H}-\mathrm{FABP}$ isolated from rat heart were compared to validate the use of recombinant rat $\mathrm{H}-\mathrm{FABP}$ in in vitro studies.

\section{Materials and Methods}

The expression vector pET3a and $E$. coli strain BL21( $\lambda$ DE3)pLysS were obtained from Novagen (Madison, WI, USA). Restriction enzymes, T4 DNA ligase and SuperscriptII reverse transcriptase were from Gibco BRL (Life Technologies, Gaithersburg, MD, USA). Pfu polymerase was purchased from Stratagene (La Jolla, CA, USA). For DNA sequence analysis the T7 deaza G/A sequencing kit from Pharmacia LKB (Uppsala, Sweden) was used. Chemicals were of analytical grade and were purchased from various vendors. 


\section{Construction of the expression vector}

Total RNA was isolated from adult rat heart (male Wistar) by the guanidinium isothiocyanate method ${ }^{9}$ and $2.5 \mu \mathrm{g}$ was transcribed with reverse transcriptase. Reaction products were amplified using 25 cycles of PCR consisting of 1 min denaturation $\left(94^{\circ} \mathrm{C}\right), 1 \mathrm{~min}$ annealing $\left(55^{\circ} \mathrm{C}\right)$ and $1 \mathrm{~min}$ elongation $\left(72^{\circ} \mathrm{C}\right)$. PCR products were separated on a $1.2 \%$ agarose gel. The resulting $422 \mathrm{bp}$ fragment was purified from gel and ligated into SmaI-digested pUC19. A 412 bp NdeI-BamHI fragment, which encompassed the entire coding region, was isolated from this construct and ligated into the pET3a expression vector. The resulting construct will be referred to as pET3a-rHFABP.

The sense primer (5'-CCATATGGCGGACGCCTTTGTCGGTA) used in PCR was identical to nt $37-58$ of the rat H-FABP cDNA sequence ${ }^{18}$ except for some modifications which created an NdeI restriction site (underlined). The antisense primer (5'-TGACGGAGGATCCAGGTCACGCCT) used for first strand cDNA synthesis and in PCR was basically complementary to nt $431-454$ of the rat H-FABP cDNA sequence and introduced a BamHI restriction site (underlined). Primers were purchased from MWG Biotech (Ebersberg, Germany).

\section{Expression of rat $H-F A B P$ in E.coli}

E. coli strain BL21( $\lambda \mathrm{DE} 3) \mathrm{pLysS}^{38}$ was transformed with pET3a-rHFABP. Cells were grown at $37^{\circ} \mathrm{C}$ in $250 \mathrm{ml} 2 \mathrm{YT}$ medium with ampicillin and chloramphenicol until an optical density of 0.6 at $600 \mathrm{~nm}$ was reached. Then isopropyl- $\beta$-thiogalactoside [IPTG] (Sigma, St. Louis, MO, USA) was added in a final concentration of $0.5 \mathrm{mM}$. Cells were grown for three more hours and harvested by centrifugation (15 min, $1500 \mathrm{~g}$ ). Cells were resuspended in $15 \mathrm{ml}$ ice-cold $10 \mathrm{mM}$ imidazole $(\mathrm{pH} \mathrm{7.0)}$ ) and lysed by sonication. Chromosomal DNA was further sheared by repeated passage of the cell lysate through a small gauge needle.

\section{Purification of recombinant rat $H-F A B P$}

The obtained cell lysate was cleared by centrifugation $(15 \mathrm{~min}, 1000 \mathrm{~g})$ and the supernatant was loaded onto a column (20x2 cm I.D.) containing the anion-exchanger Q Sepharose FF (Pharmacia LKB) equilibrated in $10 \mathrm{mM}$ imidazole ( $\mathrm{pH} \mathrm{7.0)}$ ). Following an initial washing step with $100 \mathrm{ml}$ of this buffer, proteins were eluted with a linear gradient of $\mathrm{NaCl}(0-100 \mathrm{mM}$ in $10 \mathrm{hrs})$ in $10 \mathrm{mM}$ imidazole $\mathrm{pH} 7.0$ (flow rate: $1 \mathrm{ml} \cdot \mathrm{min}^{-1}$ ). All operations were performed at $4^{\circ} \mathrm{C}$. Fractions of $7.5 \mathrm{ml}$ were collected.

\section{Identification of rat $H-F A B P$ containing fractions}

Two methods were used to identify fractions containing rat H-FABP. The first employed the radiochemical Lipidex-1000 assay developed by Glatz and Veerkamp ${ }^{14}$ 
which allows for a functional (fatty acid-binding capacity) screening of fractions. Briefly, fractions were incubated with $\left[1-{ }^{14} \mathrm{C}\right]$ oleate (Amersham International, Little Chalford, UK) at $37^{\circ} \mathrm{C}$. Next, Lipidex-1000 (Packard Instrument Company, Downers Grove, IL, USA) was added and incubation proceeded at $0^{\circ} \mathrm{C}$. At this temperature non-protein-bound fatty acid is captured by Lipidex-1000 whereas protein-bound fatty acid remains unaffected. After centrifugation, radioactivity in the supernatant, representing protein-bound fatty acid, was determined.

Rat H-FABP containing fractions were also identified immunochemically using the enzyme linked immunosorbent assay (ELISA) described by Vork et al. ${ }^{46}$. Briefly, proteins from each fraction were directly coated onto PVC microtiter plates. After incubation with a biotinylated anti-rat H-FABP antibody, avidin-conjugated horseradish peroxidase was added. For staining of rat H-FABP containing fractions $o$-phenylenediamine was used.

Rat H-FABP containing fractions were pooled, concentrated by ultrafiltration through Amicon YM-3 filters (Amicon, Beverly, MA, USA), and stored at $-20^{\circ} \mathrm{C}$. Protein concentrations were determined using the bicinchoninic acid assay (Pierce, Rockford, IL, USA) with bovine serum albumin serving as the standard. Rat H-FABP concentrations were quantified with a sandwich ELISA method developed by Vork et $a l^{46}$. H-FABP isolated from rat heart according to the method of van Nieuwenhoven $e t a l .{ }^{43}$ was used as the standard.

\section{Characterization of the recombinant protein}

For $\mathrm{N}$-terminal sequence analysis, recombinant rat $\mathrm{H}$-FABP was subjected to Edman degradation and the first 10 amino acids were determined. Sequencing was performed at the central sequencing facility of the Sonderforschungsbereich 310, Department of Physiological Chemistry, Münster University, Germany.

SDS-PAGE gels $(15 \% \mathrm{~T}, 2.7 \% \mathrm{C})$ were run according to $\mathrm{Laemmli}^{24}$ and stained with Coomassie Brilliant Blue. Molecular mass markers were obtained from Pharmacia LKB. Western blots were immunostained using (cross-reactive) peroxidaseconjugated monoclonal anti-human H-FABP antibodies ${ }^{34}$ with tetramethylbenzidine as substrate. Native isoelectric focusing (IEF) was performed as described earlier ${ }^{21}$ with ampholytes ( $\mathrm{pH} 4.0-6.5)$ from Pharmacia LKB. Both FABP isolated from rat heart (essentially according to van Nieuwenhoven et $a l^{43}$ ) and recombinant rat H-FABP were investigated. H-FABPs from other species were included in IEF analysis to study isoelectric heterogeneity. For this, H-FABP was isolated from bovine heart ${ }^{21}$ and human heart ${ }^{39}$, and recombinant bovine, human, and mouse H-FABP were isolated according to Rump et al. ${ }^{35}$. All tissue-derived and recombinant H-FABPs employed in this study were homogenous in SDS-PAGE (at least $95 \%$ pure).

Apparent dissociation constants $\left(K_{\mathrm{d}}\right)$ for oleate/rat H-FABP complexes were determined using the Lipidex procedure as described by Vork et $a{ }^{45}$. Fixed amounts 
(125 pmol) of (non-delipidated) recombinant rat H-FABP were used while oleate quantities varied from $0-500$ pmol. Binding data (16 data points obtained in two individual experiments) was evaluated by methods described by Zivin and Waud ${ }^{52}$.

To quantify the amount of fatty acids present in recombinant rat H-FABP preparations, fatty acids were extracted from $250 \mathrm{nmol}$ protein, esterified and analyzed by gas chromatography as described elsewhere ${ }^{42}$.

\section{Results and Discussion}

\section{Cloning of rat $H-F A B P ~ c D N A$}

Rat H-FABP cDNA was cloned by RT-PCR and subjected to sequence analysis. The obtained sequence was identical with the one published by Heuckeroth et al. ${ }^{18}$. Next, rat $\mathrm{H}-\mathrm{FABP}$ cDNA was cloned into the pET3a vector and expressed in $E$. coli. The pET expression system utilizes an engineered $E$. coli strain (e.g. BL21[ $\lambda$ DE3]pLysS) which contains a chromosomal copy of the T7 RNA polymerase gene under control of an IPTG-inducible promoter, and a vector which allows transcription of genes from a strong T7 promoter $^{38}$.

\section{Expression and purification of rat $H-F A B P$}

Mid-log phase cultures of E.coli strain BL21( $\lambda$ DE3)pLyS transformed with the expression vector pET3a-rHFABP were induced by addition of IPTG. Figure 4.1a shows the marked induction of a $15-\mathrm{kDa}$ protein in cell lysates from induced cultures (lane 3 ) in comparison with cell lysates from induced cultures lacking pET3a-rHFABP (lane 2). This protein comigrated with H-FABP isolated from rat heart (lane 7) and was confirmed to be rat H-FABP by Western blotting (Figure 4.1b: lanes 3 and 7).

Cleared cell lysate was applied to an anion-exchange column and proteins were eluted with a linear gradient of $0-100 \mathrm{mM} \mathrm{NaCl}$ in $10 \mathrm{mM}$ imidazole $(\mathrm{pH} 7.0)$. The elution profile monitored by measuring absorption at $280 \mathrm{~nm}$ (Figure 4.2 , thick line) and showed four peaks. Peak A represents proteins which eluted from the column during washing (Figure 4.1a: lane 4). Peak B represents unidentified substances which do not appear to be proteins as judged by SDS-PAGE (data not shown). Fractions which contained rat H-FABP were identified both immunochemically by ELISA and by the Lipidex binding assay (Figure 4.2). Rat H-FABP (peak C) eluted at an ionic strength of 35-45 mM NaCl. Peak D contained proteins (Figure 4.1a: lane 6) which eluted from the column by rinsing with $2 \mathrm{M} \mathrm{NaCl}$.

As judged from SDS-PAGE analysis (Figure 4.1a: lane 5), no contaminating proteins were observed in FABP-containing peak fractions even when large amounts $(25 \mu \mathrm{g})$ of protein were loaded on the gel (lane 8). Taken into consideration the detection limit of our electrophoresis system (approximately $100 \mathrm{ng}$ per band) it was 


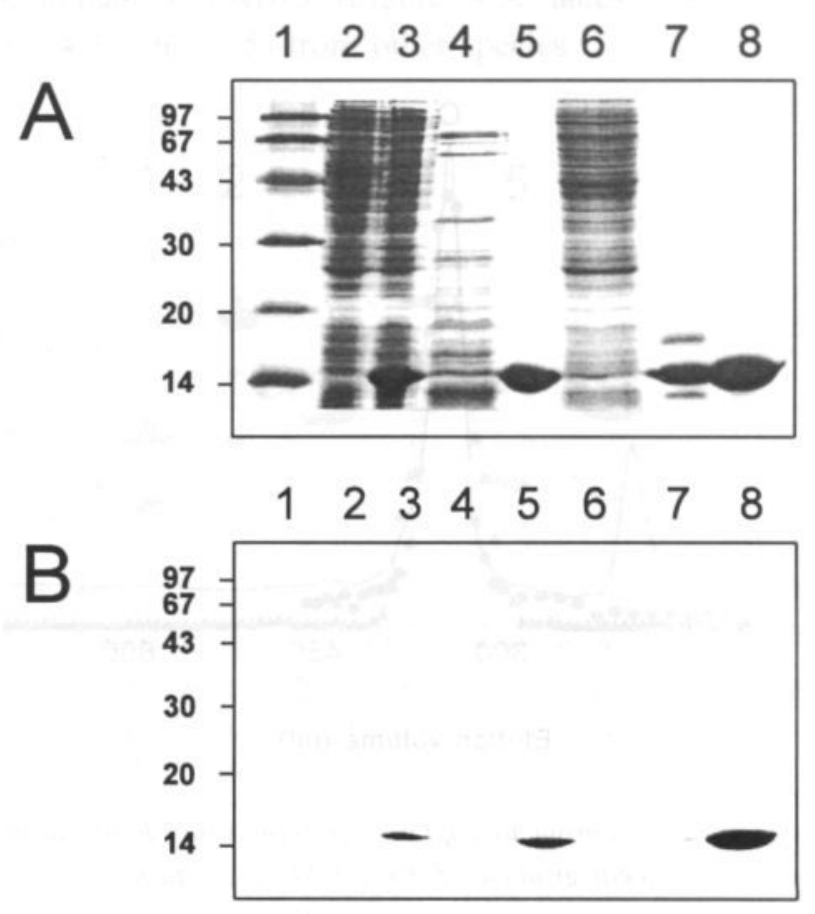

Figure 4.1 Expression of rat H-FABP in E. coli and progress of the purification procedure. Equal amounts of protein $(10 \mu \mathrm{g})$ were separated by SDS-PAGE. Proteins were stained with Coomassie blue (panel A) and H-FABP was detected by immunostaining (panel B). For the latter, proteins were transferred to nitrocellulose membrane and probed with a horseradish peroxidaseconjugated monoclonal anti-human H-FABP antibody. Lane 1: molecular mass markers (masses shown in $k D a$ ), lane 2: untransformed $E$. coli lysate after induction, lane 3: pET3a-rHFABP transformed $E$. coli lysate after induction, lanes 4-6: fractions eluted at respectively 0, 40, and 2000 $m M \mathrm{NaCl}$, lane 7: $\mathrm{H}-\mathrm{FABP}$ isolated from rat heart, lane 8: $25 \mu \mathrm{g}$ recombinant rat $H-F A B P$.

estimated that the protein was at least $99 \%$ pure. Moreover, ultraviolet spectra recordings proved the absence of contaminating nucleic acids (data not shown). Hence, rat H-FABP expressed in E. coli could be purified from cell lysates in a single step. The recombinant protein made up approximately $25 \%$ of total soluble protein in E. coli and was obtained in yields ranging from $30-40 \mathrm{mg} \cdot \mathrm{l}^{-1}$ culture.

Recombinant rat H-FABP isolated from $E$. coli was found to contain fatty acids. Gas chromatographical analysis revealed that approximately 0.2 mol fatty acid was bound per mol H-FABP (data not shown). Oleate constituted circa $40 \%$ of fatty acids complexed to recombinant rat H-FABP. 


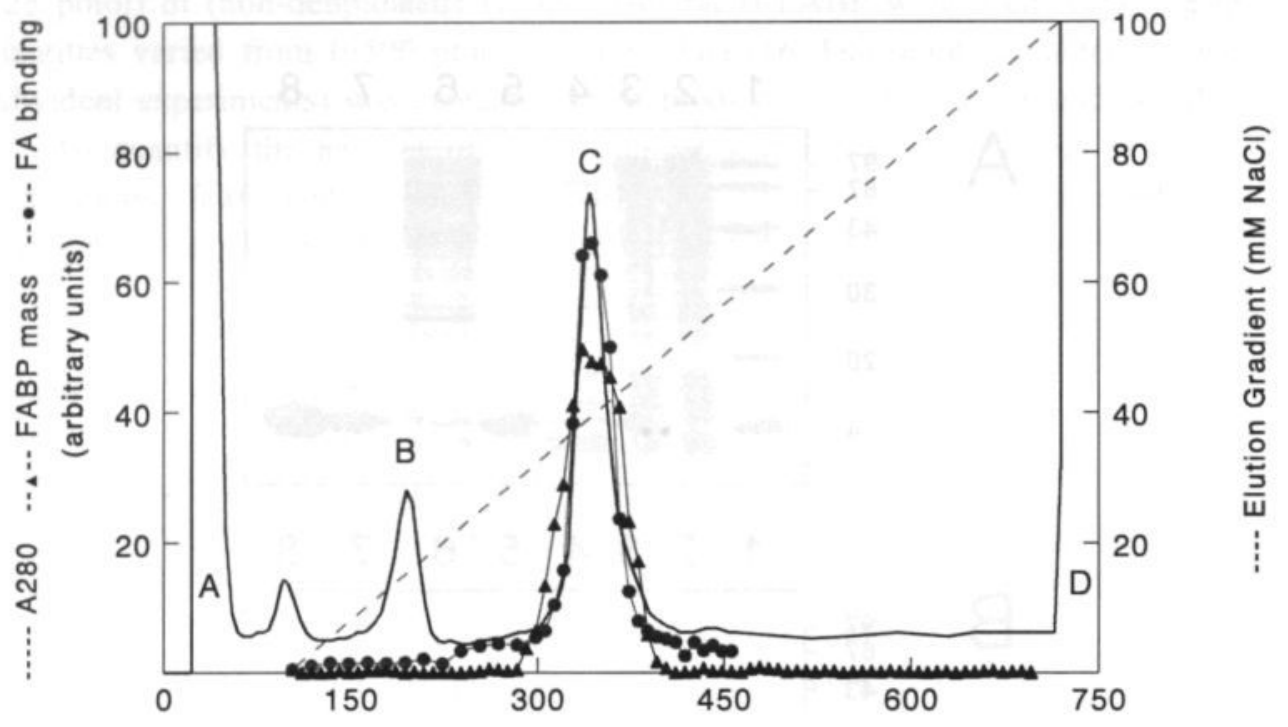

Elution volume $(\mathrm{ml})$

Figure 4.2 Anion-exchange chromatography on $Q$ Sepharose $F F$ of bacterial cell lysate. Rat $H-F A B P$ was eluted with a linear gradient of $0-100 \mathrm{mM} \mathrm{NaCl}$ (dashed line) in $10 \mathrm{mM}$ imidazole ( $\mathrm{pH}$ 7.0). Elution was monitored by measuring absorption at $280 \mathrm{~nm}(-)$. Fractions were screened for the presence of rat $H-F A B P$ both immunochemically $(\boldsymbol{\Lambda}-\mathbf{\Lambda})$ and by determining fatty acid binding activity (-0).

Expression and purification of human H-FABP

Contributing to the success of our purification method is the high-level expression of rat $\mathrm{H}-\mathrm{FABP}$ driven by the $\mathrm{pET}$ system. To test whether our purification scheme was suitable for the purification of another recombinant FABP as well, we expressed human H-FABP in E. coli using the pET system and followed the same chromatographic protocol to purify the recombinant protein. Heterologously expressed human H-FABP eluted at an ionic strength of $25-35 \mathrm{mM} \mathrm{NaCl}$ and, as judged by SDS-PAGE, was over $99 \%$ pure (data not shown).

\section{Characterization of recombinant rat $H-F A B P$}

As expected, recombinant rat $\mathrm{H}-\mathrm{FABP}$ and $\mathrm{H}-\mathrm{FABP}$ isolated from rat heart have similar molecular masses as concluded from SDS-PAGE analysis (Figure 4.1). However, in IEF gels two isoforms (pI 5.0 and pI 5.2) were visible for recombinant rat $\mathrm{H}-\mathrm{FABP}$ (Figure 4.3: lane 6) while the tissue-derived protein migrated as a single pI 5.0 isoform (Figure 4.3: lane 5). Isoelectric heterogeneity, due to the existence of 
$\mathrm{N}$-terminal variants in recombinant protein preparations, was also observed when comparing recombinant H-FABPs (Figure 4.3: lanes 2,4,7) and tissue-derived H-FABPs (Figure 4.3: lanes 1,5) from other species.

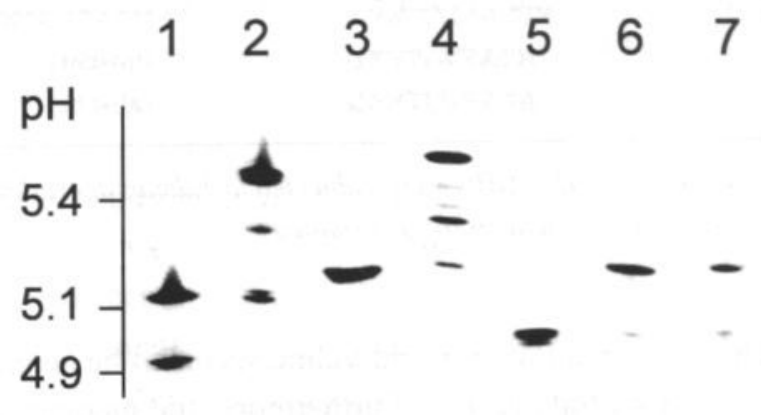

Figure 4.3 Isoelectric heterogeneityof recombinant and tissue-derivedH-FABPs. Proteins were separated on an isoelectric focusing gel (pH 4.0-6.5) and stained with Coomassie blue. Lane 1,3,5: $H-F A B P$ isolated from bovine, human, and rat heart, respectively. Lanes 2,4,6, 7: recombinant bovine, human, rat and mouse $H-F A B P$, respectively.

The two bands observed for H-FABP from bovine heart (Figure 4.3: lane 1) represent the two isoforms described by Unterberg et al. ${ }^{40}$ which contain either Asp 98 (pI 4.9 isoform) or Asn98 (pI 5.1 isoform). FABPs isolated from tissue seem resistant towards Edman degradation indicating that they are $\mathrm{N}$-terminally blocked. For example, the $N$-terminus of human H-FABP consists of $N$-acetylvaline ${ }^{5}$. Apparently, the most acidic variants of the recombinant proteins comigrate with the FABPs isolated from tissue suggesting that they have a blocked $N$-terminus as well. For heterologously expressed bovine H-FABP this variant corresponds to unprocessed $\mathrm{N}$-formylated protein ${ }^{37}$. The unblocked isoforms have an additional free amino group at the $\mathrm{N}$-terminus making the protein more basic.

$N$-terminal sequences of recombinant H-FABPs are shown in Table 4.1. Recombinant rat H-FABP starts with alanine, thus the $N$-terminal methionine is removed by methionyl aminopeptidase (MAP). The faint, more acidic species visible in IEF, presumably originating from formylated rat $\mathrm{H}-\mathrm{FABP}$, did not yield a sequence in Edman degradation. The same result was found for recombinant mouse H-FABP. This is consistent with findings that MAP activity depends on the amino acid adjacent to the starter methionine, small amino acids increasing and bulky and charged amino acids decreasing its activity ${ }^{19}$. In the case of recombinant bovine and human H-FABP the $N$-terminal methionine was incompletely removed by MAP. Accordingly, a secondary sequence can be read upon $N$-terminal Edman degradation, starting with 


\begin{tabular}{lll}
\hline Species & Predominant Sequence & Minor Sequence \\
\hline bovine & MVDAFVGTWK & VDAFVGTWKL \\
human & MVDAFLGTWK & VDAFLGTWKL \\
mouse & ADAFVGTWKL & (absent) \\
rat & ADAFVGTWKL & (absent) \\
\hline
\end{tabular}

Purified recombinant H-FABPs were subjected to Edman degradation and the first 10 amino acids were determined.

valine (Table 4.1). Thus, the small amino acid valine seems to be an exception to the rule as was also observed by Flinta et al. ${ }^{13}$. Furthermore, the incomplete cleavage of the starter methionine increases the number of possible variants ${ }^{37}$.

In order to functionally characterize the recombinant protein, the binding of oleate to recombinant rat $\mathrm{H}-\mathrm{FABP}$ was determined. The apparent dissociation constant $\left(K_{\mathrm{d}}\right)$ was $0.29 \pm 0.11 \mu \mathrm{M}$ and the binding stoichiometry $\left(B_{\max }\right)$ was $0.85 \pm 0.21 \mathrm{~mol}$ oleate per mol H-FABP. Taken into account the small amount of endogenously bound fatty acids, which results in an underestimation of $B_{\max }$, these results are in agreement with the results obtained for H-FABP isolated from rat heart $\left(K_{\mathrm{d}}=0.33 \mu \mathrm{M}, B_{\max }=\right.$ $1.11 \mathrm{~mol} \cdot \mathrm{mol}^{-1}$ ) as reported by Vork et al..$^{45}$.

\section{Concluding remarks and future prospects}

High-level expression of rat H-FABP in E. coli was achieved. The recombinant protein constituted approximately $25 \%$ of the proteins in cell lysates and yields varied from $30-40 \mathrm{mg} \cdot \mathrm{l}^{-1}$ culture. Moreover, time-consuming procedures for purifying the recombinant protein were eliminated by the development of a one-step purification method. In addition, another recombinant FABP (human H-FABP) expressed with the same expression system could be purified using this purification scheme.

In contrast to $\mathrm{H}-\mathrm{FABP}$ isolated from rat heart, the recombinant protein exhibited isoelectric heterogeneity due to the existence of $N$-terminal variants. As deduced from the tertiary structure of human H-FABP and other FABPs ${ }^{1}$, the $N$-terminus is located on the exterior of the protein and does not seem to take part in protein-function. Binding data confirms this assumption, since binding stoichiometry and apparent dissociation constant for oleate-binding were similar for recombinant rat H-FABP and $\mathrm{H}-\mathrm{FABP}$ isolated from rat heart. Therefore, the recombinant rat H-FABP seems suitable for use in in vitro studies.

Besides the use as standard in ELISA and radiochemical assays, the availability of vast amounts of pure H-FABP allows to study several interesting questions. For 
instance, by comparing cellular uptake of fatty acids presented as complexes with either albumin or H-FABP, but yielding the same non-protein-bound fatty acid concentration, information on the function of albumin-binding proteins on the surface of cardiac myocytes can be gathered. In addition, a possible interaction between the sarcolemmal fatty acid-transport protein FATP, which is hypothesized to have one or more cytoplasmic domains (see Chapter 5), and H-FABP can be studied. For studying an interaction with proteins, H-FABP could be coupled to cyanogenbromide-activated column material.

$\mathrm{H}-\mathrm{FABP}$ has been reported to induce cardiac hypertrophy in isolated neonatal rat cardiac myocytes ${ }^{8}$. Recently, Vork and coworkers (unpublished results) found that adding our purified recombinant rat H-FABP to cultured neonatal cardiac myocytes did not elicit any change in cellular protein synthesis in contrast to the original observation of Burton et al. ${ }^{8}$. However it should be kept in mind that the latter investigators employed an H-FABP preparation of questionable origin as it was present as major contaminant in a commercially available enzyme preparation.

\section{Acknowledgements}

We thank Maurice Pelsers for isolating H-FABP from rat heart, Theo Roemen for analyzing fatty acid content of recombinant rat H-FABP, and Rainer Rump for providing recombinant mouse H-FABP. 


\section{PART 2:}

\section{A METHOD FOR ISOLATING ADULT MOUSE CARDIAC MYOCYTES}

\section{Introduction}

Isolated cardiac myocytes have found widespread use for the study of different aspects of cardiac physiology, such as metabolic processes, electrophysiology of ion channels, and determination of contractile parameters. In the intact heart, cardiac muscle cells are tightly coupled by intercalated discs and are held together by the extracellular matrix making them large, rigid cells that are susceptible to mechanical damage $e^{12,29}$. Hence, techniques for isolating viable cells proved difficult to establish.

A method for isolating intact cardiac myocytes from adult rats was first reported by Powell and Twist in $1976^{30}$. Although the yield and quality of obtained cell preparations has greatly improved since then, the basic isolation principle has not changed. Heart tissue, either tissue chunks or a Langendorff-perfused heart, is exposed to a medium containing proteolytic enzymes and low levels of $\mathrm{Ca}^{2+}$. The latter serves to weaken intercellular connections by disrupting the $\mathrm{Ca}^{2+}$-dependent desmosome structures in the intercalated discs, while proteolytic enzymes degrade the proteins linking individual cells to the extracellular matrix ${ }^{29}$.

Among experimental animals, isolation of cardiac myocytes from rats appeared least troublesome. High-yield preparations consisting of $70-90 \%$ intact cells are routinely obtained nowadays. At the beginning of this study, few reports had appeared on the isolation of cardiac myocytes from adult mice ${ }^{11,23,49}$. Such method would be highly desirable in view of the increasing availability of transgenic mice which relates to the relative ease with which the mouse genome, and thus cardiac phenotype, can be manipulated. In this section, a relatively high-yield procedure for isolating cardiac myocytes from adult mice is presented. Application of this method to study substrate utilization by cardiac myocytes from H-FABP knock-out mice is described in Chapter 6.

\section{Methodological background}

The protocol for isolating mouse cardiac myocytes was adapted from the method to isolate these cells from rat as described in essence by Linssen et al. ${ }^{25}$. For this, rat hearts are retrogradely perfused (coronary flow rate circa $8 \mathrm{ml} \cdot \mathrm{min}^{-1}$ ) for $5 \mathrm{~min}$ with buffer devoid of $\mathrm{Ca}^{2+}$, followed by $30-45 \mathrm{~min}$ perfusion in a circulating manner with medium containing $200 \mu \mathrm{M} \mathrm{Ca}^{2+}$ and $0.08 \%$ collagenase. When this protocol was directly applied to mouse hearts, albeit the coronary flow rate was adjusted to circa $2 \mathrm{ml} \cdot \mathrm{min}^{-1}$, cells were obtained in a low-yield (in terms of wet mass) and contained only a low percentage $(<15 \%)$ of trypan blue-excluding cells with rod-shaped morphology. Moreover, many of these cells showed spontaneous contractions indicative for loss of sarcolemmal integrity. 
Several parameters influence the overall quality of isolated cardiac myocytes ${ }^{29}$. Among these are (i) the duration of exposure to, and the amount and type of proteolytic enzyme used, and (ii) the duration of initial $\mathrm{Ca}^{2+}$-free perfusion.

(i) Collagenase is most frequently employed to digest extracellular matrix components and hence detach individual cardiac myocytes. However, collagenase is a poorly defined mixture of enzymes including several proteolytic activities which each may also harm the cell by cleaving essential membrane proteins. Hence, the time of exposure to collagenase, and the amount of collagenase employed, need to be optimized. Due to destruction of the microvascular bed upon collagenase perfusion, the microcirculation of the heart is obstructed and cellular supply of oxygen and substrates is impeded. To prevent ischemic injury, careful choice of perfusion time may be essential. The quantity and composition of contaminating proteases, which nonetheless are essential for successful cell isolations, vary between commercial collagenase batches. Hence, the choice of a suitable collagenase batch may require empirical establishment ${ }^{23,48}$.

(ii) During perfusion with medium containing low levels of $\mathrm{Ca}^{2+}$, the cellular cation balance is disturbed resulting in a massive $\mathrm{Ca}^{2+} / \mathrm{Na}^{+}$exchange upon restoring physiological (millimolar) $\mathrm{Ca}^{2+}$ levels $\mathrm{s}^{12,30}$. This phenomenon, the so-called calcium paradox, renders cells intolerant to $\mathrm{Ca}^{2+}$ and causes hypercontracture and deterioration of cells. Thus, the method for recalcifying cell suspensions may affect the quality of the obtained cell preparation.

\section{Modifications}

The major improvement in the method for isolating mouse cardiac myocytes was brought about by miniaturizing the equipment for Langendorff-perfusion and by minimizing the length of connecting tubings. This effectively reduced the volume of the perfusion set-up from circa $25 \mathrm{ml}$ to $8 \mathrm{ml}$. As noted by other groups, the time of initial perfusion with $\mathrm{Ca}^{2+}$-free medium should be less than 5 minutes ${ }^{31,48}$. With a coronary flow rate of circa $2 \mathrm{ml} \cdot \mathrm{min}^{-1}$ this period was diminished from 12.5 to $4 \mathrm{~min}$. This modification increased the percentage of viable cells, based on trypan-blue exclusion and rod-shaped morphology, to circa $50 \%$. Spontaneous contractions were still numerous in these cell preparations, and the observed marked decrease in the percentage of viable cells with time presumably reflected dying of these hyperpermeable, leaky cells.

Further improvements in the overall stability of isolated cells were made by the combined effects of (i) lowering the amount of collagenase in the perfusion buffer from $0.08 \%$ to $0.06 \%$, (ii) decreasing the duration of collagenase perfusion from 30 to $7.5 \mathrm{~min}$, and (iii) maintaining low $\mathrm{Ca}^{2+}$ levels $(25 \mu \mathrm{M}$ vs. $200 \mu \mathrm{M}$ for the rat) during collagenase perfusion. The reason for the first two modifications has been discussed above, while the rationale for the latter modification is that the activity of 
collagenase is dependent on $\mathrm{Ca}^{2+}$ concentrations. Employing collagenases from different suppliers gave no further improvement in quality of the obtained cell preparations.

The current protocol, which is described in detail below, yields a cell suspension containing on average $45 \%$ (range $25-70 \%$ ) rod-shaped cells. These cells exclude trypan blue indicating that they are structurally and functionally intact. Only a minor percentage of the cells with rod-shaped morphology showed spontaneous contractions. A single mouse heart of circa $125 \mathrm{mg}$ typically yields $40-50 \mathrm{mg}$ wet mass of isolated myocytes. Following perishing of already-dying cells, the percentage of rod-shaped cardiac myocytes in the cell preparation remained stable for at least 1.5 hours.

\section{Materials and Methods}

Collagenase (Type I) was obtained from Life Technologies (Gaithersburg, MD, USA), butanediene monoxime and bovine serum albumin (BSA, Fraction V) were derived from Sigma (St. Louis, MO, USA). All other chemicals were of analytical grade and were purchased from various suppliers.

\section{Standard protocol for isolating mouse cardiac myocytes}

The following procedure appeared successful for isolating cardiac myocytes from adult Swiss, C57BL/6, and 129xBalb/c mice. Mice of the latter strain varying in age between 3-15 months appeared equally suitable for isolation of cardiac myocytes. Adult mice were anaesthetized by i.p. injection of pentobarbital combined with heparin or were killed directly by cervical dislocation. Hearts were quickly removed and placed in a dish containing ice-cold buffer $\mathrm{A}$ (in mM: $115 \mathrm{NaCl}, 2.6 \mathrm{KCl}, 1.2$ $\mathrm{MgSO}_{4}, 1.2 \mathrm{KH}_{2} \mathrm{PO}_{4}, 10 \mathrm{NaHCO}_{3}, 10$ HEPES, 0.4 taurine, 11 glucose, $\mathrm{pH} 7.4$ [at $\left.\left.37^{\circ} \mathrm{C}\right]\right)$ saturated with carbogen $\left(95 \% \mathrm{O}_{2}, 5 \% \mathrm{CO}_{2}\right)$. The aorta was mounted on a cannula (diameter $0.9 \mathrm{~mm}$ ) and hearts were perfused in a Langendorff apparatus at $37^{\circ} \mathrm{C}$ for $5 \mathrm{~min}$ with buffer $\mathrm{A}$ followed by $7.5 \mathrm{~min}$ perfusion with buffer $\mathrm{A}$ supplemented with $25 \mu \mathrm{M} \mathrm{CaCl}_{2}, 0.06 \%$ collagenase, $0.7 \% \mathrm{BSA}$, and $15 \mathrm{mM}$ butanediene monoxime. A constant flow rate of $2.1 \mathrm{ml} \cdot \mathrm{min}^{-1}$ was applied. All solutions used during perfusion and subsequent steps were continuously aerated with carbogen. At the end of the perfusion period, hearts were removed from the perfusion apparatus, carefully opened and incubated in $15 \mathrm{ml}$ medium A supplemented with $0.03 \%$ collagenase, $25 \mu \mathrm{M} \mathrm{CaCl}_{2}, 1.4 \% \mathrm{BSA}$, and $7.5 \mathrm{mM}$ butanediene monoxime for 10 min in a shaking waterbath $\left(37^{\circ} \mathrm{C}, 200 \mathrm{rpm}\right)$ (HT Infors - model WTR, Bottmingen, Switzerland). Incubation proceeded for five more minutes $\left(37^{\circ} \mathrm{C}, 100 \mathrm{rpm}\right)$ while the $\mathrm{Ca}^{2+}$ concentration was raised in $200 \mu \mathrm{M}$ intervals to $1.0 \mathrm{mM}$. Next, the cell suspension was filtered through $0.2 \mathrm{~mm}$ nylon mesh and cardiac myocytes were pelleted by centrifugation $(2 \mathrm{~min}, 23 \mathrm{~g}$ ). The cell pellet was resuspended in medium $\mathrm{B}$ (medium A supplemented with $1.0 \mathrm{mM} \mathrm{CaCl}_{2}$ and $2.0 \% \mathrm{BSA}$ ), washed once, and suspended in medium B. 


\section{Cannulate aorta $\left(4^{\circ} \mathrm{C}\right)$}

Langendorff-perfusion $\left(37^{\circ} \mathrm{C}\right)$

$\checkmark 5$ min $\mathrm{Ca}^{2+}$-free medium

$\sqrt{ } 7.5 \mathrm{~min}$ medium with collagenase $(0.06 \%)$

\section{Dissociation into isolated cells}

$\checkmark$ Perfused heart in flask in shaking waterbath $\left(37^{\circ} \mathrm{C}\right)$

$\checkmark 15 \mathrm{~min}$ incubation in medium with collagenase $(0.03 \%)$

$\checkmark$ Last $5 \mathrm{~min}$ : recalcification $\left(200 \mu \mathrm{M} \mathrm{Ca}^{2+} \cdot \mathrm{min}^{-1}\right.$ steps $)$

\section{Purification of myocytes $\left(25^{\circ} \mathrm{C}\right)$}

$\checkmark$ Filtrate cell suspension, centrifugate ( $2 \mathrm{~min}, 23 \mathrm{~g}$ )

$\checkmark$ Discard supernatant (mostly non-myocyte cells)

$\checkmark$ Wash cell pellet (cardiac myocytes)

Figure 4.4 The various steps in isolating myocytes from adult mouse hearts. Following cannulation of the aorta, the heart is consecutively perfused with $\mathrm{Ca}^{2+}$-free medium and collagenasecontaining medium. In the next stage, the perfused heart dissociates into individual cells through combined mechanical and enzymatic action. Physiological $\mathrm{Ca}^{2+}$ concentrations are restored, and contaminating cell types are removed by centrifugation yielding a preparation consisting mainly of single cardiac myocytes. The total isolation procedure typically lasts about 45 minutes. 
A flow-chart depicting the several steps of the protocol for isolating adult mouse cardiac myocytes is shown in Figure 4.4. The percentage of cells with rod-shaped cell morphology was determined by counting a minimum of 250 cells, fixation in $2.0 \%$ glutaraldehyde allowed determination of this value after ending of further experimental procedures.

\section{Discussion and future prospects}

When initiating the development of the method described above, isolation of murine cardiac myocytes was scarcely documented ${ }^{11,23}$. Nowadays several groups have described methods for isolation of mouse cardiac myocytes ${ }^{20,22,48}$, although the quantitative and qualitative yield of the obtained cell preparations is often not mentioned. Moreover, isolated cardiac myocytes were apparently used in studies sufficing with relatively few intact cells such as electrophysiological studies ${ }^{17}$ and measurement of contractile parameters ${ }^{26,48,49}$. As we intended to study substrate utilization by isolated cardiac myocytes, relatively large amounts of calcium-tolerant cells are required (see Chapter 6 ). The method we have developed typically yields circa $40-50 \mathrm{mg}$ wet mass per single heart of about $125 \mathrm{mg}$, and contains on average $45 \%$ trypan blue-excluding, quiescent cells with rod-shaped morphology.

The availability of techniques for manipulating the mouse genome in a targeted manner ${ }^{16,32}$ and the ability to create mutant strains by $N$-ethyl- $N$-nitrosourea-induced mutagenesis ${ }^{7}$, have made the mouse the preferred model for studying normal and disordered biological processes in mammals. Detailed structural analysis of the C57BL/6J mouse genome is currently being initiated ${ }^{3}$ and will eventually procure the complete genomic sequence of this strain. This effort will greatly accelerate the discovery of genes implicated in (patho)physiological processes. For studying the molecular mechanisms underlying such processes in the myocardium, isolated cardiac myocytes are proving invaluable ${ }^{10}$. When viewed in a broader perspective, it is essential that the method for isolating mouse cardiac myocytes is further refined. For this, attention may be focused on further optimizing the exposure to collagenase, and to preserve cellular cation homeostasis during the $\mathrm{Ca}^{2+}$-free perfusion period. The latter may be achieved by inclusion of ion channel modulators in the perfusion media.

\section{References}

1) Banaszak L, Winter N, Xu Z, Bernlohr DA, Cowan S, and Jones TA: Lipid binding proteins: a family of fatty acid and retinoid transport proteins. Adv Protein Chem 45:89-151 (1994)

2) Bass NM, Raghupathy E, Rhoads DE, Manning JA, and Ockner RK: Partial purification of molecular weight 12,000 fatty acid-binding proteins from rat brain and their effect on synaptosomal $\mathrm{Na}^{+}$-dependent amino acid uptake. Biochemistry 23:6539-6544(1984)

3) Battey J, Jordan E, Cox D, and Dove W: An action plan for mouse genomics. Nat Genet 21:73-75 (1999) 
4) Böhmer FD, Kraft R, Otto A, Wernstedt C, Hellman U, Kurtz A, Müller T, Rohde K, Etzold G, Lehmann W, Langen P, Heldin CH, and Grosse R: Identification of a polypeptide growth inhibitor from bovine mammary gland. Sequence homology to fatty acid- and retinoid-binding proteins. $J$ Biol Chem 262:15137-15143(1987)

5) Börchers T, Højrup P, Nielsen SU, Roepstorff P, Spener F, and Knudsen J: Revision of the amino acid sequence of human heart fatty acid-binding protein. Mol Cell Biochem 98:127-133 (1990)

6) Börchers T and Spener F: Fatty acid-binding proteins. Curr Top Membr 40:261-294 (1994)

7) Brown SD and Nolan PM: Mouse mutagenesis-systematic studies of mammalian gene function. Hum Mol Genet 7:1627-1633(1998)

8) Burton PB, Hogben CE, Joannou CL, Clark AG, Hsuan JJ, Totty NF, Sorensen C, Evans RW, and Tynan MJ: Heart fatty acid-binding protein is a novel regulator of cardiac myocyte hypertrophy. Biochem Biophys Res Commun 205:1822-1828(1994)

9) Chomczynski P: A reagent for the single-step simultaneous isolation of RNA, DNA, and proteins from cell and tissue samples. Biotechniques 15:532-534(1993)

10) Christensen G, Wang Y, and Chien KR: Physiological assessment of complex cardiac phenotypes in genetically engineered mice. Am J Physiol 272:H2513-2524(1997)

11) Dorn II GW, Robbins J, Ball N, and Walsh RA: Myosin heavy chain regulation and myocyte contractile depression after LV hypertrophy in aortic-banded mice. Am J Physiol 267:H400-405 (1994)

12) Dow JW, Harding NG, and Powell T: Isolated cardiac myocytes. I. Preparation of adult myocytes and their homology with the intact tissue. Cardiovasc Res 15:483-514 (1981)

13) Flinta C, Persson B, Jornvall H, and von Heijne G: Sequence determinants of cytosolic $N$-terminal protein processing. Eur J Biochem 154:193-196(1986)

14) Glatz JFC and Veerkamp JH: A radiochemical procedure for the assay of fatty acid binding by proteins. Anal Biochem 132:89-95 (1983)

15) Glatz JFC, Börchers T, Spener F, and van der Vusse GJ: Fatty acids in cell signalling: modulation by lipid binding proteins. Prostaglandins Leukot Essent Fatty Acids 52:121-127 (1995)

16) Gordon JW: Production of transgenic mice. Methods Enzymol 225:747-771 (1993)

17) Han X, Kubota I, Feron O, Opel DJ, Arstall MA, Zhao YY, Huang P, Fishman MC, Michel T, and Kelly RA: Muscarinic cholinergic regulation of cardiac myocyte $\mathrm{IC}_{\alpha}-\mathrm{L}$ is absent in mice with targeted disruption of endothelial nitric oxide synthase. Proc Natl Acad Sci US A 95:6510-6515(1998)

18) Heuckeroth RO, Birkenmeier EH, Levin MS, and Gordon JI: Analysis of the tissue-specific expression, developmental regulation, and linkage relationships of a rodent gene encoding heart fatty acid- binding protein. $J$ Biol Chem 262:9709-9717(1987)

19) Hirel PH, Schmitter MJ, Dessen P, Fayat G, and Blanquet S: Extent of $\boldsymbol{N}$-terminal methionine excision from Escherichia coli proteins is governed by the side-chain length of the penultimate amino acid. Proc Natl Acad Sci U S A 86:8247-8251 (1989)

20) Hutter JJ, Mestril R, Tam EK, Sievers RE, Dillmann WH, and Wolfe CL: Overexpression of heat shock protein 72 in transgenic mice decreases infarct size in vivo. Circulation 94:1408-1411 (1996) 
21) Jagschies G, Reers M, Unterberg C, and Spener F: Bovine fatty acid-binding proteins. Isolation and characterisation of two cardiac fatty acid binding proteins that are distinct from corresponding hepatic proteins. Eur J Biochem 152:537-545(1985)

22) Kadambi VJ, Ponniah S, Harrer JM, Hoit BD, Dorn II GW, Walsh RA, and Kranias EG: Cardiac-specific overexpression of phospholamban alters calcium kinetics and resultant cardiomyocyte mechanics in transgenic mice. J Clin Invest 97:533-539(1996)

23) Kruppenbacher JP, May T, Eggers HJ, and Piper HM: Cardiomyocytes of adult mice in long-term culture. Naturwissenschaften 80:132-134 (1993)

24) Laemmli UK: Cleavage of structural proteins during the assembly of the head of bacteriophage T4. Nature 227:680-685(1970)

25) Linssen MC, Vork MM, de Jong YF, Glatz JFC, and van der Vusse GJ: Fatty acid oxidation capacity and fatty acid-binding protein content of different cell types isolated from rat heart. Mol Cell Biochem 98:19-25 (1990)

26) Luo W, Wolska BM, Grupp IL, Harrer JM, Haghighi K, Ferguson DG, Slack JP, Grupp G, Doetschman T, Solaro RJ, and Kranias EG: Phospholamban gene dosage effects in the mammalian heart. Circ Res 78:839-847 (1996)

27) Ockner RK: Historic overview of studies on fatty acid-binding proteins. Mol Cell Biochem 98:3-9 (1990)

28) Oudenampsen E, Kupsch EM, Wissel T, Spener F, and Lezius A: Expression of fatty acid-binding protein from bovine heart in Escherichia coli. Mol Cell Biochem 98:75-79 (1990)

29) Piper H: Cell culture techniques in heart and vessel research. Springer Verlag - Berlin (1990)

30) Powell T and Twist VW: A rapid technique for the isolation and purification of adult cardiac muscle cells having respiratory control and a tolerance to calcium. Biochem Biophys Res Commun 72:327-333(1976)

31) Powell T: The calcium paradox and isolated myocytes. Eur Heart J 4SH:105-111 (1983)

32) Ramírez-Solis R, Davis AC, and Bradley A: Gene targeting in embryonic stem cells. Methods Enzymol 225:855-878(1993)

33) Richieri GV, Ogata RT, and Kleinfeld AM: Equilibrium constants for the binding of fatty acids with fatty acid-binding proteins from adipocyte, intestine, heart, and liver measured with the fluorescent probe ADIFAB. J Biol Chem 269:23918-23930(1994)

34) Roos W, Eymann E, Symannek M, Duppenthaler J, Wodzig KW, Pelsers MMAL, and Glatz JFC: Monoclonal antibodies to human heart fatty acid-binding protein. J Immunol Methods 183:149-153(1995)

35) Rump R, Buhlmann C, Börchers T, and Spener F: Differentiation-dependent expression of heart-type fatty acid-binding protein in C2C12 muscle cells. Eur J Cell Biol 69:135-142 (1996)

36) Sacchettini JC, Banaszak LJ, and Gordon JI: Expression of rat intestinal fatty acid-binding protein in $E$. coli and its subsequent structural analysis: a model system for studying the molecular details of fatty acid-protein interaction. Mol Cell Biochem 98:81-93 (1990)

37) Specht B, Oudenampsen-Krüger E, Ingendoh A, Hillenkamp F, Lezius AG, and Spener F: $\mathrm{N}$-terminal variants of fatty acid-binding protein from bovine heart overexpressed in Escherichia coli. J Biotechnol 33:259-269(1994)

38) Studier FW, Rosenberg AH, Dunn JJ, and Dubendorff JW: Use of T7 RNA polymerase to direct expression of cloned genes. Methods Enzymol 185:60-89 (1990) 
39) Unterberg C, Heidl G, von Bassewitz DB, and Spener F: Isolation and characterization of the fatty acid- binding protein from human heart. $J$ Lipid Res 27:1287-1293(1986)

40) Unterberg C, Börchers T, Højrup P, Roepstorff P, Knudsen J, and Spener F: Cardiac fatty acid-binding proteins. Isolation and characterization of the mitochondrial fatty acid-binding protein and its structural relationship with the cytosolic isoforms. $\mathrm{J} \mathrm{Biol} \mathrm{Chem}$ 265:16255-16261(1990)

41) van der Vusse GJ, Glatz JFC, Stam HC, and Reneman RS: Fatty acid homeostasis in the normoxic and ischemic heart. Physiol Rev 72:881-940(1992)

42) van der Vusse GJ and Roemen TH: Gradient of fatty acids from blood plasma to skeletal muscle in dogs. J Appl Physiol 78:1839-1843(1995)

43) van Nieuwenhoven FA, Vork MM, Surtel DA, Kleine AH, van der Vusse GJ, and Glatz JFC: High-yield two-step chromatographic procedure for purification of fatty acid-binding protein from human heart. $J$ Chromatogr 570:173-179(1991)

44) Veerkamp JH and Maatman RG: Cytoplasmic fatty acid-binding proteins: their structure and genes. Prog Lipid Res 34:17-52 (1995)

45) Vork MM, Glatz JFC, Surtel DA, and van der Vusse GJ: Assay of the binding of fatty acids by proteins: evaluation of the Lipidex-1000 procedure. Mol Cell Biochem 98:111-117(1990)

46) Vork MM, Glatz JFC, Surtel DA, Knubben HJ, and van der Vusse GJ: A sandwich enzyme linked immunosorbent assay for the determination of rat heart fatty acid-binding protein using the streptavidin-biotin system. Application to tissue and effluent samples from normoxic rat heart perfusion. Biochim Biophys Acta 1075:199-205(1991)

47) Vork MM, Glatz JFC, and van der Vusse GJ: On the mechanism of long-chain fatty acid transport in cardiomyocytes as facilitated by cytoplasmic fatty acid-binding protein. JTheor Biol 160:207-222 (1993)

48) Wolska BM and Solaro RJ: Method for isolation of adult mouse cardiac myocytes for studies of contraction and microfluorimetry. Am J Physiol 271:H1250-1255(1996)

49) Wolska BM, Stojanovic MO, Luo W, Kranias EG, and Solaro RJ: Effect of ablation of phospholamban on dynamics of cardiac myocyte contraction and intracellular $\mathrm{Ca}^{2+} . \mathrm{Am} J$ Physiol 271:C391-397(1996)

50) $\mathrm{Xu} \mathrm{ZH}$, Buelt MK, Banaszak LJ, and Bernlohr DA: Expression, purification, and crystallization of the adipocyte lipid binding protein. J Biol Chem 266:14367-14370(1991)

51) Yang Y, Spitzer E, Kenney N, Zschiesche W, Li M, Kromminga A, Müller T, Spener F, Lezius A, Veerkamp JH, Smith GH, Salomon DS, and Grosse R: Members of the fatty acid-binding protein family are differentiation factors for the mammary gland. $J$ Cell Biol 127:1097-1109 (1994)

52) Zivin JA and Waud DR: How to analyze binding, enzyme and uptake data: the simplest case, a single phase. Life Sci 30:1407-1422(1982) 


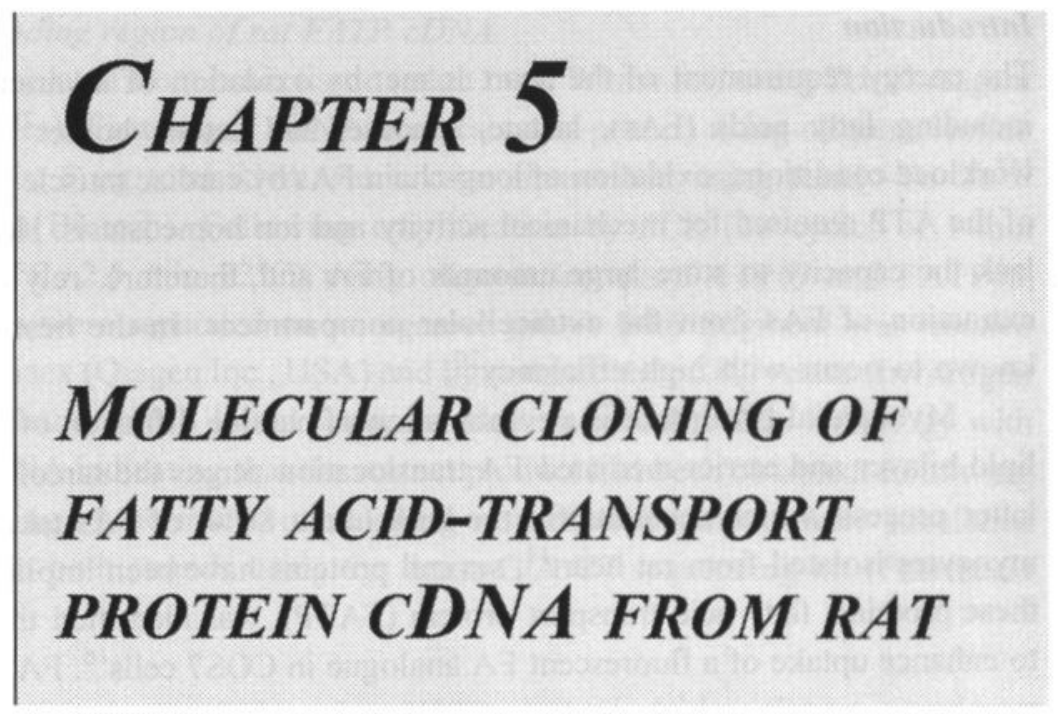

Adapted from:

Schaap FG, Hamers L, van der Vusse GJ, and Glatz JFC: Biochim Biophys Acta 1354:29-34 (1997) 


\section{Abstract}

Mitochondrial oxidation of long-chain fatty acids provides the majority of the energy required for cardiac functioning. Several proteins, including the integral membrane protein FATP (fatty acid-transport protein), are being implicated in the process of myocardial fatty acid uptake. Rat FATP cDNA was cloned in order to initiate studies on the role of FATP in myocardial fatty acid utilization in the rat. The inferred amino acid sequence indicates that rat FATP is highly homologous $(97 \%$ amino acid identity) with its murine equivalent. Moreover, rodent FATPs share several wellconserved regions with putative counterparts found in yeast and nematode. Given the large evolutionary distance between these species, these regions might be important for protein function. The predicted membrane topology of rat FATP is discussed.

\section{Introduction}

The energy requirement of the heart is met by oxidation of a variety of substrates, including fatty acids (FAs), lactate, glucose, and ketone bodies ${ }^{20}$. Under normal workload conditions, oxidation of long-chain FAs by cardiac muscle yields up to $70 \%$ of the ATP required for mechanical activity and ion homeostasis. Heart muscle cells lack the capacity to store large amounts of FA and, therefore, rely on a continuous extraction of FAs from the extracellular compartment. In the heart this process is known to occur with high efficiency ${ }^{20}$.

Myocardial FA uptake is a combination of passive diffusion of FAs through the lipid bilayer and carrier-mediated FA translocation across the sarcolemma ${ }^{4,17}$. In this latter process, which accounts for the bulk (circa $80 \%$ ) of FAs taken up by resting myocytes isolated from rat heart ${ }^{11}$, several proteins have been implicated ${ }^{4,17}$. One of these proteins, fatty acid-transport protein (FATP), was identified through its ability to enhance uptake of a fluorescent FA analogue in COS7 cells ${ }^{16}$. FATP is an integral membrane protein which is expressed in several tissues engaged in fatty acid metabolism such as adipose tissue, heart muscle, intestine, and brain ${ }^{16}$. When expressed in 3T3-L1 adipocytes, FATP specifically stimulates uptake of long-chain FAs with an apparent preference for arachidonic acid ${ }^{16}$.

To gain more insight into the role of this protein in cardiac FA utilization in the rat, we cloned FATP cDNA from this species. In this report we present the complete nucleotide sequence of rat FATP cDNA and discuss the homology of the deduced protein with counterparts found in other species.

\section{Materials and Methods}

Reverse transcriptase, restriction and modification enzymes were from Life Technologies (Breda, The Netherlands). Taq DNA polymerase was purchased from Pharmacia Biotech (Roosendaal, The Netherlands). All other chemicals were of 
analytical grade and purchased from various suppliers. The following oligonucleotides were employed in this study: FATP\#1 corresponds to nt 1-24 of the coding region of mouse FATP cDNA (5'ATGCGGGCTCCTGGAGCAGGAACA), FATP\#2 is complementary to the terminal part of the coding region of mouse FATP cDNA (5'TCAGAGTGAGAAGTCGCCTGCACA), FATP\#3 (5'GCTAGTTATTGCTCAGCGGTTTTTTTTTTTTTTTTTTV) contains a poly-T stretch anchored to FATP\#4 (5'GCTAGTTATTGCTCAGCGG), FATP\#5 is basically identical to nt 751-771 of the coding region of rat FATP cDNA (5'GGGACCACCGGGCTTCCYAAG), FATP\#6 (5'GAAGGCTGCGATGCGGTAGTA) andFATP\#7 (5'CCAGGAACACAGCCACCACAT) are complementary to nt 796-816 and 386-406, respectively, of the coding region of rat FATP cDNA. All oligonucleotides were obtained from Pharmacia Biotech.

\section{Cloning of the coding region of rat FATP $C D N A$}

Total RNA was isolated from brain tissue (adult male Wistar rat) using Trizol reagent (Life Technologies). First strand cDNA synthesis was primed using oligonucleotide FATP\#2. For this, $5 \mu \mathrm{g}$ total RNA was reverse transcribed using Ready-To-Go ${ }^{\mathrm{TM}}$ beads (Pharmacia Biotech). Following amplification by PCR (30 cycles of $1 \mathrm{~min}$ $94^{\circ} \mathrm{C}, 1 \mathrm{~min} 50^{\circ} \mathrm{C}, 2.5 \mathrm{~min} 72^{\circ} \mathrm{C}$ ) using oligonucleotides FATP\#1 and FATP\#2, reaction products were separated on an agarose gel. A 2-kb fragment was isolated from gel using Qiaex (Qiagen Inc., USA) and ligated into the $\mathrm{pCR}_{\mathrm{II}}$ vector (Invitrogen BV, Leek, The Netherlands). Initial sequence analysis revealed high homology with mouse FATP cDNA indicating that the correct product had been obtained. Following restriction mapping of the insert, overlapping restriction fragments were subcloned and sequenced on both strands using the deaza G/A T7 sequencing kit (Pharmacia Biotech).

\section{Cloning of the untranslated regions of rat FATP $c D N A$}

PCR-based methods were used to obtain the 5' and 3' untranslated regions (UTR) of rat FATP cDNA. For this, poly- $\mathrm{A}^{+}$RNA was purified from total brain RNA using oligo-T cellulose (Pharmacia Biotech). The 3' UTR of rat FATP cDNA was cloned by reverse transcribing $0.5 \mu \mathrm{g}$ poly- $\mathrm{A}^{+} \mathrm{RNA}$ using oligonucleotide $\mathrm{FATP} \# 3$ as primer. Reaction products were amplified by PCR $\left(30\right.$ cycles of $1 \min 94^{\circ} \mathrm{C}, 1 \mathrm{~min} 55^{\circ} \mathrm{C}, 3.5$ $\min 72^{\circ} \mathrm{C}$ ) employing oligonucleotides FATP\#4 and FATP\#5. After separation of PCR products on an agarose gel, a fragment of the expected size (circa $2.5 \mathrm{~kb}$ ) was obtained and cloned into the $\mathrm{pCR}_{\mathrm{II}}$ vector. Relevant regions of the insert were subcloned and sequenced.

The 5' UTR of rat FATP cDNA was obtained by RACE-PCR (rapid amplification of cDNA ends-PCR) using a 5' RACE system kit (Life Technologies). Briefly, $0.5 \mu \mathrm{g}$ poly- $\mathrm{A}^{+}$RNA was reverse transcribed using oligonucleotide FATP\#6. 
Single-stranded DNA was tailed with $\mathrm{dCTP}$ and reaction products were amplified by PCR ( 30 cycles of $1 \mathrm{~min} 94^{\circ} \mathrm{C}, 1 \mathrm{~min} 55^{\circ} \mathrm{C}, 1 \mathrm{~min} 72^{\circ} \mathrm{C}$ ) using nested primer FATP\#7 and an oligo-G based primer. Following separation of reaction products, a fragment of the expected size (circa $550 \mathrm{bp}$ ) was purified from gel, cloned in the $\mathrm{pCR}_{\mathrm{II}}$ vector, and sequenced.

\section{Results and Discussion}

For the present study we first examined the distribution of FATP mRNA in several tissues of rat. Northern blot analysis, for which mouse FATP cDNA was used as a probe, revealed the highest levels of FATP mRNA in brain tissue (Figure 5.1). Therefore, brain RNA was chosen as a template for first strand cDNA synthesis. Subsequent amplification of first strand cDNA using RT-PCR and RACE-PCR procedures, yielded the coding region and the untranslated regions (UTRs) of FATP cDNA. The composite sequence has been deposited at the GenBank/EMBL/DDBJ databases under accession number U89529. The nucleotide sequence of a non-specific RT-PCR product, which most likely encodes part of the rat titin protein, has been submitted to these databases under accession numbers U89530 and U89531.

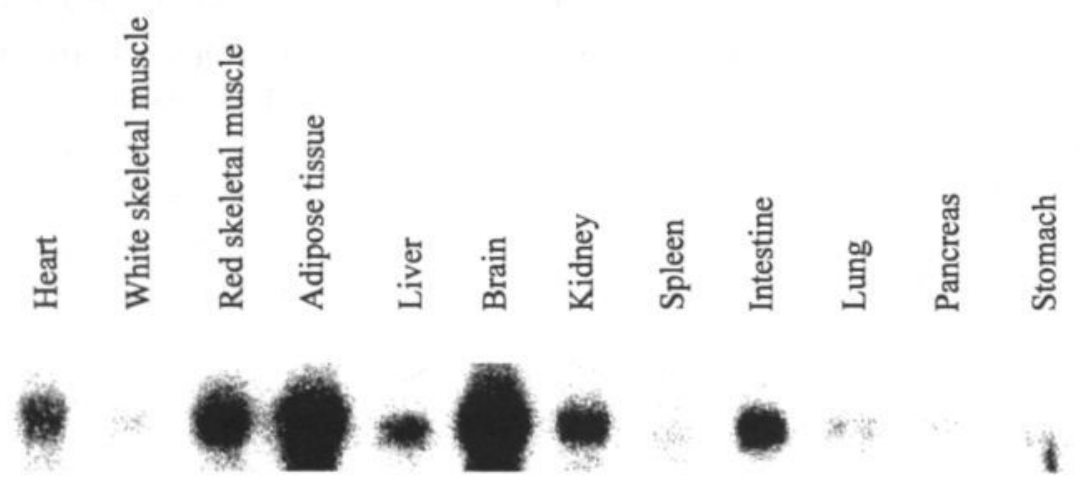

Figure 5.1 Distribution of FATP $m R N A$ in rat tissues assessed by Northern analysis. RNA was isolated from the indicated tissues, separated on a formaldehyde-containing agarose gel, and transferred to nylon membrane. Uniformity of gel loading was controlled by methylene-bluestaining. For hybridization, a radiolabeled fragment of mouse FATP cDNA was used.

As deduced from Northern blot analysis (Figure 5.1), a single hybridizing band of approximately $3.5 \mathrm{~kb}$ was present in RNAs isolated from several rat tissues. Taking into consideration an average poly-A tail length of $250 \mathrm{nt}$, this value is in good agreement with the size of the cloned cDNA $(3.1 \mathrm{~kb})$. The sequence of rat FATP cDNA is shown in Figure 5.2 (top). Rat FATP cDNA contains a large open reading 
aagttcecactccagacttetgcgagaaccegtgaggaagcagcgagaaecgggggtttgcaagccagagaaggATGCGCACTCCCGGAGCAOCANCAGC CTCTGTOCCCTCATTGGGGCTGCTTTGGCTTCTGGGACTTCCGTGGACCTGGAGCGCGGCGGCGGCGTTCGGTGTGTACGTGOGTAGCGGTGGCTCGCGA TTPCTGCGTATCGTCTGCAAGACGGCGAGCCGAGACCTCTTTGGCCTCTCTGTTCTGATCCGCGTGCGGCTAGAGCTACGACGACACCOGCGAGCAGGAG ACACGATCCCACGCATCTTCCAGGCCGTGGCCCAGCGACAGCCGGAGCGCCTGGCGCTGGTAGATGCGAGTAGCGGTATCTGCTGGACCTTCGCACAGCT AGACACCTACTCCAATGCTGTGGCCAATCTGTRCCTCCAGCTGCGCTTTGCGCCAGGCGATGTGGTGGCTGTGTTCCTGGAAGGCCGGCCCGAGTTCGTC GGACTGTGGCTGGGCCTGGCCAAGGCCGGTGTAGTGGCTGCGCTTCTCAATGTCAACCTGAGGCGGGAGCCCCTTGCCTTCTGCTTGGGCACATCAGCTG CCAAGGCCCTCATTTATGGCGGGGAGATGGCAGCGGCGGTGGCGGAGGTGAGTGAGCAGCTGGGGAAGAGCCTGCTCAAGTTCTGCTCTGGAGATCTGCG GCCTGAGAGCGTCCTGCCTGACACGCAGCTTCTGGACCCCATGCTTGCTGAGGCGCCCACCACACCCCTGGCACAGGCCCCAGGCAAGGGCATGGATGAT CGGCTATTTTACATCTATACTTCTGGGACCACCGGACTTCCTAMOGCGGCCATTGTGGTGCACAGCAGGTACTACOGCATCGCAGCCTTCGGCCACCATT CCTACAGCATGCGGGCCAACGATGTGCTCTATGACTGCCTACCTCTCTACCACTCAGCAGGGAACATCATGGGCGTGGGACAGTGTATCATCTACGCGTT AACGGTGGTACTGCGCAAGAAGTTCTCCGCCAGCOGCTTCTGGGACGACTGTGTCAAATATAATTGCACGOTAGTGCAGTACATCGGTGAATATGCCGC TACCTGCTAAGGCAGCCGGTTCGCGATGTAGAGCGGCGGCACCGCGTGCGCCTGGCCGTGGGTAACGGACTGCGGCCAGCCATCTGGGAGGAGTTCACGC AGGGTTTCGGTGTGCGACAGATTGGCGAGTTCTACGGCGCCACCGAATGCAACTGCAGCATTGCCAACATGCACGGCAACGTCGGCTCCTGCGGCTTCAA CAGCCGTATCCTCACGCATGTGTACCCCATCCGTCTGGTCAAGGTCAACGAGGACACGATGGAGCCACTGAGGGACTCCCAAGGCCTCTGCATCCCGTGC CAGCCCGGGGAACCTGGGCTTCTCGTGGGCCAGATCAACCAGCAAGACCCTCTGCGGCGCTTCGATGGCTATGTTAGTGACAGCGCCACCAACAAGAAGA TTGCCCACAGCGTGTTCCGAAAGGGCGACAGCGCCTACCTTTCAGGTGACGTGCTAGTGATGGACGAGCTGGGGTACATGTACTTCCGTGACCGCAGCGG GGATACCTTCCGATGGCGCGGCGAGAACGTATCCACCACGGAGGTGGAAGCCGTGCTGAGCCGCCTGTTGGGCCAGACGGACGTGGCTGTGTATGGAGTE GCTGTGCCAGGAGTGGAGGGGAAAGCGGCATGGCGGCCATTGCAGACCCCCACAACCAGCTGGACCCTAACTCAATGTACCAGGAATTGCAGAAGGTTC TTGCATCCTATGCCCAGCCCATCTTCCTGCGTCTTCTGCCCCAAGTGGATACAACAGGCACCTTCAAGATCCAGAAGACCCGACTACAGCGTGAAGGCTT TGACCCCCGCCAGACCTCAGACCGGCTCTTCTTTCTAGACCTGAAACAGGGACGCTACCTACCCCTGGATGAGAGAGTCCATGCCCGCATCTGCGCAGGC GACTTCTCACTCTGAgCctggtgagtgggatggecetggaettgtgagaccagggagecggacaccectgttcaggtgtttetectgcctggccacgtgg ccagcagcacctgtgggtgcaggaaactggaacctgagtggecgggtgtccctt cctacaacccaccatgcacacatctagcetctgcct tctccatctetttcctccgtgcceagcaggagccccacagacacattggctgctgtgtcetgeagtgggaceggtgtctaggggtecatgctgcaggetg tgacccgcactggtgeccacctccttcccattgtgecttaggttcctccactgtgcgecggtgaageaagtggggacccacatagctgttgtccetge tgagggttggtagcaaatgcacctcatgtcagetgggagacacatgcagtctcceactgaceccaatcaactgaagatactgtttgtattattgtt tgagatagggtctcactgtggaggecaagctggcetcaggctcaccactetactgcctccgggcaccagectgcagtttgatgacatgtatgeactattg ttctaagggt cttctgagt cectgetttccctcatgtcctaaaacttccagaactgactetgatcact tggatgtagctagtgttggccetgeccacg tgtgtcaattcaggggtcccaggcatcatctctggaggcctaaccttggcaaagettggatgtectcacatcacagcaggagacccaggaaggttget gtggtgtctettgggeaccetggeggeagecgtggacatgettccetgetgtgatagcccaaactgttgectatgacatttgaggtctacecttctgge tgccatggtccceattgagatctttggtgactcacctcagccaccaagccaggcctctgecttcettcagctctaagggcatgaagggtgtggacagagc agccacaggetgeccacagtcacccacatgcaagtgttattecttgttegtttcaaaaaataaacatgetgagccttgaaaaaaaaaaaaaaa YGGEMANAVA EVSEQLGKSL LKFCSGDLGP ESVLPDTOLL DPMLAEAPTT PLAQAPGKGM DDRLFY๋TYTS GTTGLPKAAT VVHSRYYRIA

AVGNGLRPAI WEEFTOGFGV RQIGEFYGAT ECNCSIANMD GKVGSCGFNS RILTHVYPIR LVKVNEDTME PLRDSOGLCI PCOPGEPGLL

VGOINOQDPL RRFDGYVSDS ATNKKIAHSV FRKGDSAYLS GDVLVMDELG YMYFRDRSGD TFRWRGENVS THEVEAVLSK LLGOTDVAVY

GVAVPGVEGK SGMAAIADPH NOLDPNSMYO ELOKVLASYA QPIFLRLLPQ VDTTGTFKIO KTRLOREGFD PROTSDRLFF LDLKOGRYLP

Figure 5.2 Top: Nucleotide sequence of rat FATP cDNA. The coding region is shown in upper case, the poly adenylation site is underlined. Bottom: Deduced amino acid sequence of FATP. A putative signal peptide is underlined, the AMP binding domain is double underlined, and potential glycosylation (*) and phosphorylation sites (+) are marked.

frame of $1941 \mathrm{nt}$ which is flanked by $74 \mathrm{nt} 5$ ' UTR and $1065 \mathrm{nt}$ 3' UTR. The start codon appears to be in a poor context for translation initiation ${ }^{2}$. A consensus polyadenylation site ${ }^{22}$ is found $14 \mathrm{nt}$ upstream of the poly-A tail. Sequence analysis of an FATP cDNA fragment (nt 824-1574) obtained by PCR-amplification of reversetranscribed heart poly- $\mathrm{A}^{+} \mathrm{RNA}$, revealed an identical nucleotide sequence. Hence, there are no indications for the existence of tissue-specific FATP forms in brain and heart tissue. 
The deduced amino acid sequence of rat FATP is shown in Figure 5.2 (bottom). Rat FATP consists of 646 amino acids and has a calculated mass of $71.3 \mathrm{kDa}$. A putative signal peptide (aa 1-31) for plasmamembrane localization is found in the $N$-terminus ${ }^{14}$. The difference between the observed $(63 \mathrm{kDa})$ and calculated $(71 \mathrm{kDa})$ molecular mass of mouse FATP suggests that this signal peptide might be cleaved ${ }^{16}$. Rat FATP contains potential sites for $N$-linked glycosylation and for phosphorylation by various kinases (Figure 5.2, bottom). Little is known about (post-translational) modification of FATP. Mouse FATP appears to lack $\mathrm{N}$-linked oligosaccharides ${ }^{16}$ suggesting that the motifs for $\mathrm{N}$-linked glycosylation are non-functional or reside on a cytoplasmic part of the protein.

Rat FATP is highly homologous to mouse FATP both at nucleotide level (93\%) and at protein level $(97 \%)$. Database searches revealed the existence of putative counterparts in the genomes of Saccharomycescerevisiae and Caenorhabditiselegans. An alignment of rodent FATPs and the putative orthologues found in yeast $(27 \%$ identity) and nematode ( $41 \%$ identity) is shown in Figure 5.3.

An AMP-binding domain (aa 246-257) is found in rat FATP and appears to be strongly conserved among the four species. This motif is found in several prokaryotic and eukaryotic enzymes that apparently act by coupling AMP to their substrates. Acyl-CoA synthetases, which catalyze the formation of acyl-CoA esters via an adenylated intermediate, are among the enzymes that contain such an AMP-binding domain. Interestingly, long-chain acyl-CoA synthetase was found to stimulate cellular FA uptake by apparently promoting further intracellular metabolism and, thus, by preventing cellular FA efflux ${ }^{16}$.

The presence of a strongly conserved AMP-binding domain suggests that FATP might possess enzymatic activity. Although such an activity was not ruled out by Schaffer and Lodish ${ }^{16}$, preliminary data obtained by these authors indicated that the majority of oleate taken up by cell lines transfected with mouse FATP cDNA remains in the non-esterified form implying that FATP stimulates cellular uptake of FAs rather than stimulating their intracellular metabolism ${ }^{16}$. The recent observation that very long-chain acyl-CoA synthetase (VLACS) shares significant homology with FATP ${ }^{19}$ alludes to an enzymatic action of FATP. Homology between rat FATP and rat VLACS is highest in their $C$-terminal parts ( $44 \%$ identity, $57 \%$ similarity from aa $\left.246-646^{\circ}\right)$, whereas they share $37 \%$ overall identity $\left(48 \%\right.$ similarity $\left.{ }^{*}\right)$ (Figure 5.4$)$. Notably, the homology of FATP with long-chain acyl-CoA synthetase and an arachidonate-preferring acyl-CoA synthetase ${ }^{9}$ is much lower (circa $10 \%$ identity).

'BLOSUM62 matrix 
RAGD - - THPRHFQAVAQRQPERL - ATVDASSGI CWYYAQLDTYSNAVAN - - - LFLQLGFAP SEVVAVFLEGRPE

\section{AMP binding domain}

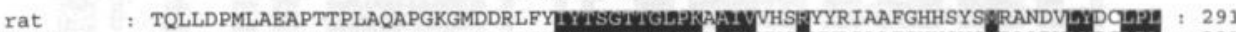

mouse : TQLLDPMLAEAPTTPLAQAPGKGMDDRLFYIYTSGTTGLPKAAIVVHSRYYRIAAFGHHSYS RAADVLYDCLPL: 291 nematode : FKNLKKKLDAQITTEPKTLDIVDFKSILCFIYTSGTTGMPKAAVIKHF YYSIAVGAAKSFGIRPSDR MYVSYPI : 290 yeast : LLNSQSPEFLQQDNVRTPLGLTDFKP-SML IYTSGTTGLPKSAINSWR SSVGCQVFGHVLH TNESTVFTAMPL: 299

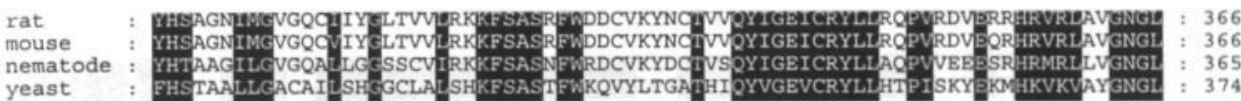

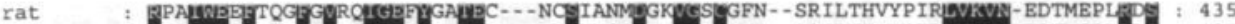

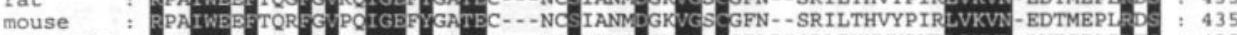

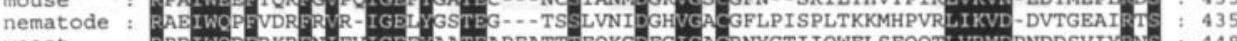

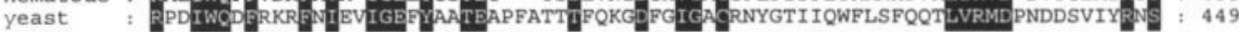

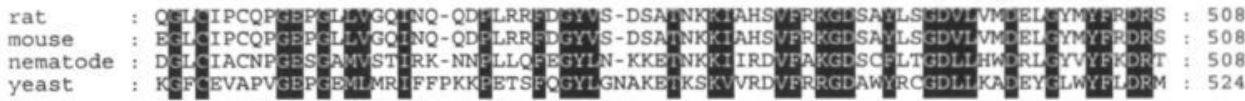

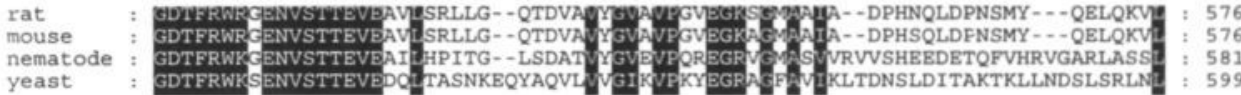

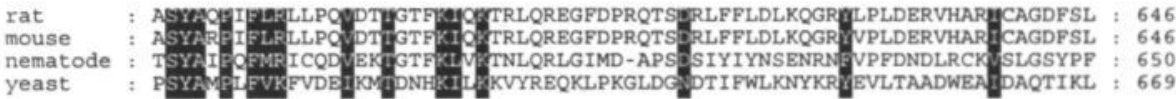

Figure 5.3 Alignment of FATP sequencesof rat, mouse, nematode, and yeast (GenBankaccession numbers: U89529, U15976, Z70684, and AF065148). Identical or conservatively substituted (BLOSUM62 matrix) residues are shaded. Gaps (-) were inserted to maximize homology. 


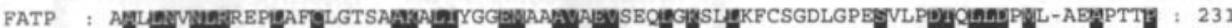

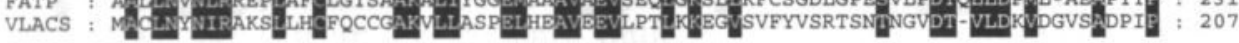

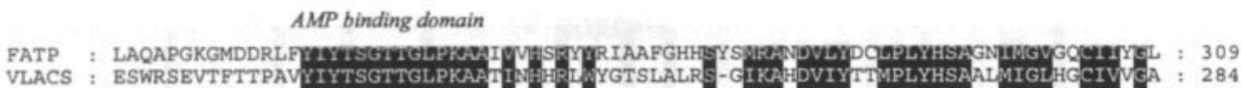

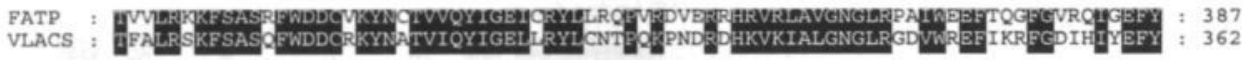

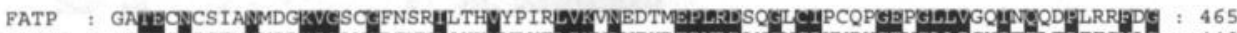

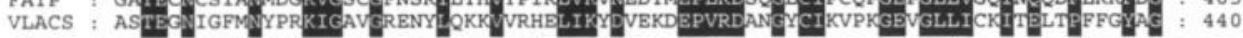

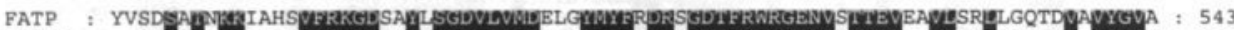

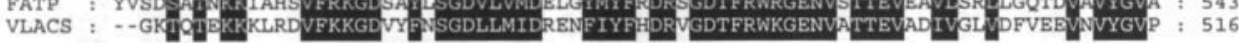

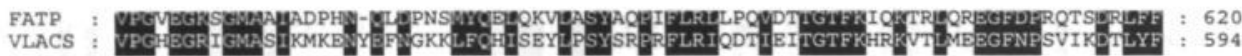

FATP : IELLFGRTIPEDPRQHARHCAGDFSE : 646

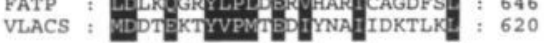

Figure 5.4 Alignment of rat FATP with rat very long-chain acyl CoA synthetase (GenBank accession numbers: U89529 and D85100). Identical or similar (BLOSUM62 matrix) amino acids are shaded. Gaps (-) were introduced to maximize homology.

Using hydropathy analysis according to Kyte and Doolittle, six membrane spanning $\alpha$-helices were predicted for mouse FATP $^{16}$. We used four different programs available through the Internet ${ }^{* *}$ to predict the number of transmembrane regions for rat FATP. When applicable, the minimum number of $\alpha$-helical arranged amino acids required to span the hydrophobic core of the lipid bilayer ${ }^{5}$, was set to 17 . The prediction methods produced conflicting results, indicating either a single membranespanning domain ${ }^{10}$ or a polytopic membrane topology consisting of 3-6 transmembrane regions ${ }^{8,15}$. Whereas the number of membrane-spanning segments

\footnotetext{
“"http://psort.nibb.ac.jp/form.html ${ }^{10}$

http://ulrec3.unil.ch/software/TMPRED_form.html ${ }^{8}$ http://www.tuat.ac.jp/ mitaku/sosui ${ }^{6}$ http://www.embl-heidelberg.de/tmap/tmap_sin.html ${ }^{15}$
} 


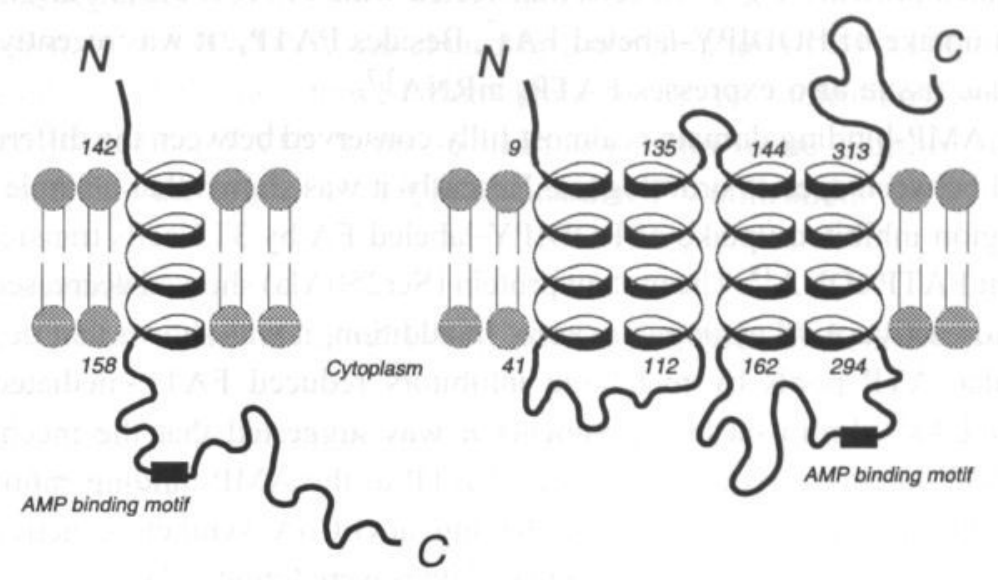

Figure 5.5 Two possible models showing the predicted membrane topology for rat FATP (not drawn to scale). The boundaries of the membrane spanning $\alpha$-helices are indicated by the numbers of the amino acid residues.

could not be predicted unambiguously, all employed programs indicated that a large non-transmembrane region is present in the $C$-terminus. Assuming that the highly conserved AMP-binding domain resides intracellularly, and taking into account the positive-inside rule ${ }^{10}$, two possible models depicting the membrane topology of rat FATP have been made (Figure 5.5). The apparent lack of $N$-linked carbohydrates in FATP $^{16}$ can be explained by the topology predicted by the method of Klein et al. ${ }^{10}$ in which the $\mathrm{N}$-linked glycosylation sites reside on an intracellular part of the protein (Figure 5.5, left model). The model indicating four transmembrane regions for rat FATP (Figure 5.5, right model) is supported by the methods of Hofmann et al. ${ }^{8}$ (maximum helix length: 35 residues) and Hirokawa et al. ${ }^{6}$.

\section{Recent developments}

Puzzled by the apparent lack of FATP mRNA in liver (cf. Figure 5.1), an organ having a large capacity for uptake of FAs, Hirsch et al. started a search for FATP homologues ${ }^{7}$. This resulted in the discovery of a family of fatty acid transporters which are expressed in numerous tissues including those with prominent FA metabolism. Currently, six FATP-related proteins have been identified in humans, and orthologous proteins are found in species as distantly related as Mycobacterium tuberculosis. Amino acid identity between mammalian family members ranges between 33 and $63 \%$. In the nomenclature proposed by Hirsch et al. ${ }^{7}$, the original FATP $^{16}$ is renamed FATP 1 . Functionality in FA uptake was tested for some of the 
FATP related proteins, e.g. COS cells transfected with VLACS/FATP 2 CDNA showed increased uptake of BODIPY-labeled $\mathrm{FAs}^{7}$. Besides $\mathrm{FATP}_{1}$, it was recently reported that cardiac tissue also expresses $\mathrm{FATP}_{4} \mathrm{mRNA}^{3,7}$.

The AMP-binding domain is almost fully conserved between the different FATP types and between species orthologues. Recently it was shown that a single mutation in this region inhibited uptake of BODIPY-labeled FA by 3 T3 cells transfected with the mutant FATP cDNA $^{18}$. The mutant protein (Ser250Ala) showed decreased labeling by a photoreactive ATP analogue in vitro. In addition, it was shown that depletion of intracellular ATP pools by metabolic inhibitors reduced FATP-mediated cellular uptake of $\mathrm{FAs}^{18}$. From these experiments it was suggested that the mechanism by which FATP operates, requires binding of ATP to the AMP-binding motif.

Recent findings question FATP having acyl-CoA synthetase activity. First, membrane fractions of FATP-expressing cell lines were found to lack long-chain acylCoA synthetase activity ${ }^{18}$. Second as noted by Stuhlsatz-Krouper et al. ${ }^{18}$, a sequence motif (DGWLHTGDIGXWXPXGXLKIIDRKK) containing residues essential for catalytic activity and for determining substrate specificity ${ }^{1}$ is not present in FATP. Thus far this motif has been found in all known acyl-CoA synthetases acting on short-, medium- and long-chain FAs ${ }^{1}$.

\section{Future Prospects}

Coordinate expression of FATP and other proteins implicated in cellular FA utilization, such as fatty acid translocase (FAT), plasmalemmal fatty acid-binding protein $\left(\mathrm{FABP}_{\mathrm{pm}}\right)$ and acyl-CoA synthetase, has been described in several tissues $^{12,13,21}$ and is suggestive for a role of FATP in cellular FA handling. Although identified via a functional approach ${ }^{16}$ and despite observation of increased cellular uptake of BODIPY-FAs in transfected cell lines ${ }^{7,16}$, evidence for a physiological role of FATP in cellular FA utilization has not been obtained yet. Moreover, as myocardial LCFA uptake most likely involves several membrane-associated proteins, the contribution of FATP herein needs to be established.

The cloned FATP cDNA can be useful in studying the function of FATP in myocardial FA utilization. For this, isolated cardiac myocytes transiently transfected with sense or antisense FATP cDNA can be employed to determine cellular FA uptake and metabolism. The availability of antibodies may be useful in defining individual contributions of FATP, FAT and $\mathrm{FABP}_{\mathrm{pm}}$, to uptake of fatty acids by cardiac myocytes. In addition, such antibodies will allow the development of an ELISA for quantifying FATP protein levels. Presumed cytoplasmic FATP domains are currently being expressed in E. coli, and can be used for raising such antibodies. Besides, these domains can be employed to study a possible interaction with cytoplasmic H-FABP or sarcolemmal FA transporters. 


\section{Concluding remarks}

In conclusion, rat FATP cDNA was cloned by a combination of RT-PCR and RACEPCR procedures. Although derived from brain tissue, no indications exist for the occurrence of distinct FATP forms in heart and brain tissue. Further studies are required to define the role of FATP in myocardial FA utilization.

\section{Acknowledgements}

Analysis of tissue distribution of FATP mRNA by Peter Willemsen was greatly appreciated.

We thank Dr Jean Schaffer (Washington University, St. Louis, USA) for providing mouse FATP cDNA.

\section{References}

1) Black PN, Zhang Q, Weimar JD, and DiRusso CC: Mutational analysis of a fatty acyl-coenzyme A synthetase signature motif identifies seven amino acid residues that modulate fatty acid substrate specificity. J Biol Chem 272:4896-4903(1997)

2) Cavener DR and Ray SC: Eukaryotic start and stop translation sites. Nucleic Acids Res 19:3185-3192(1991)

3) Fitscher BA, Riedel HD, Young KC, and Stremmel W: Tissue distribution and cDNA cloning of a human fatty acid transport protein (hsFATP 4 ). Biochim Biophys Acta 1443:381-385 (1998)

4) Glatz JFC and van der Vusse GJ: Cellular fatty acid-binding proteins: their function and physiological significance. Prog Lipid Res 35:243-282 (1996)

5) Haltia $T$ and Freire E: Forces and factors that contribute to the structural stability of membrane proteins. Biochim Biophys Acta 1228:1-27(1995)

6) Hirokawa $T$, Boon-Chieng S, and Mitaku S: SOSUI: classification and secondary structure prediction system for membrane proteins. Bioinformatics 14:378-379(1998)

7) Hirsch D, Stahl A, and Lodish HF: A family of fatty acid transporters conserved from mycobacterium to man. Proc Natl Acad Sci U S A 95:8625-8629(1998)

8) Hofmann $\mathrm{K}$ and Stoffel W: TMbase - a database of membrane spanning protein segments. Biol Chem Hoppe-Seyler 374:166 (1993)

9) Kang MJ, Fujino T, Sasano H, Minekura H, Yabuki N, Nagura H, lijima H, and Yamamoto TT: A novel arachidonate-preferring acyl-CoA synthetase is present in steroidogenic cells of the rat adrenal, ovary, and testis. Proc Natl Acad Sci U S A 94:2880-2884(1997)

10) Klein $P, K a n e h i s a ~ M$, and DeLisi $C$ : The detection and classification of membrane-spanning proteins. Biochim Biophys Acta 815:468-476(1985)

11) Luiken JJFP, van Nieuwenhoven FA, America G, van der Vusse GJ, and Glatz JFC: Uptake and metabolism of palmitate by isolated cardiac myocytes from adult rats: involvement of sarcolemmal proteins. J Lipid Res 38:745-758 (1997)

12) Martin G, Schoonjans K, Lefebvre AM, Staels B, and Auwerx J: Coordinate regulation of the expression of the fatty acid-transport protein and acyl-CoA synthetase genes by PPAR ${ }_{\alpha}$ and PPAR $_{\tau}$ activators. $J$ Biol Chem 272:28210-28217(1997) 
13) Motojima K, Passilly P, Peters JM, Gonzalez FJ, and Latruffe N: Expression of putative fatty acid transporter genes are regulated by peroxisome proliferator-activated receptor $\alpha$ and $\tau$ activators in a tissue- and inducer-specific manner. $J$ Biol Chem 273:16710-16714(1998)

14) Nielsen H, Engelbrecht J, Brunak S, and von Heijne G: Identification of prokaryotic and eukaryotic signal peptides and prediction of their cleavage sites. Protein Eng 10:1-6(1997)

15) Rost B: PHD: predicting one-dimensional protein structure by profile-based neural networks. Methods Enzymol 266:525-539(1996)

16) Schaffer JE and Lodish HF: Expression cloning and characterization of a novel adipocyte long-chain fatty acid-transport protein. Cell 79:427-436(1994)

17) Schaffer JE and Lodish HF: Molecular mechanism of long-chain fatty acid uptake. Trends Cardiovasc Med 5:218-224 (1995)

18) Stuhlsatz-Krouper SM, Bennett NE, and Schaffer JE: Substitution of alanine for serine 250 in the murine fatty acid-transport protein inhibits long-chain fatty acid transport. $J$ Biol Chem 273:28642-28650(1998)

19) Uchiyama A, Aoyama T, Kamijo K, Uchida Y, Kondo N, Orii T, and Hashimoto T: Molecular cloning of cDNA encoding rat very long-chain acyl-CoA synthetase. $J$ Biol Chem 271:30360-30365(1996)

20) van der Vusse GJ, Glatz JFC, Stam HC, and Reneman RS: Fatty acid homeostasis in the normoxic and ischemic heart. Physiol Rev 72:881-940 (1992)

21) van Nieuwenhoven FA, Willemsen PHM, van der Vusse GJ, and Glatz JFC: Co-expression in rat heart and skeletal muscle of four genes coding for proteins implicated in long-chain fatty acid uptake. Int J Biochem Cell Biol 31:489-98 (1999)

22) Wahle E and Keller W: The biochemistry of poly-adenylation.Trends Biochem Sci 21:247-250 (1996) 


\section{Chapter 6}

\section{IMPAIRED LONG-CHAIN FATTY}

ACID UTILIZATION BY CARDIAC

MYOCYTES FROM MICE LACKING

\section{THE H-FABP GENE}

Adapted from:

Schaap FG, Binas B, Danneberg H, van der Vusse GJ, and Glatz JFC: Circ Res, under revision 


\section{Abstract}

In normal workload conditions, long-chain fatty acids (LCFAs) are the principal energy source for the heart. Heart-type fatty acid-binding protein (H-FABP), abundantly expressed in cardiac myocytes, has been postulated to facilitate the cardiac uptake of LCFAs and to promote their intracellular trafficking to sites of metabolic conversion. Mice with a disrupted H-FABP gene were recently shown to have elevated plasma LCFA levels, decreased cardiac deposition of a LCFA-analogue, and increased cardiac deoxyglucose uptake, which qualitatively establishes a requirement for H-FABP in cardiac LCFA utilization.

To study the underlying defect we developed a method to isolate intact, electrically stimulatable cardiac myocytes from adult mice, and then studied substrate utilization under defined conditions in quiescent and in contracting cells from wildtype and $\mathrm{H}-\mathrm{FABP}^{-/ 2}$ mice.

Our results demonstrate that in resting and in contracting myocytes from $\mathrm{H}-\mathrm{FABP}^{/ /}$mice both uptake and oxidation of palmitate are markedly reduced (between $-45 \%$ and $-65 \%$ ), while cellular octanoate uptake, the capacities of heart homogenates for palmitate oxidation and for octanoate oxidation, and the cardiac levels of mRNAs encoding sarcolemmal FA transporters, remain unaltered. In contrast, in resting $\mathrm{H}-\mathrm{FABP}^{-/}$cardiac myocytes glucose oxidation is increased $(+80 \%)$ to a level which would require electrical stimulation in wild-type cells.

These findings provide a physiological demonstration of a crucial role of H-FABP in uptake and oxidation of LCFAs in cardiac muscle cells, and indicate that in $\mathrm{H}-\mathrm{FABP}^{-/-}$mice the diminished contribution of LCFAs to cardiac energy production is, at least in part, compensated by an increase in glucose oxidation.

\section{Introduction}

Long-chain fatty acids (LCFAs) serve important roles as fuel molecules and as components of phospholipid membranes and triacylglycerol stores. Due to their hydrophobic nature, LCFAs are virtually insoluble in aqueous environments and therefore rely on specific mechanisms for efficient vascular transport, cellular entry and intracellular movement. This is especially apparent in heart muscle which depends on an unimpeded supply of blood-borne FAs to energize its contractile function ${ }^{35}$.

LCFAs are delivered to the heart by albumin, a plasma and interstitial protein with multiple high-affinity binding sites for hydrophobic molecules. Although the molecular mechanism by which FAs cross the cellular membrane is largely unknown, evidence is accumulating that in heart muscle, as well as in other organs, FAs enter parenchymal cells both through passive diffusion and through a carrier-mediated mechanism ${ }^{5,9,15,21,32,46}$. Inside the cell, cytoplasmic proteins with high-affinity for LCFAs are proposed to be indispensable for efficient transcytoplasmic trafficking of LCFAs $^{12}$. 
The search for such cytoplasmic proteins was initiated in tissues with particular high FA fluxes like intestine, liver, adipose tissue, and heart. In the late $60 \mathrm{~s}$, Levi and coworkers found in liver cytosol three protein fractions which were capable of binding $\mathrm{FAs}^{18}$. One of these fractions was further characterized by Ockner et al. and resulted in the identification of a low molecular mass protein, designated fatty acid-binding protein (FABP), in cytosolic preparations of various tissues ${ }^{25}$. Nowadays, FABP is known to be a member of the family of intracellular lipid-binding proteins which currently comprises at least 13 different proteins ${ }^{3,6,12,40}$. A wide variety of hydrophobic ligands, such as LCFAs, bile salts, and retinoids, are bound with highaffinity by distinct members of this protein family. For example, heart-type FABP (H-FABP), which is abundantly expressed in cardiac myocytes, binds LCFAs with affinities in the low nanomolar range ${ }^{26}$.

Because of their abundance in tissues with a high rate of FA metabolism, FABPs are thought to facilitate plasmalemmal uptake of FAs and promote subsequent intracellular transport to metabolizing organelles. Until recently, however, only circumstantial evidence has been provided for this role of FABP in cellular FA handling ${ }^{12}$, e.g. (i) correlation between H-FABP content and oxidative capacity observed during development and among different muscle types ${ }^{19,38}$, (ii) enhanced transfer of FA-derivatives between model membranes by FABPs ${ }^{33}$ and (iii) augmented uptake and/or metabolism of FAs in cell lines transfected with liver-type or intestinaltype FABP cDNA ${ }^{23,24}$.

To study the role of H-FABP in a physiological environment, and to test the hypothesis that H-FABP is required for an adequate rate of cardiac LCFA utilization, mice with a disrupted H-FABP gene were created by Binas et al ${ }^{4}$. Initial studies by these authors revealed that plasma LCFA levels were elevated in H-FABP nullizygous mice. Moreover, systemic administration of a radiolabeled FA analogue ( ${ }^{125} \mathrm{I}$-labeled 15-(p-iodophenyl)-3(R,S)-methylpentadecanoic acid: ${ }^{125} \mathrm{I}$-BMIPP) was found to result in diminished accumulation of this compound in cardiac and skeletal muscle of $\mathrm{H}-\mathrm{FABP}^{-/}$mice. Taken together these findings indicated that $\mathrm{FA}$ utilization was hindered in tissues normally expressing $\mathrm{H}-\mathrm{FABP}^{4}$.

This initial study, however, was mainly qualitative and did not address the metabolic fate of FAs in hearts of H-FABP nullizygous mice. Moreover, because of the in vivo approach, possible involvement of, for instance, hemodynamic factors in the diminished deposition of ${ }^{125} \mathrm{I}$-BMIPP in $\mathrm{H}-\mathrm{FABP}^{-/}$hearts could not be excluded. The present study aimed at characterizing cardiac $\mathrm{FA}$ metabolism in $\mathrm{H}-\mathrm{FABP}^{-/}$mice in more detail. Specifically, the cellular uptake and/or metabolism of (LC)FAs by isolated cardiac myocytes was determined, and it was investigated whether the absence of $\mathrm{H}-\mathrm{FABP}$ in hearts of $\mathrm{H}-\mathrm{FABP}^{-/}$mice invoked adaptive pathways, such as expression of other, including unknown, FABP types or usage of alternative energy substrates. 
Our results show that the absence of H-FABP markedly limits myocardial LCFA utilization. In hearts of $\mathrm{H}-\mathrm{FABP}^{-/}$mice, the diminished availability of LCFAs is most likely compensated by an augmented usage of glucose for energy production. To the best of our knowledge, and in support of the previous in vivo data ${ }^{17}$, the present findings are the first physiological demonstration of a role of FABP in FA oxidation in cardiac myocytes.

\section{Materials and Methods}

Chemicals were obtained from the indicated suppliers. Collagenase (Type I, Life Technologies, Gaithersburg, MD, USA), $\left[8-{ }^{3} \mathrm{H}\right]$ octanoic acid and $\left[9,10-{ }^{3} \mathrm{H}\right]$ palmitic acid (Arc Inc., St. Louis, MO, USA), $\left[1-{ }^{14} \mathrm{C}\right]$ octanoic acid (DuPont NEN, Boston, MA, USA), $\left[1-{ }^{14} \mathrm{C}\right]$ palmitic acid, $\left[1-{ }^{14} \mathrm{C}\right]$ oleic acid, 2-deoxy-D- $\left[1-{ }^{3} \mathrm{H}\right]$ glucose, and D-[U- $\left.{ }^{14} \mathrm{C}\right]$ glucose (Amersham Life Science, England), octanoic acid, palmitic acid, 2-deoxy-D-glucose, phloretin, and bovine serum albumin (BSA, Fraction V) (Sigma, St. Louis, MO, USA), Lipidex-1000 (Packard Instrument BV, Groningen, The Netherlands). The FA content of the BSA batch used, was analyzed by gas chromatography and found to be below 0.10 mol FA per mol BSA (data not shown). All other chemicals were of analytical grade and were purchased from various suppliers.

\section{Animals}

Mice with a targeted deletion of the entire H-FABP locus were created as previously described and were shown to be viable, fertile, and exhibit no gross abnormalities ${ }^{4}$. Adult mice (4-10 months of age) of either $\mathrm{H}-\mathrm{FABP}^{-/ \cdot}$ or $\mathrm{H}-\mathrm{FABP}^{+/+}$genotype, of a mixed $129 \mathrm{xBalb} / \mathrm{c}$ background were employed in all experiments. Mice were bred at the Animal Facility of the Max Delbrück Center in Berlin. For isolation of cardiac myocytes and other experimental procedures, mice were transferred to the Centralized Animal Facility of Maastricht University where they had unrestricted access to food (SRM-A: a standard commercial diet [Hope Farms BV, Woerden, The Netherlands] containing $27.5 \%$ protein, $42.5 \%$ carbohydrate, and $7.5 \%$ fat) and water. This study was approved by the local Ethical Committee on Animal Experimentation.

\section{Studies with isolated cardiac myocytes}

Cardiac myocytes were isolated from hearts of wild-type and H-FABP nullizygous mice as described in detail in Chapter 4. Briefly, hearts were rinsed for $5 \mathrm{~min}$ by perfusing with $\mathrm{Ca}^{2+}$-free medium $\mathrm{A}$ (containing in $\mathrm{mM}$ : $115 \mathrm{NaCl}, 2.6 \mathrm{KCl}, 1.2$ $\mathrm{MgSO}_{4}, 1.2 \mathrm{KH}_{2} \mathrm{PO}_{4}, 10 \mathrm{NaHCO}_{3}, 10$ HEPES, 0.4 taurine, 11 glucose, $\mathrm{pH} 7.4$ ), followed by 7.5 min perfusion with medium A containing collagenase and low $\mathrm{Ca}^{2+}$ levels $(25 \mu \mathrm{M})$. Isolated cardiac myocytes were released from the perfused heart by mechanical agitation, and physiological $\mathrm{Ca}^{2+}$ levels were restored by recalcification 
of the cell suspension. Low-speed centrifugation ( $2 \mathrm{~min}, 23 \mathrm{~g}$ ) sedimented cardiac myocytes while other cell types remained in solution. The ensuing cell pellet, which consisted almost entirely of cardiac myocytes, was resuspended in medium B (medium A supplemented with $1.0 \mathrm{mM} \mathrm{CaCl}_{2}$ and $2.0 \%$ BSA $[=0.3 \mathrm{mM} \mathrm{BSA}$, the interstitial albumin concentration]), washed once, and suspended in an appropriate volume of medium B yielding circa 3-5 mg cellular wet mass per $\mathrm{ml}$. In case cardiac myocytes were used to determine uptake and/or oxidation of (deoxy)glucose, cells were suspended in medium B devoid of glucose.

\section{Cellular uptake of octanoate, palmitate and deoxyglucose by cardiac myocytes}

For determination of the cellular uptake of various substrates, $0.9 \mathrm{ml}$ of a suspension of freshly-isolated cardiac myocytes was incubated in a capped $20-\mathrm{ml}$ glass vial in a shaking waterbath $\left(37^{\circ} \mathrm{C}, 120 \mathrm{rpm}\right)$ (HT Infors - model WTR, Bottmingen, Switzerland). A carbogen atmosphere was maintained in the incubation vials. Following thermal equilibration, $0.3 \mathrm{ml}$ substrate solution was added and incubation proceeded for three $\min$. Next, $1.0 \mathrm{ml}$ of the incubation mixture was rapidly transferred to a tube containing $9.0 \mathrm{ml}$ ice-cold stop solution (medium A supplemented with $0.1 \% \mathrm{BSA}, 1.0 \mathrm{mM} \mathrm{CaCl}_{2}$, and $200 \mu \mathrm{M}$ phloretin $)^{21}$. Cells were pelleted by centrifugation $\left(2 \mathrm{~min}, 75 \mathrm{~g}, 4^{\circ} \mathrm{C}\right)$ and washed twice with $7.5 \mathrm{ml}$ ice-cold stop solution. Cell-associated radioactivity was assayed after dissolving the final cell pellet in liquid scintillation fluid. All measurements were performed in duplicate, and controls were included to correct for extracellular-associated radioactivity. Substrate solutions consisted of (i) $0.4 \mathrm{mM}\left[8-{ }^{3} \mathrm{H}\right]$ octanoate and $0.4 \mathrm{mM}\left[1-{ }^{14} \mathrm{C}\right]$ palmitate complexed to $0.3 \mathrm{mM}$ BSA in medium A supplemented with $1.0 \mathrm{mM} \mathrm{CaCl}_{2}$, or (ii) $0.4 \mathrm{mM}\left[2-{ }^{3} \mathrm{H}\right]$ deoxyglucose and $0.4 \mathrm{mM}\left[1-{ }^{14} \mathrm{C}\right]$ palmitate complexed to $0.3 \mathrm{mM}$ BSA in medium A lacking glucose but supplemented with $1.0 \mathrm{mM} \mathrm{CaCl}_{2}$.

Pilot studies with cardiac myocytes isolated from either wild-type or $\mathrm{H}-\mathrm{FABP}^{-/}$ mice indicated that uptake of octanoate, palmitate, and deoxyglucose was linear up to at least three minutes.

\section{Oxidation of palmitate and of glucose by cardiac myocytes}

For determination of oxidation of palmitate and glucose, incubations were performed as described above with the following modifications. Substrate solutions consisted of (i) $0.4 \mathrm{mM}\left[1-{ }^{14} \mathrm{C}\right]$ palmitate complexed to $0.3 \mathrm{mM}$ BSA in medium A supplemented with $1.0 \mathrm{mM} \mathrm{CaCl}_{2}$, or (ii) $0.4 \mathrm{mM}\left[\mathrm{U}^{-14} \mathrm{C}\right]$ glucose in medium A with $1.0 \mathrm{mM} \mathrm{CaCl}_{2}$. Incubations were carried out for $30 \mathrm{~min}$ and were stopped by addition of perchloric acid to a concentration of $0.6 \mathrm{M}$. Radiolabeled $\mathrm{CO}_{2}$ was trapped in $200 \mu \mathrm{l}$ ethanolamine/ethyleneglycol (1:2 v/v). In case oxidation of palmitate was measured, acid-soluble oxidation intermediates were determined by extracting $900 \mu \mathrm{l}$ of the acidsoluble supernatant $(2 \mathrm{~min}, 10,000 \mathrm{~g})$ with $4.5 \mathrm{ml}$ chloroform/methanol $(2: 1 \mathrm{v} / \mathrm{v})^{21}$. 
For determination of cellular uptake and/or oxidation of substrates by electrically stimulated cardiac myocytes, incubations were performed in $20-\mathrm{ml}$ incubation vials using $1.5 \mathrm{ml}$ cell suspension and $0.5 \mathrm{ml}$ substrate solution as described above. Electric stimuli were generated by a pulse generator (Strotmann Laboratory Supplies, Aachen, Germany) and were delivered to the cardiac myocyte suspension by two platinum electrodes immersed in the incubation medium. For this, the platinum electrodes were mounted in the cap of the incubation vial ${ }^{22}$. To prevent electrolysis of cells, pulses were biphasic. The pulse parameters (frequency: $2 \mathrm{~Hz}, 200 \mathrm{~V}$ top to top, monophasic pulse duration: $250 \mu \mathrm{s}$, phase shift duration: $10 \mu \mathrm{s}$ ) were empirically set to trigger contraction of cardiac myocytes without causing excessive cellular damage ${ }^{22}$. Electrical stimulation for up to $10 \mathrm{~min}$ did not affect the percentage of rod-shaped cells (data not shown).

\section{Calculations}

Preparations consisting solely of trypan-blue positive, rounded-up cells did not show measurable uptake and/or oxidation of substrates (data not shown). Moreover, pilot studies with cardiac myocytes isolated from either wild-type or $\mathrm{H}-\mathrm{FABP}^{-/}$mice indicated that oxidation products of palmitate were not yet detectable after three minutes. Hence uptake data need not be corrected for loss of radiolabeled $\mathrm{CO}_{2}$. Palmitate oxidation is given as the sum of radiolabeled $\mathrm{CO}_{2}$ and the amount of acidsoluble oxidation intermediates, whereas glucose oxidation is expressed as the amount of ${ }^{14} \mathrm{CO}_{2}$ produced. As a linear relationship was observed between this percentage and the measured parameters (data not shown), all results were normalized to a $100 \%$ rodshaped cell suspension.

\section{Western blotting}

For analysis of GLUT4 expression, isolated cardiac myocytes were dissolved (5\% $\mathrm{m} / \mathrm{v})$ in $1 \%$ sodium dodecylsulphate. Total protein $(30 \mu \mathrm{g})$ was separated on a $10 \%$ denaturing polyacrylamide gel, electroblotted onto nylon membrane and stained with a polyclonal anti-rat GLUT4 antibody combined with chemiluminescent detection as described $^{8}$. Signals were quantified by densitometric scanning of X-ray films. For detection of $\mathrm{H}-\mathrm{FABP}$, total protein $(30 \mu \mathrm{g})$ was separated on a $15 \%$ denaturing polyacrylamide gel, transferred to nylon membrane and immunostained with monoclonal anti-human H-FABP antibodies as reported ${ }^{28}$.

\section{Studies in heart homogenates}

Homogenates $(5 \% \mathrm{~m} / \mathrm{v})$ of adult hearts $(\mathrm{n}=4-5)$ were prepared in $0.25 \mathrm{M}$ sucrose, 10 $\mathrm{mM}$ Tris, $0.1 \mathrm{mM}$ EDTA $(\mathrm{pH}$ 7.4) using a Potter-Elvejhem tissue homogenizer and three pestles with increasing diameter ${ }^{10}$. Oxidation of $\left[1-{ }^{14} \mathrm{C}\right]$ octanoate was measured 
as described by Veerkamp et al. ${ }^{39},\left[1-{ }^{14} \mathrm{C}\right]$ palmitate oxidation was performed according to Glatz et al. ${ }^{10}$. Oxidation rates are calculated as the sum of ${ }^{14} \mathrm{CO}_{2}$ produced and the amount of radiolabeled acid-soluble oxidation intermediates.

For determination of enzyme activities and H-FABP levels, the above-mentioned homogenates were sonicated ${ }^{37}$. Activities of citrate synthase, B-hydroxyacyl-CoA dehydrogenase and lactate dehydrogenase were assayed as described earlier ${ }^{37}$. H-FABP content was determined in heart homogenates $(n=7)$ with a sensitive ELISA of the antibody capture type (sandwich ELISA) according to Wodzig et al. ${ }^{45}$. Moreover, H-FABP levels were measured in tissue homogenates $(n=7)$ prepared from lower hindlimb skeletal muscle, kidney, and liver. For the ELISA, anti-human H-FABP monoclonal antibodies cross-reactive with mouse H-FABP were employed, and recombinant mouse H-FABP, a kind gift of Dr Börchers (Institute for Biochemical Sensor Research, Münster, Germany), was used as a standard.

\section{Determination of cytosolic FA binding capacity and radiochromatography}

Hearts were collected from adult mice $(n=3)$. In order to remove extracellular albumin, hearts were perfused for 5 inin with buffer A supplemented with $1.0 \mathrm{mM}$ $\mathrm{CaCl}_{2}$ as described in the section Isolation of cardiac myocytes. Hearts were homogenized in ice-cold PBS $(5 \% \mathrm{~m} / \mathrm{v})$ by successive ultraturrax treatment and sonication ${ }^{37}$. Cellular debris was pelleted by brief centrifugation $\left(10 \mathrm{~min}, 600 \mathrm{~g}, 4^{\circ} \mathrm{C}\right)$ and the supernatant was subjected to ultracentrifugation $\left(90 \mathrm{~min}, 105,000 \mathrm{~g}, 4^{\circ} \mathrm{C}\right)$. The resulting cytosolic preparations were delipidated using Lipidex-1000 extraction ${ }^{11}$ and were dealbuminized by passage through columns containing BlueSepharose CL-6B (Pharmacia Biotech, Uppsala, Sweden). For measurement of cytosolic FA binding capacity, 20-30 $\mu \mathrm{g}$ protein was incubated with $\left[1-{ }^{14} \mathrm{C}\right]$ oleate $(1 \mu \mathrm{M})$ for $30 \mathrm{~min}$ at $37^{\circ} \mathrm{C}$. Protein-associated FA was determined using the Lipidex-1000 assay as previously described ${ }^{11}$.

For radiochromatography, a $105,000 \mathrm{~g}$ supernatant was prepared from isolated cardiac myocytes. Cytosolic protein $\left(5-10 \mathrm{mg} \cdot \mathrm{ml}^{-1}\right)$ was incubated with ${ }^{3} \mathrm{H}$-labeled palmitate for $30 \mathrm{~min}$ at $37^{\circ} \mathrm{C}$. Thereafter, $100 \mu \mathrm{l}$ of the incubation was loaded on a Superdex 75 HR 10/30 column (Pharmacia, Uppsala, Sweden) and eluted with PBS at a flow-rate of $0.65 \mathrm{ml} \cdot \mathrm{min}^{-1}$. Absorbance was monitored at $280 \mathrm{~nm}$ and radioactivity was determined on-line with a radiochromatography detector (type A-250, Radiometric Instruments \& Chemical Co, Meriden, MT, USA). Using this system, the lower limit of radioactive detection corresponded to the amount of ${ }^{3} \mathrm{H}$-palmitate bound to $3 \mu \mathrm{g}$ recombinant rat $\mathrm{H}$-FABP. Globular proteins with known molecular masses were used as retention time markers. Recombinant rat $\mathrm{H}-\mathrm{FABP}^{28}$ complexed with ${ }^{3} \mathrm{H}$-labeled palmitate was used to determine the time delay between absorbance and radioactivity detection. 
Total RNA was isolated from hearts $(n=5)$ homogenized in TrizolTM reagent (Life Technologies, Gaithersburg, MD, USA). RNA (15 $\mu \mathrm{g})$ was separated on formaldehyde-containing agarose gels and transferred to Hybond- $\mathrm{N}^{+}$membranes (Amersham, Buckinghamshire, England). Filters were hybridized with ${ }^{32} \mathrm{P}$-labeled cDNA fragments, washed, and exposed to PhosphorImager screens and X-ray films. Signals were quantified using ImageQuant software (Molecular Dynamics, Sunnyvale, CA, USA) and were normalized against the $18 \mathrm{~S}$ rRNA signal which was obtained by reprobing stripped filters with a radiolabeled $18 \mathrm{~S}$ rRNA probe. cDNA probes for detecting cardiac expression of FABP types besides H-FABP were as described ${ }^{4}$. The other cDNA fragments used for hybridization were: mouse fatty acid-transport protein (1250 bp XbaI-BglII fragment), rat fatty acid translocase (2.4 kb EcoRI-EcoRI fragment), rat acyl-CoA binding protein (450 bp EcoRI-EcoRI fragment), rat mitochondrial aspartate aminotransferase/plasmalemmal FABP ${ }^{34}(1.6 \mathrm{~kb} \mathrm{NcoI}-\mathrm{HIndIII}$ fragment), rat H-FABP (676 bp EcoRI-BamHI), rat acyl-CoA synthetase (520 bp EcoRV-HIndIII fragment), rat GLUT4 (1.6 kb XbaI-Xhol fragment), rat hexokinase type II (1.5 kb NcoI-XhoI), and mouse 18S rRNA (750 bp EcoRI-EcoRI fragment). The respective cDNAs were kindly provided by Dr J. Schaffer (Washington University, St. Louis, MO, USA), Dr N. Abumrad (State University of New York, Stony Brook, NY, USA), Dr J. Knudsen (Odense University, Denmark), Dr A. Iriarte (University of Missouri, Kansas City, MO, USA), Dr P. Brecher (Boston University, Boston, MA, USA), Dr T. Yamamoto (Tohoku University, Sendai, Japan), Dr D. James (Washington University, St. Louis, MO, USA), Dr J. Wilson (Michigan State University, East Lansing, USA), and Dr I. Oberbäumer (Max Planck Institute for Biochemistry, Martinsried, Germany).

\section{Microscopy}

For electron and light microscopy, hearts $(n=2)$ were perfused for 5 min with medium A supplemented with $1.0 \mathrm{mM} \mathrm{CaCl}_{2}$ as described in the section Isolation of cardiac myocytes. To better preserve heart ultrastructure, hearts were perfused with a fixed hydrostatic pressure of $60 \mathrm{~cm} \mathrm{H}_{2} \mathrm{O}$. Heart tissue was fixated by subsequently perfusing for $10 \mathrm{~min}$ with $2.5 \%$ glutaraldehyde in $0.1 \mathrm{M}$ phosphate buffer $(\mathrm{pH} 7.4)$. Pieces of left ventricular tissue then were embedded in epoxy resin ${ }^{20}$. For electron microscopy, coupes of about $100 \mathrm{~nm}$ were prepared and stained using standard procedures. For light microscopy, $1 \mu \mathrm{m}$ coupes were stained with toluidine blue.

\section{Other Procedures}

Cardiac glycogen and triacylglycerol contents were determined in perfused hearts $(n=3)$ as described before ${ }^{37}$. Protein content was determined with the bicinchoninic acid method (Pierce, Rockford, IL, USA) with BSA serving as a protein standard. 


\section{Data presentation and analysis}

Data are expressed as mean value \pm standard deviation. The number (n) of wild-type and $\mathrm{H}-\mathrm{FABP}^{-/}$mice employed in the experiments/measurements is indicated in parentheses. Mann-Whitney testing was used to evaluate statistical difference of measured parameters in wild-type and $\mathrm{H}-\mathrm{FABP}^{-/-}$mice. $p<0.05$ was considered to denote a statistically significant difference.

\section{Results}

Absence of $H-F A B P$ in hearts of $H-F A B P^{-/}$mice

The absence of $\mathrm{H}-\mathrm{FABP}$ in cardiac tissue derived from $\mathrm{H}-\mathrm{FABP}$ nullizygous mice was confirmed by Western analysis (data not shown) and Northern-blotting (Figure 6.1a),

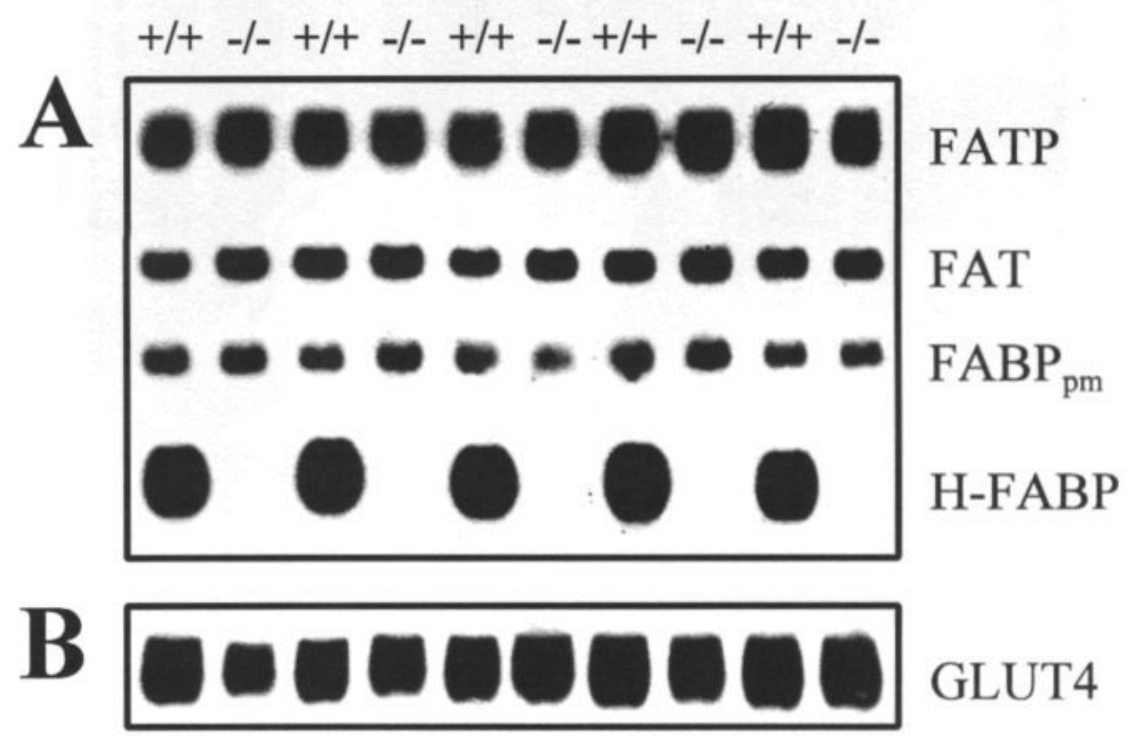

Figure 6.1 Panel A: Cardiac expression of sarcolemmal FA transporters and H-FABP. Total heart RNA (15 $\mu \mathrm{g})$ was isolated from wild-type (+/+) or H-FABP nullizygous (-/-) mice and analyzed by Northern blotting using the following cDNA probes for hybridization: Fatty Acid-Transport Protein (FATP), Fatty Acid Translocase (FAT), plasmalemmal FABP (FABP $\left.p_{p m}\right)$, and H-FABP. Signals were quantified using PhosphorImager technology and normalized to the $18 S$ rRNA signal. Panel B: Expression of GLUT4 in cardiac myocytes. Total protein $(30 \mu \mathrm{g})$ derived from cardiac myocytes isolated from wild-type (+/+) or H-FABP nullizygous (-/-) mice was analyzed by Western blotting. Signals were quantified by densitometry. 
and by direct measurement of H-FABP levels using a sensitive ELISA. In wild-type mice, H-FABP expression was highest in cardiac muscle $\left(1.9 \pm 0.2 \mathrm{mg} \cdot \mathrm{g}^{-1}\right.$ wet mass) and markedly lower in lower hindlimb skeletal muscle $\left(0.15 \pm 0.01 \mathrm{mg} \cdot \mathrm{g}^{-1}\right.$ wet mass) and kidney $\left(0.056 \pm 0.006 \mathrm{mg} \cdot \mathrm{g}^{-1}\right.$ wet mass). As expected, H-FABP was absent in liver or in tissues derived from $\mathrm{H}-\mathrm{FABP}^{-/ *}$ mice.

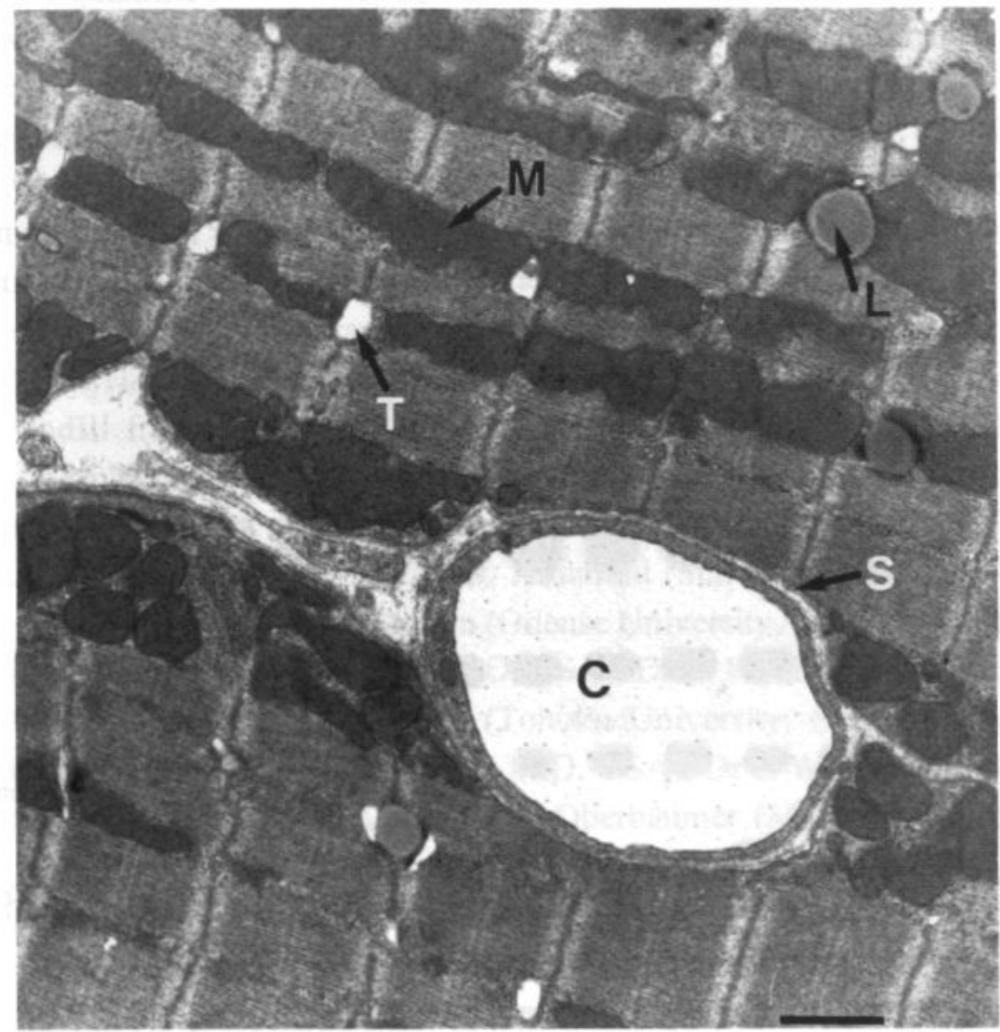

Figure 6.2 Microphotographsfrom a representative section of left ventricular heart tissue from wild-type (this page) or H-FABP nullizygous (next page) mice as obtained by electron microscopy. Notice the ordered, linear arrays of mitochondria which line the sarcomeres. The bar represents 1 $\mu \mathrm{m}$. Abbreviations: $C=$ capillary, $L=$ lipid droplet, $M=$ mitochondrion, $S=$ sarcolemma, $T=T$-tubule.

\section{Heart structure}

While $\mathrm{H}-\mathrm{FABP}^{-/}$mice were previously reported to be normal on histological sections ${ }^{4}$, we now explored whether disruption of the H-FABP gene caused ultrastructural adaptations, paying special attention to mitochondrial localization. For this, heart sections were studied using electron (Figure 6.2) and light microscopy (data 
not shown). In cross-sections of left ventricular heart tissue derived from either wild-type or $\mathrm{H}-\mathrm{FABP}^{-/}$mice, linear arrays of mitochondria lining the sarcomeres were observed, and mitochondria appeared evenly distributed throughout the sarcoplasm of the cardiac myocyte. There were no indications for an altered subcellular localization of mitochondria in cardiac myocytes of $\mathrm{H}-\mathrm{FABP}^{-/ 2}$ mice.

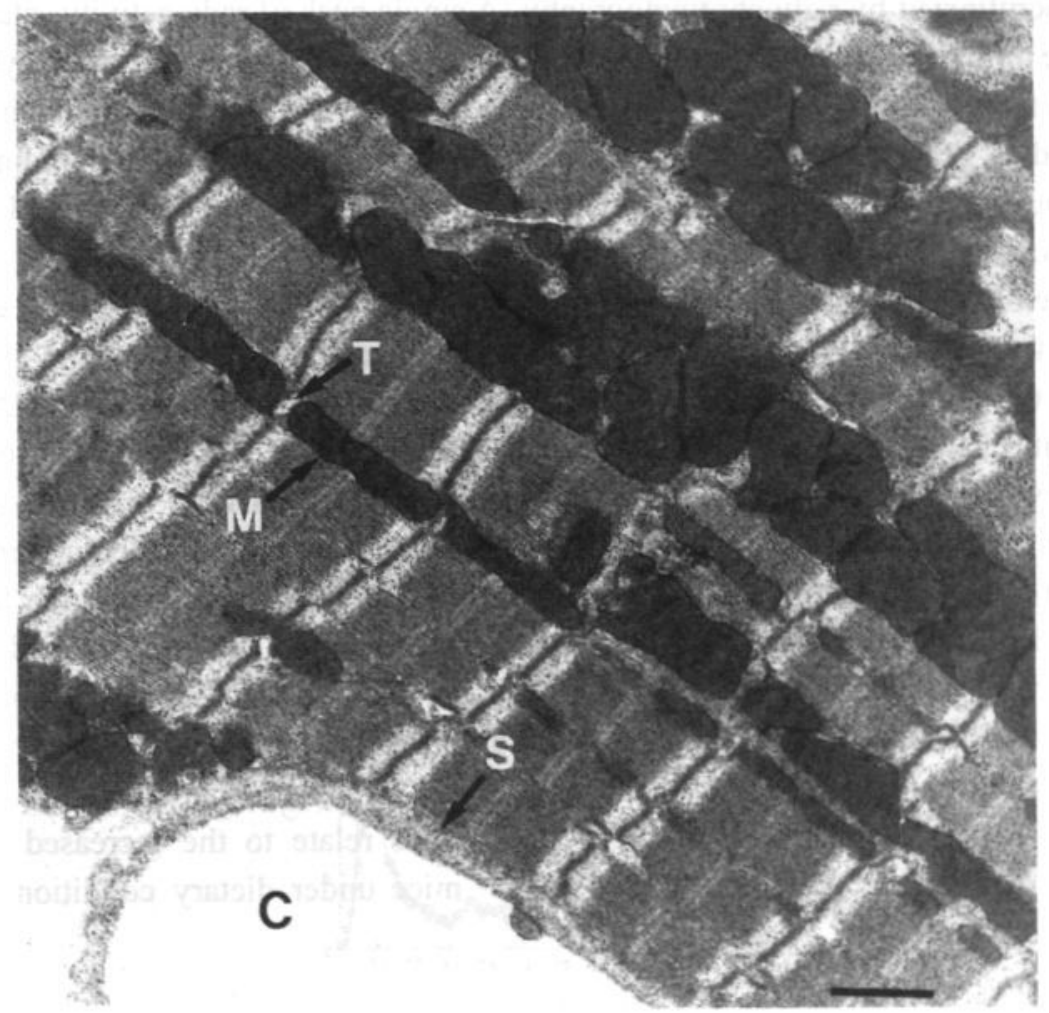

Figure 6.2 (continued)

\section{Cytosolic FA binding capacity of hearts}

The possible compensatory expression of other FABP types in cardiac muscle of $\mathrm{H}-\mathrm{FABP}^{-/}$mice was studied specifically by Northern analysis of known FABP types, and functionally by determining cytosolic FA binding capacity and by radiochromatographic analysis. Neither mRNA coding for brain-type FABP (B-FABP), epidermal-type FABP (E-FABP), adipocyte lipid binding protein (ALBP), or liver-type FABP (L-FABP) were detectable in cardiac muscle of either wild-type or $\mathrm{H}-\mathrm{FABP}^{-/}$mice, whereas clear signals were observed in the respective control 
tissues. In cytosolic preparations derived from heart tissue of $\mathrm{H}-\mathrm{FABP}^{-/}$mice, the capacity to bind oleate was reduced by $55 \%$ as determined using the Lipidex- 1000 assay $\left(2.1 \pm 0.1 \mathrm{vs}\right.$. $1.0 \pm 0.1 \mathrm{nmol}$ oleate $/ \mathrm{mg}$ protein for wild-type and $\mathrm{H}-\mathrm{FABP}^{-/}$heart cytosol, respectively). However, radiochromatographic analysis of the preparations used for this assay, revealed that residual binding capacity in hearts of $\mathrm{H}-\mathrm{FABP}^{-/}$ mice may, in part, be explained by incomplete removal of albumin.

Expression of other FABP types in cardiac myocytes of $\mathrm{H}_{-} \mathrm{FABP}^{-/}$mice, was further scrutinized by radiochromatography. A single peak of radioactivity, eluting at the same time as recombinant rat H-FABP (Figure 6.3a), was observed when cytosolic proteins from wild-type cardiac myocytes were incubated with ${ }^{3} \mathrm{H}$-palmitate and then subjected to gel filtration (Figure 6.3b). However, proteins capable of binding FAs were not detected in cytosol derived from isolated cardiac myocytes of H-FABP nullizygous mice (Figure $6.3 \mathrm{c}$ ).

The observed tendency of increased fatty acid-binding capacity of liver cytosol derived from $\mathrm{H}-\mathrm{FABP}^{-/}$mice (data not shown), prompted us to determine L-FABP levels in the employed cytosolic preparations. Preliminary analysis $(n=3)$ indicates that the hepatic L-FABP content is elevated in $\mathrm{H}-\mathrm{FABP}{ }^{-/}$mice $(25.0 \pm 3.3$ vs. $36.7 \pm 2.7$ $\mathrm{mg} \cdot \mathrm{g}^{-1}$ cytosolic protein for wild-type and $\mathrm{H}-\mathrm{FABP}^{-/}$liver tissue, resp.). However, Northern analysis revealed that hepatic L-FABP mRNA levels were identical in wildtype and H-FABP nullizygous mice (data not shown). Upon fasting or upon feeding a lipid-rich diet, the plasma concentration of ketone bodies was found to be significantly elevated in $\mathrm{H}-\mathrm{FABP}^{* /}$ mice $^{4}$. Hepatic LCFA $\mathrm{B}$-oxidation provides substrates for ketone body formation. These compounds are used by the liver and extra-hepatic tissues as glucose-replacing fuel ${ }^{14}$. The elevated L-FABP content may facilitate hepatic degradation of LCFAs, and thus relate to the increased plasma concentration of ketone bodies in $\mathrm{H}-\mathrm{FABP}^{-/}$mice under dietary conditions when glucose is scarce.

\section{Expression of putative sarcolemmal $F A$ transporters and $F A$ metabolizing enzymes}

Cardiac expression of several proteins involved in cellular uptake, metabolism, and intracellular transport of metabolites of FAs was examined by Northern blotting. Levels of mRNA coding for (i) fatty acid-transport protein (FATP) ${ }^{30}$, fatty acid translocase $(\mathrm{FAT})^{1}$, and plasmalemmal FABP $\left(\mathrm{FABP}_{\mathrm{pm}}\right)^{34}$, three membrane-associated proteins putatively involved in sarcolemmal FA uptake, (ii) acyl-CoA synthetase, a mitochondrial and sarcoplasmic reticular membrane-bound enzyme catalyzing the first step in FA metabolism ${ }^{44}$, and (iii) acyl-CoA binding protein, a cytoplasmic protein involved in binding and transport of acyl-CoA esters ${ }^{17}$, were all not different in heart tissue from wild-type and $\mathrm{H}-\mathrm{FABP}^{-/}$mice (Figure $6.1 \mathrm{a}$, data not shown). 

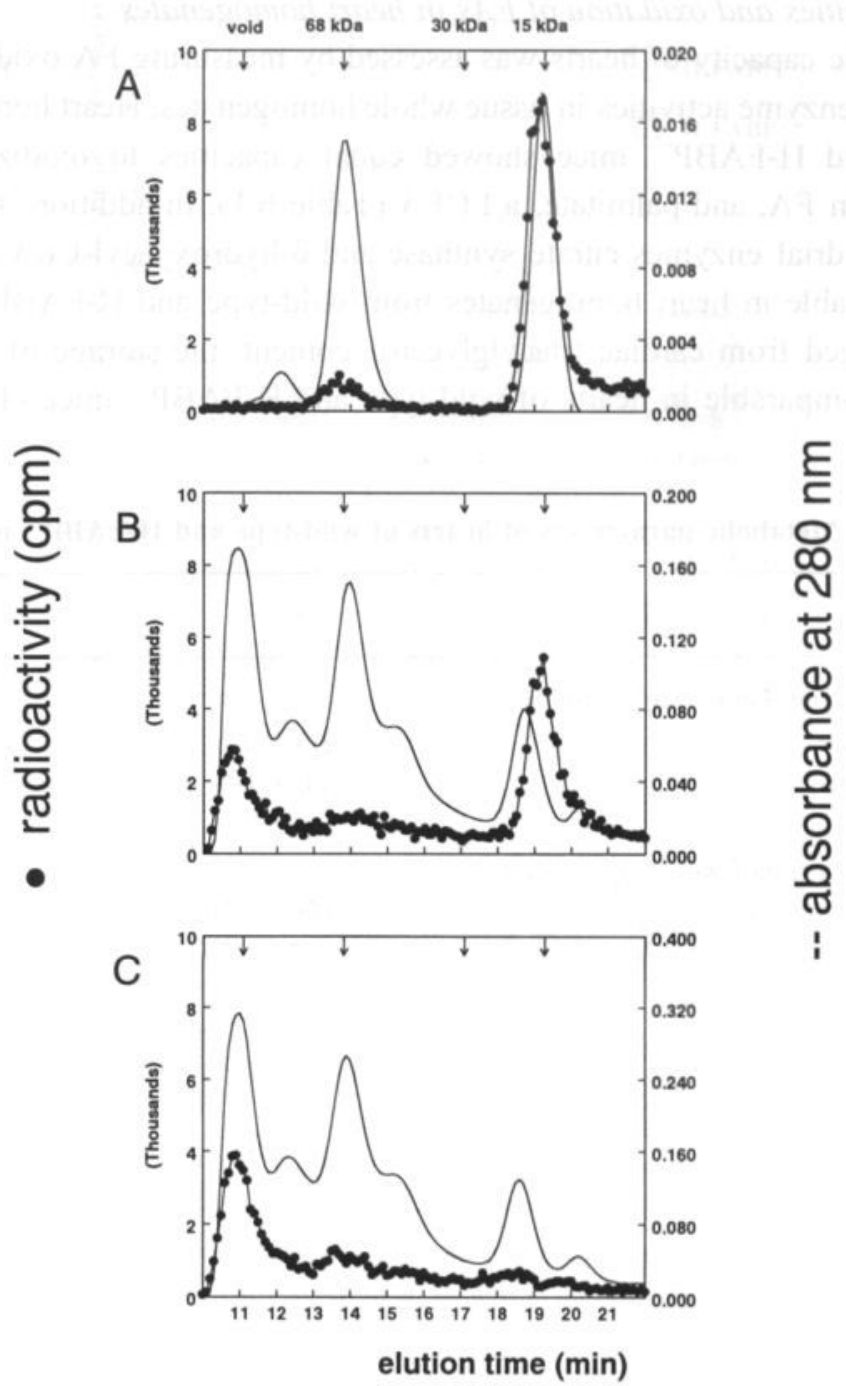

Figure 6.3 Representative gel filtration pattern of $(A)$ a mixture of albumin (20 $\mu \mathrm{g})$ and purified rat $H$-FABP $(10 \mu \mathrm{g}),(B)$ cytosolic protein $(550 \mu \mathrm{g})$ from cardiac myocytes of wild-type mice, and (C) cytosolic protein $(950 \mu \mathrm{g})$ from cardiac myocytes of $\mathrm{H}-\mathrm{FABP} / \mathrm{mice}$, each preparation preincubated with ${ }^{3} \mathrm{H}$-labeled palmitate. Absorbance was monitored at $280 \mathrm{~nm}$ (solid line) and radioactivity was determined on-line with a radiochromatographydetector (line with filled circles). The void volume and molecular masses of marker proteins are indicated. 
Enzyme activities and oxidation of FAs in heart homogenates

The metabolic capacity of hearts was assessed by measuring FA oxidation rates and determining enzyme activities in tissue whole homogenates. Heart homogenates from wild-type and $\mathrm{H}-\mathrm{FABP}^{-/}$mice showed equal capacities to oxidize octanoate, a medium-chain FA, and palmitate, a LCFA (Table 6.1). In addition, the activities of the mitochondrial enzymes citrate synthase and B-hydroxyacyl-CoA dehydrogenase were comparable in heart homogenates from wild-type and $\mathrm{H}-\mathrm{FABP}^{-/ 2}$ mice (Table 6.1). As judged from cardiac triacylglycerol content, the storage of FAs as neutral lipids was comparable in hearts of wild-type and $\mathrm{H}^{-\mathrm{FABP}^{-/}}$mice (Table 6.1).

Table 6.1 Metabolic parameters of hearts of wild-type and H-FABP ${ }^{-/ 2}$ mice

\section{Parameter}

$+1+$

$-/$

Oxidation Rate ( $\mathrm{nmol} \cdot \mathrm{min}^{-1} \cdot \mathrm{mg}^{-1}$ protein)

octanoate

$2.0 \pm 0.2$

$2.4 \pm 0.9$

palmitate

$3.0 \pm 1.3$

$3.0 \pm 1.4$

Enzyme Activities ( $\mu \mathrm{mol} \cdot \mathrm{min}^{-1} \cdot \mathrm{mg}^{-1}$ protein) citrate synthase

B-hydroxyacyl-CoA dehydrogenase lactate dehydrogenase

$\begin{array}{ll}1003 \pm 103 & 1068 \pm 106 \\ 527 \pm 170 & 692 \pm 110 \\ 1264 \pm 127 & 1108 \pm 121 \\ 49.5 \pm 6.1 & 78.3 \pm 3.7^{\circ} \\ 2.3 \pm 1.0 & 2.6 \pm 0.9\end{array}$

Glycogen content ( $\mu \mathrm{mol} \cdot \mathrm{g}^{-1}$ dry weight)

$2.3 \pm 1.0$

$2.6 \pm 0.9$

Homogenates were prepared from hearts $(n=4-5)$ of wild-type (+/+) and H-FABP nullizygous (-/-) mice. The oxidation rates and enzyme activities were determined as described in the Materials and Methods section. Cardiac triacylglycerol and glycogen contents were determined in perfused hearts $(n=3)$. An asterisk denotes a statistically significant difference $(p<0.05)$ between wild-type and $H-F A B P^{-/ 2}$ mice.

Uptake and oxidation of FAs by isolated cardiac myocytes

The initial uptake rate of palmitate, a ligand for H-FABP, was diminished by $45 \%$ in cardiac myocytes isolated from $\mathrm{H}-\mathrm{FABP}^{-/-}$mice $\left(33.7 \pm 7.9 \mathrm{vs} .18 .5 \pm 3.9 \mathrm{nmol} \cdot \mathrm{min}^{-1} \cdot \mathrm{g}^{-1}\right.$ wet mass for wild-type and $\mathrm{H}-\mathrm{FABP}^{-/}$cells, resp.). Under these conditions the uptake of octanoate, which is not bound by H-FABP, was identical in cardiac myocytes from wild-type and $\mathrm{H}-\mathrm{FABP}^{-/ .}$mice $\left(4.5 \pm 1.0 \mathrm{vs} .4 .2 \pm 1.2 \mathrm{nmol} \cdot \mathrm{min}^{-1} \cdot \mathrm{g}^{-1}\right.$ wet mass for wildtype and $\mathrm{H}-\mathrm{FABP}^{-/}$cells, resp.) (Figure $6.4 \mathrm{a}$ ). The rate of palmitate oxidation by 


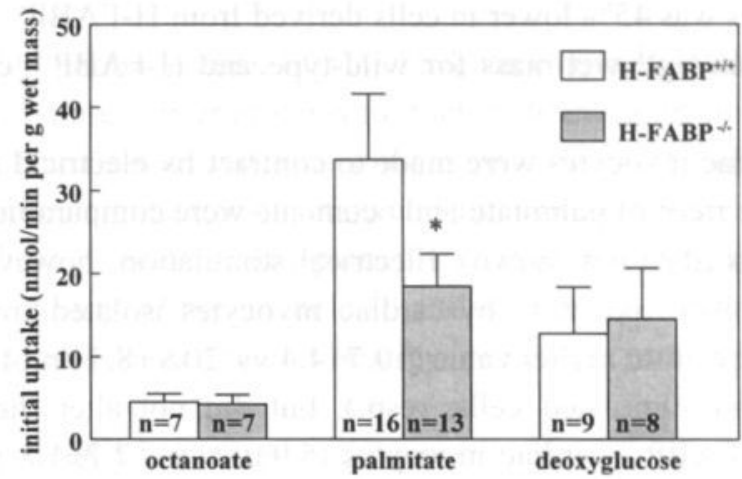

B

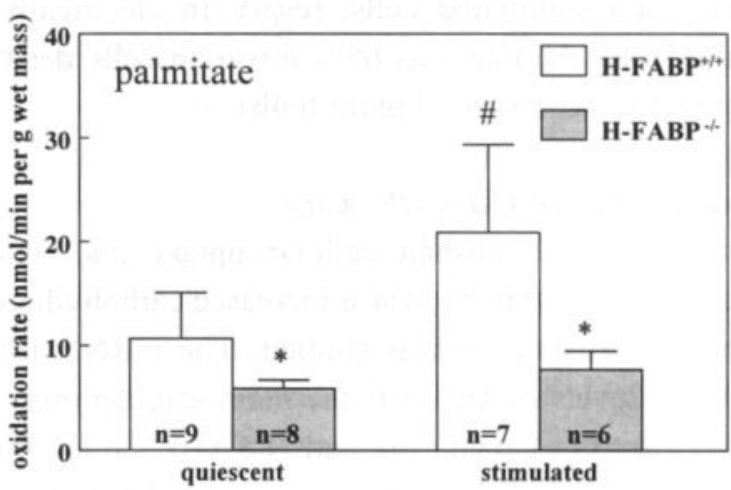

C

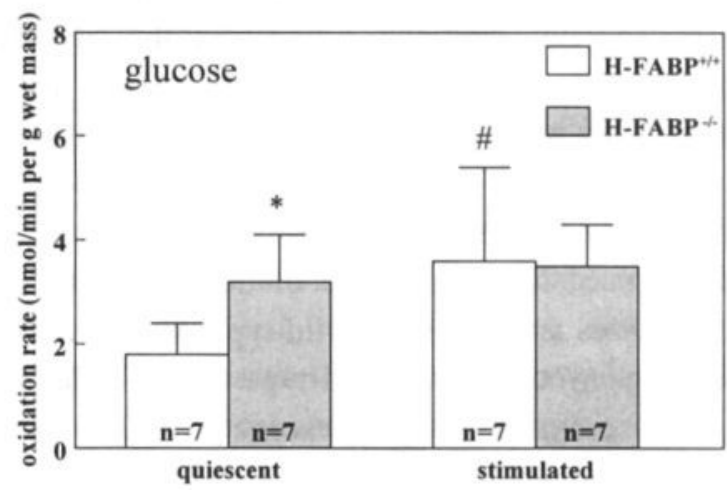

Figure 6.4 Uptake and oxidation of various substrates by cardiac myocytes isolated from wild-type (open box) and $\mathrm{H}$-FABP ${ }^{-/}$mice (grey box). (A) Initial uptake of octanoate, palmitate, and deoxyglucose by quiescent cardiac myocytes. Oxidation of palmitate (panel B) and glucose (panel C) by quiescent and electrically-stimulated cardiac myocytes. The number of animals employed in these studies is denoted by $n$. An asterisk denotes a statistically significant difference $(p<0.05)$ between wild-type and $H$-FABP ${ }^{-/}$mice preparations. \# denotes a statistically significant difference $(p<0.05)$ between quiescent and electrically-stimulated cardiac myocytes of the same H-FABP genotype. 
cardiac myocytes was $45 \%$ lower in cells derived from $\mathrm{H}-\mathrm{FABP}^{/ /-}$mice $(10.7 \pm 4.4 \mathrm{vs}$. $5.9 \pm 0.8 \mathrm{nmol} \cdot \mathrm{min}^{-1} \cdot \mathrm{g}^{-1}$ wet mass for wild-type and $\mathrm{H}-\mathrm{FABP}^{-/}$cells, resp.) (Figure $6.4 b)$.

When cardiac myocytes were made to contract by electrical stimulation $(2 \mathrm{~Hz})$, the initial uptake rates of palmitate and octanoate were comparable to those measured in quiescent cells (data not shown). Electrical stimulation, however, clearly affected the rate of palmitate oxidation by cardiac myocytes isolated from wild-type mice which showed a twofold higher value $\left(10.7 \pm 4.4 \mathrm{vs} .20 .9 \pm 8.5 \mathrm{nmol} \cdot \mathrm{min}^{-1} \cdot \mathrm{g}^{-1}\right.$ wet mass for quiescent and stimulated cells, resp.), but did not alter the rate of palmitate oxidation by $\mathrm{H}-\mathrm{FABP}^{-/}$cardiac myocytes $\left(5.9 \pm 0.8\right.$ vs. $7.7 \pm 1.8 \mathrm{nmol} \cdot \mathrm{min}^{-1} \cdot \mathrm{g}^{-1}$ wet mass for quiescent and stimulated cells, resp.). In electrically-stimulated cardiac myocytes, oxidation of palmitate was $65 \%$ lower in cells derived from $\mathrm{H}-\mathrm{FABP}^{-/}$ mice when compared to wild-type (Figure 6.4b).

\section{Cardiac glucose utilization in $\mathrm{H}-\mathrm{FABP} \mathrm{P}^{-/}$mice}

To examine whether the diminished cellular uptake and oxidation of FAs was compensated by a metabolic switch towards increased carbohydrate utilization, cellular entry and metabolism of glucose was studied. The mRNA (data not shown) and protein (Figure 6.1b) levels of GLUT4, the main sarcolemmal glucose transporter, were comparable in hearts of wild-type and $\mathrm{H}-\mathrm{FABP}^{-/}$mice. Likewise, the cardiac mRNA level of hexokinase type II (data not shown), the enzyme catalyzing the first step in glucose metabolism, and the activity of the glycolytic enzyme lactate dehydrogenase (Table 6.1) did not change in $\mathrm{H}_{-}-\mathrm{FABP}^{-/}$mice. Interestingly, the cardiac glycogen content was found to be about $60 \%$ higher in $\mathrm{H}-\mathrm{FABP}^{-/}$mice (Table 6.1).

Isolated cardiac myocytes were used to study the uptake of deoxyglucose and the oxidation of glucose. The initial rate of deoxyglucose uptake did not differ between cardiac myocytes isolated from wild-type or $\mathrm{H}_{-}-\mathrm{FABP}^{-/}$mice $(12.8 \pm 5.6 \mathrm{vs}$. $14.6 \pm 6.1 \mathrm{nmol} \cdot \mathrm{min}^{-1} \cdot \mathrm{g}^{-1}$ wet mass for wild-type and $\mathrm{H}-\mathrm{FABP}{ }^{-/}$cells, resp.) (Figure 6.4a). However, glucose oxidation by quiescent cardiac myocytes was $80 \%$ higher when cells were isolated from $\mathrm{H}-\mathrm{FABP}^{-/ 2}$ mice $\left(1.8 \pm 0.6\right.$ vs. $3.2 \pm 0.9 \mathrm{nmol} \cdot \mathrm{min}^{-1} \cdot \mathrm{g}^{-1}$ wet mass for wild-type and $\mathrm{H}-\mathrm{FABP}^{-/}$cells, resp.). Electrical stimulation $(2 \mathrm{~Hz})$ resulted in a twofold increase in the rate of glucose oxidation by cardiac myocytes from wild-type mice, but did not further augment glucose oxidation by $\mathrm{H}-\mathrm{FABP}^{-/}$ cardiac myocytes $\left(3.6 \pm 1.8\right.$ vs. $3.5 \pm 0.8 \mathrm{nmol} \cdot \mathrm{min}^{-1} \cdot \mathrm{g}^{-1}$ wet mass for wild-type and $\mathrm{H}-\mathrm{FABP}^{-/}$cells, resp.) (Figure 6.4c). 


\section{Discussion}

Because of their hydrophobic nature, LCFAs have very limited solubility in aqueous environments necessitating carrier proteins for their bulk transport in blood and inside cells. Several membrane-associated and soluble proteins have been implicated in cellular delivery, plasmalemmal translocation and intracellular transport of LCFAs ${ }^{12,29}$. The relevance of these proteins seems particularly evident in organs with high FA fluxes, such as the heart. Although able to utilize various substrates for energy production, cardiac muscle derives its energy preferably through mitochondrial oxidation of LCFAs ${ }^{35}$.

Cardiac LCFA uptake is a complex process requiring passage of LCFAs across several cell barriers, yet it proceeds with high efficiency ${ }^{35}$. By an unknown mechanism, blood-borne albumin-bound LCFAs pass the capillary vessel wall and enter the interstitial fluid ${ }^{36}$. In addition to passive diffusion, protein-assisted translocation of LCFAs across the sarcolemma is known to occur. In the heart, three membrane-associated proteins have been implicated in this process, namely FATP, $\mathrm{FAT}$, and $\mathrm{FABP}_{\mathrm{pm}}{ }^{29,31}$. For subsequent delivery to metabolizing organelles like mitochondria, LCFAs most likely associate with cytoplasmic H-FABP which can be envisioned as the intracellular counterpart of albumin. Although the collective findings from in vitro experiments ${ }^{12}$ and theoretical considerations $\mathrm{s}^{42,43}$ support a prominent role of H-FABP in intracellular FA trafficking, direct proof for such a function is lacking.

Recently it was observed that in mice with a targeted disruption of the H-FABP gene, tissue deposition of a radiolabeled FA-analogue ( ${ }^{125}$ I-BMIPP) was several-fold lower in cardiac tissue and moderately reduced in (resting) skeletal muscle of H-FABP nullizygous mice, indicating that utilization of LCFAs was obstructed in tissues normally expressing $\mathrm{H}-\mathrm{FABP}^{4}$. To allow the measurement of substrate utilization under defined conditions, and evade the potential effect of the endothelium as barrier in overall FA utilization ${ }^{36}$, the use of isolated cardiac myocytes, rather than intact hearts, is desired. To this end, we developed a method to isolate intact, electrically stimulatable cardiac myocytes from adult mice hearts, and then studied FA uptake and oxidation in both quiescent and contracting myocytes from wild-type and H-FABP nullizygous mice.

Given the predominant reliance on FAs for cardiac energy production, we have systematically investigated whether absence of $\mathrm{H}$-FABP invoked adaptations in hearts of H-FABP nullizygous mice. Possible compensatory mechanisms include (i) intracellular shift in localization of mitochondria resulting in shortened diffusion distances, (ii) expression of other FABP types in cardiac tissue, (iii) altered cellular capacity to metabolize FAs, and (iv) changes in expression of sarcolemmal LCFA transporters.

First, as judged from microscopic studies the subcellular localization of mitochondria appeared similar in left ventricular tissue from $\mathrm{H}-\mathrm{FABP}^{-/}$and wild-type 
mice. Hence, diffusion distances for exogenous FAs between sarcolemmal and mitochondrial membranes are most likely not different in hearts of wild-type and $\mathrm{H}_{-} \mathrm{FABP}^{-/}$mice. In addition, the activity of citrate synthase, a marker enzyme for mitochondrial density, was not different in heart homogenates from wild-type and $\mathrm{H}-\mathrm{FABP}^{-/ 2}$ mice.

Second, as H-FABP is a member of a large family of intracellular lipid binding proteins $^{3,12}$, expression of other FABP types in cardiac tissue was investigated. Two experimental approaches demonstrate that in cardiac myocytes of H-FABP nullizygous mice no other FABP types are expressed. Northern analysis using specific probes failed to detect expression of B-FABP, E-FABP, ALBP and L-FABP mRNA in hearts of $\mathrm{H}-\mathrm{FABP}^{-/}$mice ${ }^{4}$. More importantly, using a functional test (FA binding capacity of cytosolic proteins) it was found that no substantial expression of other FABP types occurs in hearts of H-FABP nullizygous mice. Interestingly, disruption of the murine gene encoding ALBP resulted in an elevated expression of E-FABP in adipose tissue $^{16}$. This compensation probably explains the lack of an obvious phenotype of ALBP nullizygous mice.

Third, the metabolic capacity of $\mathrm{H}-\mathrm{FABP}^{-/-}$hearts was assessed by measuring the rate of FA oxidation in homogenates. In such cell-free preparations, the delivery of FAs to intact mitochondria for subsequent oxidation is independent on the presence of H-FABP because FAs are provided complexed to albumin. It appeared that octanoate and palmitate each were oxidized at similar rates in heart homogenates of wild-type and $\mathrm{H}-\mathrm{FABP}^{-/ *}$ mice indicating that hearts of $\mathrm{H}-\mathrm{FABP}^{-/ *}$ mice had equal capacity to oxidize FAs. Supporting this notion are the observations that the activity of B-hydroxyacyl-CoA dehydrogenase, an enzyme involved in the B-oxidative pathway, and the mRNA level of acyl-CoA synthetase, the enzyme catalyzing the first step in FA metabolism, were comparable in hearts of wild-type and $\mathrm{H}-\mathrm{FABP}^{-/ \tau}$ mice. In addition, the comparable cardiac triacylglycerol content suggests that the capacity to store FAs in neutral lipids is not altered in H-FABP nullizygous mice.

Fourth, the expression of membrane-associated FA transporters was evaluated by Northern-blotting and revealed comparable levels of the mRNAs coding for FATP, $\mathrm{FAT}$, and $\mathrm{FABP}_{\mathrm{pm}}$ in hearts of wild-type and $\mathrm{H}-\mathrm{FABP}^{-/}$mice. It can not be excluded, however, that protein levels and/or the localization of these FA transporters is altered. Membrane-bound acyl-CoA synthetases catalyze the conversion of FAs to acyl-CoA esters $^{44}$. The latter compounds are bound with high-affinity by acyl-CoA binding protein for subsequent delivery to metabolic sites ${ }^{17}$. Acyl-CoA synthetase and acylCoA binding protein mRNA levels were not altered in hearts of $\mathrm{H}-\mathrm{FABP}^{-/}$mice. Other transcripts measured in an earlier study ${ }^{4}$, i.e. long-chain acyl-CoA dehydrogenase and carnitine palmitoyl transferase I, were also maintained, in agreement with the conclusion of the present paper that the capacity for LCFA metabolism is not altered in hearts of $\mathrm{H}-\mathrm{FABP}^{-/ 2}$ mice. 
Having established that the potential for sarcolemmal FA translocation and FA metabolism is maintained in hearts of $\mathrm{H}-\mathrm{FABP}^{-/}$mice, and that apparently no other mechanisms operate to directly compensate the absence of H-FABP, we then determined uptake and oxidation of FAs by intact cells. Cardiac myocytes of $\mathrm{H}_{-} \mathrm{FABP}^{-/}$mice showed a significantly reduced uptake of the LCFA palmitate, whereas the uptake of the medium-chain FA octanoate was unaffected. Moreover, the rate of palmitate oxidation by cardiac myocytes derived from H-FABP nullizygous mice was markedly lower. Theoretically, this could be caused by preferential targeting of FAs to different metabolic pathways, however, the comparable triacylglycerol content of hearts of wild-type and $\mathrm{H}-\mathrm{FABP}^{-/}$mice argues against this possibility.

Although diminished, cardiac myocytes of $\mathrm{H}-\mathrm{FABP}^{-/}$mice apparently were still able to take up and oxidize palmitate. Perhaps in quiescent cardiac myocytes from $\mathrm{H}_{-} \mathrm{FABP}^{-/}$mice, cytoplasmic diffusion of non-protein bound FAs suffices to meet the cellular energy requirement. As uptake of LCFAs is thought to be driven by the maintenance of a steep FA gradient between sarcolemma and e.g. respirating mitochondria, an enhanced energy demand would imply an elevated transcytoplasmic flux of FAs. To test this, and to explore whether cardiac myocytes from $\mathrm{H}-\mathrm{FABP}^{-/}$ mice were able to attain such increased intracellular flux of FAs, cardiac myocytes were electrically stimulated to evoke rhythmical contractions of these cells. Although this treatment did not influence the initial rate of cellular uptake of palmitate or octanoate, it clearly augmented the rate of palmitate oxidation by cardiac myocytes from wild-type mice. Presumably, electrical stimulation diverted FAs from incorporation into esterified lipids towards oxidation in mitochondria. However, cardiac myocytes of $\mathrm{H}_{-} \mathrm{FABP}^{-/ 2}$ mice were unable to achieve a higher rate of palmitate oxidation thus demonstrating that LCFA utilization is impaired in cardiac myocytes from $\mathrm{H}-\mathrm{FABP}^{-/}$mice. Taken together, we conclude that $\mathrm{H}-\mathrm{FABP}$ is required for bulk transport of LCFAs in the cytoplasmic compartment of the cardiac myocyte.

The initial rate of palmitate uptake by cardiac myocytes isolated from wild-type mice is higher than in rat cardiac myocytes ${ }^{21}\left(33.6 \mathrm{vs} .21 .9 \mathrm{nmol} \cdot \mathrm{min}^{-1} \cdot \mathrm{g}^{-1}\right.$ wet mass for mouse and rat, resp.) which could be a reflection of the higher H-FABP levels found in mouse hearts $\left(1.9 \mathrm{vs} .0 .74 \mathrm{mg} \cdot \mathrm{g}^{-1}\right.$ wet mass for mouse and rat ${ }^{41}$, resp.). However, in both cases the measured values are in the same order of magnitude as values calculated from in vivo arteriovenous differences in FA concentration (circa $100 \mathrm{nmol} \cdot \mathrm{min}-1 \cdot \mathrm{g}^{-1}$ wet mass) ${ }^{36,37}$ and reflect physiological relevant values. Thus, the observed impairment of LCFA utilization by cardiac myocytes of $\mathrm{H}-\mathrm{FABP}^{/ /}$mice strongly suggests to be of physiological significance.

In view of their importance for cardiac energy production we subsequently investigated whether the impaired utilization of LCFAs in H-FABP nullizygous mice resulted in a metabolic shift from LCFAs towards carbohydrate utilization. Previous work revealed that plasma glucose levels were lowered in $\mathrm{H}_{-} \mathrm{FABP}^{-/}$mice under all 
conditions, especially in starvation and with a high-fat diet, and that cardiac deposition of deoxyglucose, a non-oxidizable glucose analogue, was elevated in fasted $\mathrm{H}-\mathrm{FABP}^{-/ 2}$ animals ${ }^{4}$. In the present study we found that, despite similar levels of GLUT4 protein and hexokinase type II mRNA, and a comparable cellular uptake rate of deoxyglucose, the rate of glucose oxidation by resting $\mathrm{H}-\mathrm{FABP}^{-/}$cardiac myocytes was elevated to a level which would require electrical stimulation of wild-type cells. Apparently, glucose oxidation by $\mathrm{H}-\mathrm{FABP}^{-/}$cardiac myocytes proceeded already at maximum rates, as electrical stimulation did not further affect this rate, suggesting that either cellular uptake or subsequent metabolism may have become rate-limiting. The cardiac glycogen content was found to be elevated in $\mathrm{H}-\mathrm{FABP}^{-/}$mice and may serve to store glucose for use during periods of increased workload ${ }^{13}$. Together these findings suggest that the impaired utilization of LCFAs in $\mathrm{H}-\mathrm{FABP}^{-/}$mice results in an increased reliance on carbohydrates to meet the cardiac energy demand.

Development of cardiac hypertrophy has been associated with disturbed cardiac energy production and is observed in several disorders pertaining to FA oxidation ${ }^{2,27}$. $\mathrm{H}-\mathrm{FABP}^{-/}$mice were previously shown to develop cardiac hypertrophy as evidenced by ventricular expression of atrial natriuretic factor at 3 months of age, and by enlargement of nuclei and an increase in myofibrillar diameter after 10-12 months of age $^{4}$. The hypertrophic response appeared confined to the septum and the near-luminal muscle layers of the ventricles. Hypertrophic heart tissue is thought to revert to an embryonic state of development that is characterized by e.g. reliance on carbohydrates for energy production and cellular deposition of glycogen ${ }^{7,27}$. In the present study we showed that FA oxidation by cardiac myocytes from $\mathrm{H}-\mathrm{FABP}{ }^{-/-}$mice is impeded, and this may relate to the development of cardiac hypertrophy.

In conclusion, we showed that cardiac myocytes isolated from $\mathrm{H}-\mathrm{FABP}^{-/}$mice have a markedly reduced ability to take up and oxidize palmitate supporting the proposed role of H-FABP in mediating cellular uptake and intracellular transport of LCFAs. Thus, in line with the previous in vivo study ${ }^{4}$, the present findings provide firm evidence for a substantial role of H-FABP in maintaining high rates of LCFA utilization by cardiac myocytes.

\section{Acknowledgements}

We are greatly indebted to Yvonne de Jong, Will Coumans, Maurice Pelsers, Theo Roemen and Peter Willemsen for expert technical assistance, to Dr Peter Frederik and Paul Bomans for performing electron and light microscopy, and to Dr Joost Luiken for pioneering studies on electrical stimulation of cardiac myocytes. Quantification of GLUT4 protein levels by Dr Yvan Fischer (RWTH Aachen, Germany) and measurement of hepatic L-FABP levels by Christian Wolfrum (University Münster, Germany), was greatly appreciated. We thank Dr Torsten Börchers (Institute for Chemical and Biochemical Sensor Research, Münster, Germany) for providing recombinant mouse H-FABP. 


\section{References}

1) Abumrad NA, el-Maghrabi MR, Amri EZ, Lopez E, and Grimaldi PA: Cloning of a rat adipocyte membrane protein implicated in binding or transport of long-chain fatty acids that is induced during pre-adipocyte differentiation. Homology with human CD36. J Biol Chem 268:17665-17668(1993)

2) Antozzi $\mathrm{C}$ and Zeviani $\mathrm{M}$ : Cardiomyopathies in disorders of oxidative metabolism. Cardiovasc Res 35:184-199(1997)

3) Banaszak L, Winter N, Xu Z, Bernlohr DA, Cowan S, and Jones TA: Lipid binding proteins: a family of fatty acid and retinoid transport proteins. Adv Protein Chem 45:89-151 (1994)

4) Binas B, Danneberg H, McWhir J, Mullins L, and Clark AJ: Requirement for the heart-type fatty acid-binding protein in cardiac fatty acid utilization. Faseb $J$ 13:805-812 (1999)

5) Bonen A, Luiken JJFP, Liu S, Dyck DJ, Kiens B, Kristiansen S, Turcotte LP, van der Vusse GJ, and Glatz JFC: Palmitate transport and fatty acid transporters in red and white muscles. Am J Physiol 275:E471-478(1998)

6) Börchers T and Spener F: Fatty acid-binding proteins. Curr Top Membr 40:261-294 (1994)

7) Depré C, Shipley GL, Chen W, Han Q, Doenst T, Moore ML, Stepkowski S, Davies PJ, and Taegtmeyer $\mathrm{H}$ : Unloaded heart in vivo replicates fetal gene expression of cardiac hypertrophy. Nat Med 4:1269-1275(1998)

8) Fischer Y, Thomas J, Sevilla L, Munoz P, Becker C, Holman G, Kozka IJ, Palacin M, Testar $\mathrm{X}$, Kammermeier $\mathrm{H}$, and Zorzano A: Insulin-induced recruitment of glucose transporter 4 (GLUT4) and GLUT1 in isolated rat cardiac myocytes. Evidence of the existence of different intracellular GLUT4 vesicle populations. J Biol Chem 272:7085-7092 (1997)

9) Fitscher BA, Elsing C, Riedel HD, Gorski J, and Stremmel W: Protein-mediated facilitated uptake processes for fatty acids, bilirubin, and other amphipathic compounds. Proc Soc Exp Biol Med 212:15-23 (1996)

10) Glatz JFC and Veerkamp JH: Palmitate oxidation by intact preparations of skeletal muscle. Biochim Biophys Acta 713:230-239(1982)

11) Glatz JFC and Veerkamp JH: A radiochemical procedure for the assay of fatty acid binding by proteins. Anal Biochem 132:89-95 (1983)

12) Glatz JFC and van der Vusse GJ: Cellular fatty acid-binding proteins: their function and physiological significance. Prog Lipid Res 35:243-282 (1996)

13) Goodwin GW, Ahmad F, Doenst T, and Taegtmeyer H: Energy provision from glycogen, glucose, and fatty acids on adrenergic stimulation of isolated working rat hearts. $\mathrm{Am} \mathrm{J}$ Physiol 274:H1239-1247(1998)

14) Guzman $M$ and Geelen MJ: Regulation of fatty acid oxidation in mammalian liver. Biochim Biophys Acta 1167:227-241 (1993)

15) Hamilton JA: Fatty acid transport: difficult or easy? J Lipid Res 39:467-481 (1998)

16) Hotamisligil GS, Johnson RS, Distel RJ, Ellis R, Papaioannou VE, and Spiegelman BM: Uncoupling of obesity from insulin resistance through a targeted mutation in aP2, the adipocyte fatty acid-binding protein. Science 274:1377-1379(1996)

17) Knudsen J, Mandrup S, Rasmussen JT, Andreasen PH, Poulsen F, and Kristiansen K: The function of acyl-CoA binding protein (ACBP)/diazepam binding inhibitor (DBI). Mol Cell Biochem 123:129-138(1993) 
18) Levi AJ, Gatmaitan Z, and Arias IM: Two hepatic cytoplasmic protein fractions, Y and Z, and their possible role in the hepatic uptake of bilirubin, sulfobromophthalein, and other anions. J Clin Invest 48:2156-2167(1969)

19) Linssen MC, Vork MM, de Jong YF, Glatz JFC, and van der Vusse GJ: Fatty acid oxidation capacity and fatty acid-binding protein content of different cell types isolated from rat heart. Mol Cell Biochem 98:19-25 (1990)

20) Luft JH: Improvements in epoxy resin embedding methods. J Biophys Biochem Cytol 9:409-414 (1961)

21) Luiken JJFP, van Nieuwenhoven FA, America G, van der Vusse GJ, and Glatz JFC: Uptake and metabolism of palmitate by isolated cardiac myocytes from adult rats: involvement of sarcolemmal proteins. J Lipid Res 38:745-758 (1997)

22) Luiken JJFP, van der Vusse GJ, and Glatz JFC: Electrical stimulation of isolated rat cardiac myocytes increases their rate of uptake of long-chain fatty acids. manuscript in preparation (1999)

23) Murphy EJ, Prows DR, Jefferson JR, and Schroeder F: Liver fatty acid-binding protein expression in transfected fibroblasts stimulates fatty acid uptake and metabolism. Biochim Biophys Acta 1301:191-198(1996)

24) Murphy EJ: L-FABP and I-FABP expression increase NBD-stearate uptake and cytoplasmic diffusion in L cells. Am J Physiol 275:G244-249(1998)

25) Ockner RK, Manning JA, Poppenhausen RB, and Ho WK: A binding protein for fatty acids in cytosol of intestinal mucosa, liver, myocardium, and other tissues. Science 177:56-58 (1972)

26) Richieri GV, Ogata RT, and Kleinfeld AM: Equilibrium constants for the binding of fatty acids with fatty acid-binding proteins from adipocyte, intestine, heart, and liver measured with the fluorescent probe ADIFAB. J Biol Chem 269:23918-23930(1994)

27) Rupp H and Jacob R: Metabolically-modulated growth and phenotype of the rat heart. Eur Heart J 13 Suppl D:56-61 (1992)

28) Schaap FG, Specht B, van der Vusse GJ, Börchers T, and Glatz JFC: One-step purification of rat heart-type fatty acid-binding protein expressed in Escherichia coli. J Chromatogr B Biomed Appl 679:61-67 (1996)

29) Schaap FG, van der Vusse GJ, and Glatz JFC: Fatty acid-binding proteins in the heart. Mol Cell Biochem 180:43-51 (1998)

30) Schaffer JE and Lodish HF: Expression cloning and characterization of a novel adipocyte long-chain fatty acid-transport protein. Cell 79:427-436(1994)

31) Schaffer JE and Lodish HF: Molecular mechanism of long-chain fatty acid uptake. Trends Cardiovasc Med 5:218-224 (1995)

32) Sorrentino D, Stump D, Potter BJ, Robinson RB, White R, Kiang CL, and Berk PD: Oleate uptake by cardiac myocytes is carrier-mediated and involves a 40-kDa plasma membrane fatty acid-binding protein similar to that in liver, adipose tissue, and gut. $J$ Clin Invest 82:928-935 (1988)

33) Storch J and Bass NM: Transfer of fluorescent fatty acids from liver and heart fatty acid-binding proteins to model membranes. J Biol Chem 265:7827-7831 (1990)

34) Stump DD, Zhou SL, and Berk PD: Comparison of plasma membrane FABP and mitochondrial isoform of aspartate aminotransferase from rat liver. Am $J$ Physiol 265:G894-902(1993) 
35) van der Vusse GJ, Glatz JFC, Stam HC, and Reneman RS: Fatty acid homeostasis in the normoxic and ischemic heart. Physiol Rev 72:881-940(1992)

36) van der Vusse GJ, Glatz JFC, van Nieuwenhoven FA, Reneman RS, and Bassingthwaighte JB: Transport of long-chain fatty acids across the muscular endothelium. Adv Exp Med Biol 441:181-191 (1998)

37) van der Vusse GJ, Dubelaar ML, Coumans WA, Seymour AM, Clarke SB, Bonen A, Drake-Holland AJ, and Noble MI: Metabolic alterations in the chronically denervated dog heart. Cardiovasc Res 37:160-170 (1998)

38) van Nieuwenhoven FA, Verstijnen CP, Abumrad NA, Willemsen PH, van Eys GJ, van der Vusse GJ, and Glatz JFC: Putative membrane fatty acid translocase and cytoplasmic fatty acid-binding protein are co-expressed in rat heart and skeletal muscles. Biochem Biophys Res Commun 207:747-752 (1995)

39) Veerkamp JH, van Moerkerk HTB, and Bakkeren JA: An accurate and sensitive assay of $\left[{ }^{14} \mathrm{C}\right]$ octanoate oxidation and its application on tissue homogenates and fibroblasts. Biochim Biophys Acta 876:133-137(1986)

40) Veerkamp JH and Maatman RGHJ: Cytoplasmic fatty acid-binding proteins: their structure and genes. Prog Lipid Res 34:17-52 (1995)

41) Vork MM, Glatz JFC, Surtel DA, Knubben HJ, and van der Vusse GJ: A sandwich enzyme linked immunosorbent assay for the determination of rat heart fatty acid-binding protein using the streptavidin-biotin system. Application to tissue and effluent samples from normoxic rat heart perfusion. Biochim Biophys Acta 1075:199-205(1991)

42) Vork MM, Glatz JFC, and van der Vusse GJ: On the mechanism of long-chain fatty acid transport in cardiomyocytesas facilitated by cytoplasmic fatty acid-binding protein. JTheor Biol 160:207-222 (1993)

43) Vork MM, Glatz JFC, and van der Vusse GJ: Modeling intracellular fatty acid transport: possible mechanistic role of cytoplasmic fatty acid-binding protein. Prostaglandins Leukot Essent Fatty Acids 57:11-16(1997)

44) Watkins PA: Fatty acid activation. Prog Lipid Res 36:55-83 (1997)

45) Wodzig KW, Pelsers MMAL, van der Vusse GJ, Roos W, and Glatz JFC: One-step enzyme-linked immunosorbent assay (ELISA) for plasma fatty acid-binding protein. Ann Clin Biochem 34:263-268 (1997)

46) Zakim D: Fatty acids enter cells by simple diffusion. Proc Soc Exp Biol Med 212:5-14 (1996) 


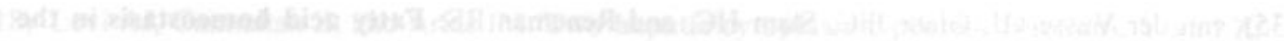

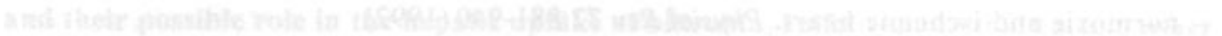

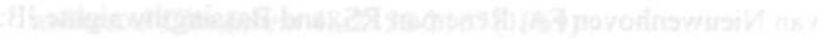

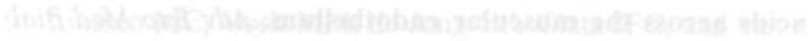

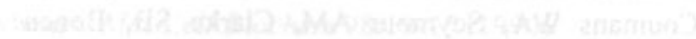

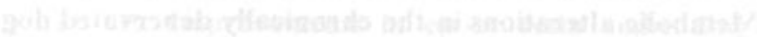


ChAPTER 7

GENERAL DISCUSSION 


\section{Introduction}

Fatty acids, ketone bodies, carbohydrates, and amino acids can each be used as substrates for energy production in cardiac muscle cells ${ }^{19}$. The omnivorous nature of the heart thus ensures that the circulation of blood is preserved under a wide range of physiological conditions. For example, oxidation of lactate supplies most of the heart's energy in periods of arduous exercise, whereas fatty acids and ketone bodies form the major energy substrates during fasting. When the body is resting or moderately active, the heart's energy demand is primarily met by oxidation of longchain fatty acids (LCFAs).

The cardiac capacity to temporarily store substrates in depots such as lipid droplets or glycogen is limited, hence, an incessant supply of these compounds from the circulation is required. Unlike the other cardiac energy substrates, LCFAs are essentially insoluble in aqueous solutions, yet cardiac extraction of LCFAs from the bloodstream proceeds with remarkable efficiency ${ }^{19}$. To ensure efficient movement through aqueous environments, LCFAs supposedly associate with binding proteins ${ }^{7}$. It is well established nowadays that the plasma protein albumin functions in vascular and interstitial transport of LCFAs ${ }^{19}$. The roles of membrane-associated and cytoplasmic fatty acid-binding proteins (FABPs) in transmembrane and intracellular movement of LCFAs are however ill-defined. Yet these proteins are implicated in several steps in myocardial FA utilization, namely passage of LCFAs across the capillary endothelium, translocation of LCFAs across the sarcolemma, and mitochondrial delivery of LCFAs. The studies described in this thesis aimed primarily at determining the physiological significance of the cytoplasmic protein heart-type FABP (H-FABP) for LCFA consumption by the cardiac myocyte.

\section{Role of H-FABP in myocardial LCFA utilization}

Cytoplasmic H-FABP is abundantly expressed in cardiac tissue. In mouse hearts, expression amounts to $1.9 \mathrm{mg} \mathrm{H}-\mathrm{FABP}$ per gram wet mass which corresponds to circa $1.4 \%$ of the total cellular protein pool. The major cardiac cell type expressing H-FABP is the myocyte, while minute amounts are apparently also present in endothelial cells ${ }^{1}$. As a clear relation is observed between tissue H-FABP content and oxidative capacity of distinct muscle types, the main functions postulated for $\mathrm{H}-\mathrm{FABP}$ pertain to a role in cellular LCFA metabolism ${ }^{7}$. By acting as an intracellular sink, H-FABP is thought to facilitate cellular uptake and cytoplasmic transport of LCFAs. From these postulates we hypothesized that H-FABP is required for bulk consumption of LCFAs in the cardiac myocyte.

This hypothesis was tested by studying LCFA utilization in isolated cardiac myocytes derived from mice with a targeted disruption of the H-FABP gene $\mathrm{e}^{4}$. These cells were employed to study the uptake of octanoate and palmitate. Octanoate $\left(\mathrm{C}_{8}\right)$ readily dissolves in water and is not a ligand for H-FABP, while palmitate $\left(\mathrm{C}_{16}\right)$ is 
water-insoluble and is tightly bound by H-FABP. Cardiac myocytes of wild-type and $\mathrm{H}-\mathrm{FABP}^{-/-}$mice showed equal rates of octanoate uptake. In contrast, cellular palmitate uptake was $45 \%$ lower when cardiac myocytes were isolated from $\mathrm{H}-\mathrm{FABP}^{-/}$mice. Palmitate oxidation by $\mathrm{H}-\mathrm{FABP}^{-/}$cardiac myocytes was decreased to almost the same extent. The impaired uptake and oxidation of palmitate by $\mathrm{H}-\mathrm{FABP}^{-/}$cardiac myocytes indicates that H-FABP is required for efficient LCFA utilization.

Cardiac influx of FAs is thought to result from the presence of a FA concentration gradient across the sarcolemma ${ }^{8,20}$. Following cellular entry, FAs are readily esterified with CoA and are subsequently oxidized in mitochondria or become incorporated into (phospho)lipids. The rapid metabolic conversion of FAs ensures that the FA gradient between extracellular and intracellular compartments is maintained. Metabolism is thus an important determinant of cellular FA uptake.

The metabolic demand of isolated cardiac myocytes can be raised by inducing cellular contractions through electrical stimulation. When palmitate utilization by cardiac myocytes was studied under these conditions, wild-type cells showed an elevated rate $(+95 \%)$ of palmitate oxidation compared with quiescent wild-type cells. In contrast, electrical stimulation did not increase the rate of cellular palmitate oxidation in the absence of H-FABP.

The impaired uptake and oxidation of palmitate by $\mathrm{H}-\mathrm{FABP}^{-/}$cardiac myocytes is most likely due to the lack of H-FABP in these cells as we demonstrated that in $\mathrm{H}-\mathrm{FABP}^{-/}$mice (i) the capacity to oxidize FAs is fully maintained in heart homogenates, (ii) the activity of $B$-hydroxyacyl-CoA dehydrogenase is not altered, (iii) the cardiac mRNA levels encoding the putative FA transporters FATP (fatty acidtransport protein), FAT/CD36 (Fatty Acid Translocase), and FABP ${ }_{\mathrm{pm}}$ (plasmalemmal FABP) are unchanged, and (iv) the subcellular localization and arrangement of mitochondria is preserved, and the mitochondrial density (citrate synthase activity) is not altered.

Under the conditions of electrical stimulation, $\mathrm{H}-\mathrm{FABP}^{-/ .}$cardiac myocytes had a $65 \%$ lower rate of palmitate oxidation compared with wild-type cells. This conclusively demonstrates the relevance of H-FABP for bulk cytoplasmic transport of LCFAs and, hence, the mitochondrial oxidation of LCFAs by cardiac myocytes. Moreover, these findings are of physiological importance as measured cellular LCFA uptake rates $\left(34 \mathrm{nmol} \cdot \mathrm{min}^{-1} \cdot \mathrm{g}^{-1}\right.$ wet mass $)$ are in the same order of magnitude as cardiac FA extraction rates $\left(50-100 \mathrm{nmol} \cdot \mathrm{min}^{-1} \cdot \mathrm{g}^{-1}\right.$ wet mass $)$ determined in $v i v o^{20,21}$.

Although notably diminished when compared with wild-type cells, H-FABP ${ }^{-/}$ cardiac myocytes still have capacity to oxidize palmitate. This is unlikely to be caused by the presence of unknown binding-proteins or other FABP types, as proteins capable of affinity binding of fatty acids were not detected in cytosol derived from $\mathrm{H}-\mathrm{FABP}^{-/ 2}$ cardiac myocytes. Cytoplasmic diffusion of LCFAs over a short distance to mitochondria located near the sarcolemma may account for the residual rate of 
palmitate oxidation by $\mathrm{H}-\mathrm{FABP}^{-/}$cardiac myocytes. Thus, $\mathrm{H}-\mathrm{FABP}$ may be seen as an evolutionary adaptation to high rates of cellular LCFA utilization.

As a consequence of diminished ability to utilize LCFAs, H-FABP ${ }^{-/}$cardiac myocytes apparently switch to carbohydrate metabolism for ATP production. Although the initial rate of deoxyglucose uptake was comparable with wild-type cells, the rate of glucose oxidation was $80 \%$ higher in quiescent $\mathrm{H}-\mathrm{FABP}^{-/}$cardiac myocytes. In $\mathrm{H}-\mathrm{FABP}^{-/}$cells, glucose oxidation apparently proceeded at maximum rates as no further effect of electrical stimulation was seen. In contrast, wild-type cells showed an elevated rate of glucose oxidation upon electrical stimulation with values equal to those in $\mathrm{H}-\mathrm{FABP}^{-/}$cells. During these incubations glucose was the only available exogenous substrate. Assuming the same basal energy demand, quiescent $\mathrm{H}-\mathrm{FABP}^{-/}$cardiac myocytes may directly furnish glucose in the glycolytic pathway, while in quiescent wild-type cells, LCFAs from endogenous pools may inhibit glycolysis (Randle cycle) causing endogenous substrates to be used for energy production.

Disturbances in cardiac energy production are often associated with the development of cardiomyopathies ${ }^{2}$. The impaired availability of LCFAs as energy substrate is presumably related to the development of localized ventricular hypertrophy in aging $\mathrm{H}-\mathrm{FABP}^{-/}$mice ${ }^{4}$. Among the changes associated with cardiac hypertrophy in the $\mathrm{H}-\mathrm{FABP}^{-/}$mice are ventricular expression of atrial natriuretic factor mRNA and an increase in myofibrillar diameter. In addition, we found that the cardiac glycogen content was elevated $(+60 \%)$ in $\mathrm{H}-\mathrm{FABP}^{-/}$mice, and that cardiac energy provision may depend more on carbohydrates. These metabolic alterations are typical for cardiac hypertrophy ${ }^{6}$.

\section{Mechanistic aspects of $\mathbf{H}-\mathrm{FABP}$ function}

The membrane-associated proteins FATP, FAT/CD36, and $\mathrm{FABP}_{\mathrm{pm}}$ most likely constitute the carrier-mediated component of LCFA uptake which is evident from kinetic analysis of palmitate uptake by cardiac myocytes ${ }^{11}$. Cytoplasmic H-FABP has also been implicated in facilitation of cellular uptake of LCFAs. Indeed, we showed that in $\mathrm{H}-\mathrm{FABP}^{-/}$cardiac myocytes both cellular influx and subsequent intracellular transport of LCFAs are apparently affected.

For facilitation of cellular FA uptake, H-FABP could directly desorb LCFAs from the cytoplasmic leaflet of the membrane bilayer, or acquire its ligand through an interaction with membrane-associated FABPs (Figure 7.1). Such an interaction was indeed reported for H-FABP and FAT/CD36 as these proteins were found to be coprecipitated by anti-CD36 antibodies ${ }^{15}$. The integral membrane protein FAT/CD36 is assumed to have one or two cytoplasmic domains of rather short size (circa 10 amino acids). It is not known yet whether an association between H-FABP and FAT/CD36 occurs in vivo. 


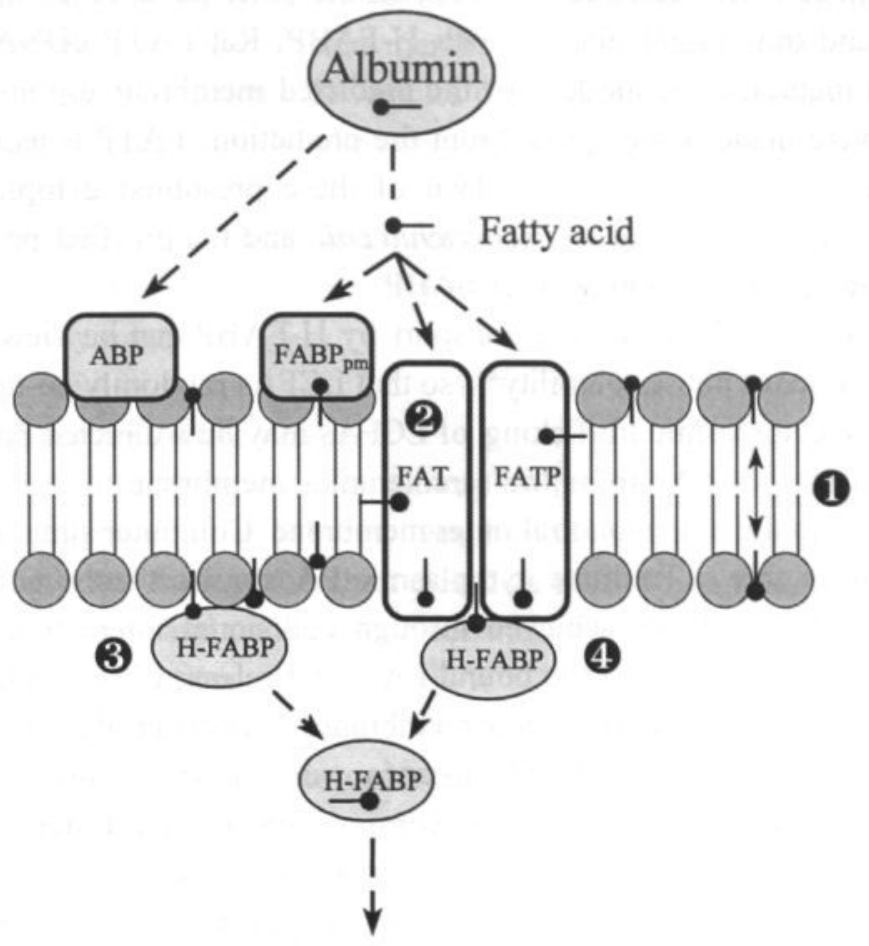

\section{Sarcolemma}

Cytoplasm

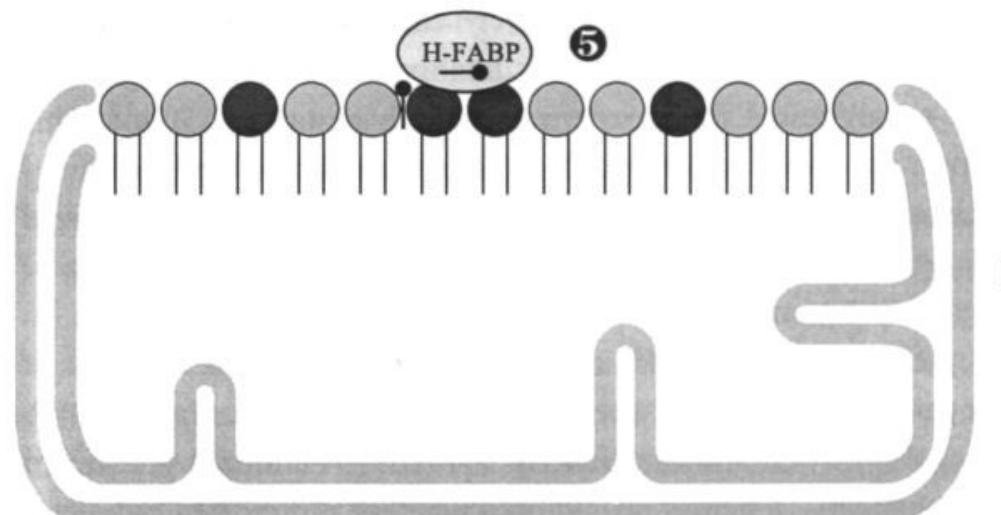

Mitochondrion

Figure 7.1 Suggested mechanisms of steps of cardiac LCFA uptake and cytoplasmic transport of LCFAs to the mitochondrion. (1) Transmembrane flip-flop of unprotonated LCFAs (passive diffusion). (2) Protein-assistedflip-flop/translocationof LCFAs across the sarcolemma. (3) Collisional transfer of LCFAs to H-FABP by interaction between H-FABP and the phospholipid bilayer. (4) Acquiring of ligand through interaction between $H-F A B P$ and membrane-associated $F A B P(s)$. (5) Release of ligand by interaction between positively-chargedresidues in $H$-FABP's portal region and negatively-chargedphospholipids. 
$\mathrm{FABP}_{\mathrm{pm}}$ is presumed to be an outer peripheral membrane protein, making it unlikely that an interaction with H-FABP can occur. FATP, on the other hand, is an integral membrane protein ${ }^{14}$ and thus might interact with H-FABP. Rat FATP cDNA was cloned by PCR-based methods, and models for the predicted membrane topology of the encoded protein were made (Chapter 5). From the prediction, FATP is assumed to have one or more cytoplasmic domains. Two of these presumed cytoplasmic domains are currently being expressed in Escherichia coli, and the purified proteins will be used to examine an interaction with H-FABP.

The facilitation of intracellular LCFA transport by H-FABP can be viewed as a simple raise in their aqueous phase solubility ${ }^{23}$, so that LCFAs randomly co-diffuse with H-FABP. Besides, cytoplasmic trafficking of LCFAs may be a directed process in which H-FABP shuttles LCFAs from the sarcolemmal membrane to a specific acceptor membrane such as the mitochondrial outer membrane. Computer simulations indicated that H-FABP is able to facilitate cytoplasmic FA transport only if (i) FA binding and release by H-FABP are achieved through collisional interaction with donor and acceptor membranes and (ii) the bound FA is not released in the aqueous phase during intermediate transfer between these membranes ${ }^{24}$. Transfer of fluorescent FA-derivatives from H-FABP to model membranes was shown to proceed by collisional interaction and was dependent on the composition of model membranes and on ionic strength ${ }^{16}$. Model membranes enriched for acidic phospholipids, such as the outer mitochondrial membrane constituent cardiolipin, appeared most effective in acquiring ligand from H-FABP (Figure 7.1). Positively charged amino acid residues in the portal region of the H-FABP molecule presumably interact with negatively charged phospholipids as suggested from experiments with mutant FABPs ${ }^{10}$. This region is thought to form a flexible structure which caps the internal binding cavity of FABPs. Through interaction with membranes, the portal region might control access to the internal ligand binding site of H-FABP. Thus, specific properties of subcellular membranes may be involved in the intracellular targeting of LCFAs.

Cellular LCFA uptake is determined by continuous intracellular metabolism of these compounds. The intimate relation between these two processes, complicates the interpretation of the results on LCFA utilization by $\mathrm{H}-\mathrm{FABP}^{-/}$cardiac myocytes in terms of underlying mechanism. Hence, it is unknown whether diminished palmitate oxidation is caused by reduced cellular uptake of palmitate or results from ineffective mitochondrial supply of palmitate. Likewise, it is uncertain whether H-FABP facilitates cellular LCFA uptake directly or indirectly, the latter brought about by facilitating their metabolic conversion in organelles and thus maintaining an inwardlydirected gradient of LCFAs across the sarcolemma which drives the cellular influx of LCFAs.

Giant sarcolemmal vesicles seem useful to address a possible direct role for H-FABP in cellular LCFA uptake. The diameter of these spherical vesicles (circa 10 
$\mu \mathrm{m})$ prevents enclosure of mitochondria or other organelles during vesicle formation and the vesicles therefore are devoid of FA metabolizing enzymes ${ }^{5}$. The giant vesicles are formed from the plasma membrane and, hence, contain membrane-associated FABPs. Giant sarcolemmal vesicles derived from (skeletal) muscle of wild-type and $\mathrm{H}-\mathrm{FABP}^{-/}$mice could be used to explore the involvement of $\mathrm{H}-\mathrm{FABP}$ in (vesicular) uptake of LCFAs.

In conclusion, although aspects of the underlying mechanism are still unresolved, evidence is accumulating that H-FABP is required for bulk utilization of LCFAs by cardiac myocytes.

\section{Directions for future research}

Myocardial LCFA uptake is a complex process requiring translocation of LCFAs across several cellular barriers. Despite the increased awareness of the involvement of a number of distinct membrane-associated and cytoplasmic proteins in this process, exact functions and underlying mechanisms are incompletely understood and require further investigation.

The cloning of rat FATP cDNA allows transfection of isolated cardiac myocytes or muscle-like cell lines in order to study the role of FATP in LCFA utilization by these cells. Recombinant-expressed FATP domains can be used to identify putative fatty acid-binding domains or to study the interaction with H-FABP. Moreover, such fragments can be employed to raise anti-FATP antibodies. When such antibodies are available an ELISA for quantifying FATP protein levels can be developed. This may help to provide more insight into the physiological importance of FATP for myocardial LCFA usage.

The three membrane-associated FABPs, i.e. FATP, FAT/CD36, and $\mathrm{FABP}_{\mathrm{pm}}$, are each present in cardiac tissue and appear to be coordinately expressed ${ }^{22}$. It is tempting to speculate that these proteins form a functional unit involved in the various steps of sarcolemmal LCFA translocation, e.g. trapping of extracellular LCFAs, transmembrane movement of LCFAs, and transfer of LCFAs to cytoplasmic H-FABP. Antibodies raised against the respective proteins may be helpful in defining the individual relevance of these proteins to cardiac LCFA uptake, and can be employed to study the possible existence of a multimeric FA translocation complex by means of immunoprecipitation.

Albumin-binding proteins are expressed at the surface of endothelial cells and cardiac myocytes ${ }^{13,17}$ (Figure 7.1). Biochemically these proteins are poorly characterized and their relevance for cellular FA uptake is unclear ${ }^{12}$. To learn more about the role of ABPs in this process, cellular LCFA uptake could be studied by presenting cardiac myocytes similar non-protein-bound LCFA concentrations complexed to either albumin or H-FABP. For this purpose, purified recombinant H-FABP, which is easily obtained in vast amounts, can be employed. 
For the future use of $\mathrm{H}-\mathrm{FABP}^{-/}$cardiac myocytes to study myocardial LCFA utilization, it is highly desirable that the method for isolating these cells from mouse hearts is further refined. For example, relatively large amounts of cells are required to study the metabolic fate (incorporation into triacylglycerols and phospholipids vs. utilization in the oxidative pathway) of radiolabeled FAs. As noted above, to define the precise role of H-FABP in cellular FA uptake, giant sarcolemmal vesicles can be prepared from muscles of wild-type and of H-FABP nullizygous mice. Finally, comparison of the proteome of wild-type and $\mathrm{H}-\mathrm{FABP}^{-/}$mice may identify proteins which are differentially, and possibly compensatorily, expressed ( $c f$. reference 9 ).

During prolonged ischemia, cardiac LCFA oxidation is impaired and these compounds readily accumulate in the cytoplasm of the cardiac myocyte ${ }^{18,19}$. The cytoplasmic LCFA levels even further increase following reperfusion. Elevated concentration of LCFAs in cardiac tissue are implicated in destabilization of cellular membranes and inhibition of certain enzymes. H-FABP has been implicated in protecting cells against such detergent-like effects of LCFAs ${ }^{7}$. To test this hypothesis, hearts from wild-type and H-FABP nullizygous mice perfused in working-heart mode, should be subjected to an ischemia/ reperfusion protocol.

H-FABP belongs to the family of intracellular lipid binding proteins (iLBPs). The evolutionary relationships between iLBPs were reconstructed using phylogenetic methods. Future availability of new iLBP sequences from non-mammalian origin allows to determine substitution rates over a longer time period and will thus improve the accuracy of estimated gene duplication times. The amino acid sequence of the ancestral iLBP protein was inferred and allows experiments to test the hypothesis that specialized binding properties arose during evolution of the iLBP family. Random mutagenesis of residues at the center of the binding site of bilin-binding protein (a lipocalin) was recently shown to alter the binding-specificity from bilin to fluorescein ${ }^{3}$.

\section{Concluding remarks}

With the use of transgenic animals, a powerful methodology is available for studying physiological processes in vivo and ex vivo. Cardiac myocytes isolated from H-FABP knock-out mice were used to convincingly demonstrate the role of H-FABP in myocardial LCFA consumption, a function which had been supposed so long. From our initial findings, many intriguing questions arose which will be addressed in the near-future. 


\section{References}

1) Antohe F, Popov D, Radulescu L, Simionescu N, Börchers T, Spener F, and Simionescu M: Heart microvessels and aortic endothelial cells express the 15 kDa heart-type fatty acid-binding protein. Eur J Cell Biol 76:102-109(1998)

2) Antozzi $\mathrm{C}$ and Zeviani $\mathrm{M}$ : Cardiomyopathies in disorders of oxidative metabolism. Cardiovasc Res 35:184-199 (1997)

3) Beste G, Schmidt FS, Stibora T, and Skerra A: Small antibody-like proteins with prescribed ligand specificities derived from the lipocalin fold. Proc Natl Acad Sci U S A 96:1898-1903 (1999)

4) Binas B, Danneberg H, McWhir J, Mullins L, and Clark AJ: Requirement for the heart-type fatty acid-binding protein in cardiac fatty acid utilization. Faseb $J$ 13:805-812 (1999)

5) Bonen A, Luiken JJFP, Liu S, Dyck DJ, Kiens B, Kristiansen S, Turcotte LP, van der Vusse GJ, and Glatz JFC: Palmitate transport and fatty acid transporters in red and white muscles. Am J Physiol 275:E471-478(1998)

6) Depré C, Shipley GL, Chen W, Han Q, Doenst T, Moore ML, Stepkowski S, Davies PJ, and Taegtmeyer $\mathrm{H}$ : Unloaded heart in vivo replicates fetal gene expression of cardiac hypertrophy. Nat Med 4:1269-1275 (1998)

7) Glatz JFC and van der Vusse GJ: Cellular fatty acid-binding proteins: their function and physiological significance. Prog Lipid Res 35:243-282 (1996)

8) Glatz JFC, Luiken JJFP, van Nieuwenhoven FA, and van der Vusse GJ: Molecular mechanism of cellular uptake and intracellular translocation of fatty acids. Prostaglandins Leukot Essent Fatty Acids 57:3-9 (1997)

9) Heinke MY, Wheeler CH, Chang D, Einstein R, Drake-Holland A, Dunn MJ, and dos Remedios CG: Protein changes observed in pacing-induced heart failure using two-dimensional electrophoresis. Electrophoresis 19:2021-2030(1998)

10) Herr FM, Aronson J, and Storch J: Role of portal region lysine residues in electrostatic interactions between heart fatty acid-binding protein and phospholipid membranes. Biochemistry 35:1296-1303(1996)

11) Luiken JJFP, van Nieuwenhoven FA, America G, van der Vusse GJ, and Glatz JFC: Uptake and metabolism of palmitate by isolated cardiac myocytes from adult rats: involvement of sarcolemmal proteins. J Lipid Res 38:745-758 (1997)

12) Luiken JJFP, Schaap FG, van Nieuwenhoven FA, van der Vusse GJ, and Glatz JFC: Cellular fatty acid transport in heart and skeletal muscle as facilitated by proteins. Lipids, in press (1999)

13) Popov D, Hasu M, Ghinea N, Simionescu N, and Simionescu M: Cardiomyocytes express albumin binding proteins. $J$ Mol Cell Cardiol 24:989-1002(1992)

14) Schaffer JE and Lodish HF: Molecular mechanism of long-chain fatty acid uptake. Trends Cardiovasc Med 5:218-224 (1995)

15) Spitsberg VL, Matitashvili E, and Gorewit RC: Association and co-expression of fatty acid-binding protein and glycoprotein CD36 in the bovine mammary gland. Eur J Biochem 230:872-878(1995)

16) Storch J, Herr FM, Kuo TH, Hye KK, Heng LL, and Smith ER: The role of membranes and intracellular binding proteins in cytoplasmic transport of hydrophobic molecules: fatty acid-binding proteins. Comp Biochem Physiol B Bioch Mol Biol 115:333-339(1996) 
17) Tiruppathi $\mathrm{C}$, Finnegan $\mathrm{A}$, and Malik $\mathrm{AB}$ : Isolation and characterization of a cell surface albumin binding protein from vascular endothelial cells. Proc Natl Acad Sci $U S A$ 93:250-254 (1996)

18) van der Vusse GJ, Roemen TH, Prinzen FW, Coumans WA, and Reneman RS: Uptake and tissue content of fatty acids in dog myocardium under normoxic and ischemic conditions. Circ Res 50:538-546(1982)

19) van der Vusse GJ, Glatz JFC, Stam HC, and Reneman RS: Fatty acid homeostasis in the normoxic and ischemic heart. Physiol Rev 72:881-940 (1992)

20) van der Vusse GJ and Roemen TH: Gradient of fatty acids from blood plasma to skeletal muscle in dogs. J Appl Physiol 78:1839-1843(1995)

21) van der Vusse GJ, Glatz JFC, van Nieuwenhoven FA, Reneman RS, and Bassingthwaighte JB: Transport of long-chain fatty acids across the muscular endothelium. Adv Exp Med Biol 441:181-191 (1998)

22) van Nieuwenhoven FA, Willemsen PHM, van der Vusse GJ, and Glatz JFC: Co-expression in rat heart and skeletal muscle of four genes coding for proteins implicated in long-chain fatty acid uptake. Int J Biochem Cell Biol 31:489-98 (1999)

23) Vork MM, Glatz JFC, and van der Vusse GJ: On the mechanism of long-chain fatty acid transport in cardiomyocytes as facilitated by cytoplasmic fatty acid-binding protein. J Theor Biol 160:207-222 (1993)

24) Vork MM, Glatz JFC, and van der Vusse GJ: Modeling intracellular fatty acid transport: possible mechanistic role of cytoplasmic fatty acid-binding protein. Prostaglandins Leukot Essent Fatty Acids 57:11-16 (1997) 
SUMmaRY

Summary | 123 
Contraction of the heart generates the pressure for adequate blood flow through the circulatory system. In this regard, the heart plays an essential role in delivering nutrients and oxygen to organs, and in removing cellular waist products. Cardiac force is developed by myocytes which use ATP for contraction and relaxation of the myofibrils. Cardiac myocytes preferentially use long-chain fatty acids (LCFAs) as a substrate for energy production, i.e. ATP regeneration.

Although LCFAs are essentially insoluble in aqueous solution, these compounds are found to be extracted with high efficiency from the coronary circulation. Proteins capable of binding LCFAs are implicated in the transport of LCFAs in the vascular compartment, and in the various transport steps which precede the oxidation of LCFAs in the mitochondria of the cardiac myocyte. While albumin is the fatty acid carrier in blood plasma and the interstitium, both translocation of LCFAs across the cellular membrane and transfer of LCFAs through the cytoplasmic compartment are thought to be mediated by membrane-associated and cytoplasmic fatty acid-binding proteins (FABPs), respectively. The studies described in this thesis sought to determine the role of cytoplasmic FABP for the cardiac myocyte.

A brief introduction to cardiac LCFA utilization and an outline of the thesis are presented in Chapter 1. Prior to mitochondrial oxidation in the cardiac myocyte, LCFAs must pass several cellular barriers and aqueous compartments. Long-thought to result from simple, passive diffusion through the membrane phospholipid bilayer, LCFAs are now known to be taken up by cells through a carrier-mediated mechanism as well. In the heart, three membrane-associated FABPs, including fatty acid-transport protein (FATP), have been implicated in carrier-mediated translocation of LCFAs across the cell membrane. In the cardiac myocyte, cytoplasmic heart-type FABP (H-FABP) is thought to facilitate the cellular uptake and intracellular transport of LCFAs. The hypothesized roles of membrane-associated FABPs and of H-FABP in cardiac LCFA utilization are reviewed in Chapter 2.

$\mathrm{H}-\mathrm{FABP}$ is a member of the family of intracellular lipid-binding proteins (iLBPs) whose expression appears restricted to higher eukaryotes. Reconstruction of the evolution of this protein family (Chapter 3 ) suggests that an ancestral iLBP gene arose at least 950 millions of years ago. Duplication of such ancestral gene and diversification of the products eventually gave rise to the 14 iLBP types currently found in vertebrates. Phylogenetic analysis revealed the presence of four groups of iLBPs with distinct ligand-binding properties. Different iLBPs may have evolved to accomplish cytoplasmic transport of a range of distinct hydrophobic compounds.

For studying the role of H-FABP in vitro, two new methods have been developed (Chapter 4). A chromatographic procedure was designed to obtain vast amounts of pure H-FABP. For this purpose, rat H-FABP was expressed in Escherichia coli. Using anion exchange chromatography of cell lysates, rat H-FABP could be purified to homogeneity in a single step. This high-level recombinant 
expression and simple purification strategy readily yields sufficient quantities of pure rat $\mathrm{H}$-FABP (30-40 mg per liter culture) for in vitro studies.

With the availability of $\mathrm{H}$-FABP nullizygous mice, a method for isolating adult mouse cardiac myocytes was highly desirable. Published protocols for obtaining these cells from mouse heart appeared to yield insufficient amounts of cells for metabolic studies. The newly-developed method (Chapter 4) allows the isolation of relatively large amounts of cardiac myocytes (40-50 mg cellular mass per adult mouse heart). Cell preparations contain on average $45 \%$ viable cells as based on morphology and dye exclusion. Moreover, these cells show rhythmical contractions upon electrical stimulation.

Rat FATP cDNA was cloned to initiate studies on the role of this integral membrane protein in myocardial LCFA uptake (Chapter 5). The deduced amino acid sequence of rat FATP was found to be highly homologous with mouse FATP $(97 \%$ amino acid identity), and comparison with putative orthologues from more distantly related species revealed several highly conserved regions. One of these, the so-called AMP-binding domain motif, which is frequently found in enzymes forming an adenylated intermediate as part of their catalytic cycle, is fully conserved between rat FATP and the putative yeast orthologue. Assuming that the AMP-binding domain resides on a cytoplasmic segment of the protein, two models depicting the membrane topology of rat FATP were created.

Cardiac LCFA utilization was studied in mice with a disrupted H-FABP gene (Chapter 6). Hearts of $\mathrm{H}-\mathrm{FABP}^{-/}$mice expressed wild-type levels of mRNAs coding for sarcolemmal LCFA transporters, and in studies on heart homogenates it was found that these mice maintained the full capacity to oxidize octanoate and palmitate. Furthermore, the absence of $\mathrm{H}-\mathrm{FABP}$ in hearts of $\mathrm{H}-\mathrm{FABP}^{-/}$mice was not counteracted by expression of other FABP types, and did not evoke subcellular relocalization of mitochondria. This inventory indicated that adaptations to compensate the absence of $\mathrm{H}-\mathrm{FABP}$ in hearts of $\mathrm{H}-\mathrm{FABP}^{-/}$mice did most likely not occur, making these mice particularly suitable for studying the role of H-FABP in myocardial LCFA consumption. To this end, both uptake and oxidation of fatty acids by isolated cardiac myocytes was studied.

$\mathrm{H}-\mathrm{FABP}^{-/ 2}$ cardiac myocytes showed a diminished rate of palmitate uptake $(-45 \%)$ and palmitate oxidation $(-45 \%)$ when compared with wild-type cells. The effect appeared specific for LCFAs, as the rate of uptake of the medium-chain fatty acid octanoate was identical in wild-type and $\mathrm{H}-\mathrm{FABP}^{-/}$cardiac myocytes. Moreover, contracting wild-type cardiac myocytes attained an elevated rate $(+95 \%)$ of palmitate oxidation when compared with quiescent cells, while $\mathrm{H}-\mathrm{FABP}^{-/}$cardiac myocytes were unable to achieve a higher rate of palmitate oxidation following electrical stimulation. 
Because the absence of H-FABP was apparently not compensated, these experiments indicate that H-FABP mediates the uptake and oxidation of LCFAs by cardiac myocytes. Hence, H-FABP is facilitating bulk transport of LCFAs in the cytoplasmic compartment of the cardiac myocyte. The absence of $\mathrm{H}-\mathrm{FABP}$ in $\mathrm{H}-\mathrm{FABP}^{-/}$cardiac myocytes limits their extent to utilize LCFAs. For their energy production, these cells may depend more heavily on carbohydrates, as suggested by an increased rate of glucose oxidation by $\mathrm{H}-\mathrm{FABP}^{-/}$cardiac myocytes $(+80 \%)$ and an elevated cardiac glycogen content $(+60 \%)$, when compared with wild-type cells or hearts.

A general discussion of the studies described in this thesis, including a recapitulation of significant findings, and possible directions for future investigations, are given in Chapter 7. 
SAMENVATtinG 
Door samentrekking van de hartspier kan bloed door het bloedvatstelsel stromen. Het bloed bevat ondermeer rode bloedcellen, met daarin eiwitten bevatten die zuurstof en koolstofdioxide (een afvalproduct) binden, en voedingsstoffen zoals glucose en vetzuren. Het hart speelt dus een essentiële rol bij de toevoer van voedingsstoffen en zuurstof naar organen, en de afvoer van aldaar gevormde stofwisselingsproducten. Het samentrekken van het hart wordt mogelijk gemaakt door contractie van de hartspiercellen (cardiomyocyten). Hiertoe gebruiken deze cellen de energie-rijke verbinding ATP om de contractiele eiwitten te laten samentrekken en te ontspannen. Tijdens dit proces wordt ATP omgezet in de energie-arme verbinding ADP. De energie die nodig is om ATP uit ADP te regenereren wordt verkregen door voedingsstoffen te verbranden (oxidatie). Hartspiercellen gebruiken hiertoe bij voorkeur lang-ketenige vetzuren (LCFAs, long-chain fatty acids).

LCFAs zijn zeer slecht oplosbaar in waterig milieu zoals het bloed. Toch worden deze verbindingen met grote efficiëntie opgenomen vanuit de kransslagaderen (de bloedvaten die het hart van bloed voorzien). Voordat LCFAs verbrand worden in de mitochondria (de 'energiecentrales') van de cardiomyocyt, moeten deze verbindingen een aantal cellulaire barrières, zoals de endotheel cellaag van de haarvaten, en een aantal waterige compartimenten, zoals het cytoplasma van de cardiomyocyt, passeren. Eiwitten, die in staat zijn LCFAs te binden, worden verondersteld betrokken te zijn bij de diverse stappen in dit proces. Het plasma eiwit albumine transporteert LCFAs in het bloed en in de interstitiële vloeistof, terwijl het transport van LCFAs over de celmembraan én het transport van LCFAs door de celvloeistof (cytoplasma) waarschijnlijk gemedieerd worden door vetzuur-bindende eiwitten (FABPs, fatty acid-binding proteins) die respectievelijk geassocieerd zijn met de celmembraan of in het cytoplasma voorkomen. De studies die in dit proefschrift beschreven worden, hadden tot doel de fysiologische rol van cytoplasmatisch FABP voor de hartspiercel vast te stellen.

Een beknopte inleiding in het gebruik van LCFAs door de hartspier, alsmede de opzet van dit proefschrift worden besproken in Hoofdstuk 1. Passieve diffusie van LCFAs door de fosfolipide bi-laag werd lang gezien als het mechanisme verantwoordelijk voor de cellulaire opname van LCFAs. Recent is aangetoond dat eiwit-gemedieerde opname van vetzuren eveneens een belangrijke rol speelt in dit proces. In het hart zijn drie membraan-geassocieerde eiwitten aangetroffen, waaronder FATP (fatty acid-transport protein, vetzuur-transporterend eiwit), die waarschijnlijk een rol spelen bij eiwit-gemedieerde translocatie van LCFAs over de celmembraan. Daarnaast komt in het cytoplasma van de cardiomyocyt een eiwit voor (H-FABP, hart-type FABP) dat mogelijk zowel de cellulaire opname van LCFAs als het intracellulaire transport van LCFAs bevordert. In Hoofdstuk 2 wordt een overzicht gegeven van de mogelijke rollen die membraan-geassocieerde FABPs en H-FABP spelen bij de opname en het gebruik van vetzuren door het hart. 
H-FABP behoort tot de familie van intracellulaire lipide-bindende eiwitten (iLBPs). Deze eiwitten komen, voor zover nu bekend is, alleen voor in hogere eukaryoten (gewervelde en ongewervelde dieren). De evolutie van de iLBP familie is gereconstrueerd (Hoofdstuk 3) en laat zien dat een gemeenschappelijk iLBP gen minimaal 950 miljoen jaar geleden is ontstaan. Door duplicatie van dit oergen en ontstaan van verscheidenheid in de gedupliceerde genen, ontstonden uiteindelijk de 14 verschillende iLBP types die momenteel geïdentificeerd zijn in gewervelde dieren. De 14 iLBP types zijn onder te verdelen in vier groepen die elk een karakteristieke reeks liganden kunnen binden. Mogelijk zijn de diverse iLBP types ontstaan om cytoplasmatisch transport van een breed scala aan hydrofobe ('vet-achtige') verbindingen te bewerkstelligen.

Om de rol van H-FABP in vitro te kunnen bestuderen zijn twee nieuwe technieken ontwikkeld (Hoofdstuk 4). Allereerst is een chromatografische methode opgezet om relatief grote hoeveelheden zuiver H-FABP te verkrijgen. Hiertoe is rat $\mathrm{H}-\mathrm{FABP}$ cDNA tot expressie gebracht in de bacterie Escherichia coli. Met behulp van anion-uitwisselings chromatografie van cellysaten, kon rat H-FABP in één stap worden opgezuiverd. De combinatie van recombinant expressie en een efficiënte zuiveringsprocedure levert op eenvoudige wijze relatief grote hoeveelheden zuiver rat H-FABP (30-40 mg per liter medium) voor in vitro onderzoek.

Recent zijn door onderzoekers in Berlijn muizen ontwikkeld die de genetische informatie missen om H-FABP te kunnen maken (zogenaamde H-FABP knock-out muizen). Om de functie van H-FABP te kunnen bestuderen is een protocol ontwikkeld om cardiomyocyten te isoleren uit het hart van volwassen muizen. De in de literatuur beschreven methodiek leverde namelijk te weinig cellen op om metabole studies te kunnen verrichten. De nieuw ontwikkelde techniek (Hoofdstuk 4) maakt het mogelijk om relatief grote hoeveelheden cardiomyocyten te isoleren (ongeveer 40-50 mg cellen per muizenhart). Op grond van morfologische kenmerken en het buitensluiten van een kleurstof, blijken de verkregen preparaten gemiddeld $45 \%$ intacte cellen te bevatten. Als de cellen electrisch geprikkeld worden gaan ze bovendien samentrekken.

Om in de toekomst de interactie tussen H-FABP en het integrale membraan eiwit FATP in relatie tot vetzuurgebruik door het hart nader te kunnen bestuderen, is rat FATP cDNA gecloneerd (Hoofdstuk 5). De van het cDNA afgeleide eiwitsequentie laat zien dat rat FATP grote homologie vertoont met muis FATP $(97 \%$ identieke aminozuren). Door rat FATP te vergelijken met orthologe eiwitten uit ver verwante organismen zijn sterk geconserveerde domeinen waargenomen. Eén van deze domeinen, het zogenaamde AMP-bindend motief, is volledig geconserveerd tussen rat FATP en het vermoedelijke gist FATP ortholoog. Het AMP-bindend motief wordt vaak aangetroffen in enzymen die een geadenyleerd tussenproduct vormen als onderdeel van hun katalytisch mechanisme. Ervan uitgaande dat dit domein een cytoplasmatische localisatie heeft, zijn twee modellen voor de membraantopologie van rat FATP opgesteld. 
In studies beschreven in Hoofdstuk 6 is het gebruik van LCFAs door het hart in

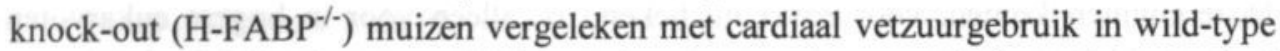
muizen. mRNA niveaus van sarcolemmale vetzuurtransporters bleken niet veranderd te zijn in hartweefsel van $\mathrm{H}-\mathrm{FABP}^{-/}$muizen, evenals de capaciteit van $\mathrm{H}-\mathrm{FABP}^{-/}$ harthomogenaten om octanoaat en palmitaat te oxideren. De afwezigheid van H-FABP in $\mathrm{H}-\mathrm{FABP}^{-/}$hartweefsel resulteerde niet in de expressie van andere FABP types, en bracht geen verandering teweeg in de subcellulaire localisatie van mitochondria. Het schijnbaar ontbreken van aanpassingen die de afwezigheid van H-FABP compenseren, maakt de H-FABP knock-out muis uiterst geschikt om de functie van H-FABP in het vetzuurgebruik door het hart te kunnen bestuderen.

Met dit doel voor ogen is de opname en oxidatie van vetzuren door geïsoleerde cardiomyocyten onderzocht. In vergelijking met wild-type cellen blijken $\mathrm{H}-\mathrm{FABP}^{-/}$ cardiomyocyten verminderd $(-45 \%)$ in staat palmitaat op te nemen én te oxideren. Dit effect was specifiek voor lang-ketenige (water onoplosbare) vetzuren, daar de opname van het middellang-ketenige (water oplosbare) vetzuur octanoaat even efficiënt verliep in controle en $\mathrm{H}-\mathrm{FABP}^{-/}$cardiomyocyten. Contraherende cellen van wild-type muizen vertoonden een verhoogde oxidatie van palmitaat $(+95 \%)$ ten opzichte van rustende cellen, maar electrische stimulatie van $\mathrm{H}_{-}-\mathrm{FABP}^{-/}$cardiomyocyten resulteerde niet in een verhoogde LCFA oxidatie.

Deze experimenten laten zien dat H-FABP betrokken is bij de opname en oxidatie van LCFAs door cardiomyocyten. Omdat compenserende mechanismen blijkbaar ontbreken, kan geconcludeerd worden dat H-FABP bulk transport van LCFAs in het cytoplasmatische compartiment van de cardiomyocyt bevordert. De afwezigheid van $\mathrm{H}-\mathrm{FABP}$ in $\mathrm{H}-\mathrm{FABP}^{-/}$cardiomyocyten beperkt de mate van vetzuurgebruik in deze cellen. De verhoogde oxidatie van glucose door $\mathrm{H}-\mathrm{FABP}^{-/}$ cardiomyocyten $(+80 \%)$ en het hogere gehalte aan glycogeen (de tijdelijke opslagvorm van glucose) in $\mathrm{H}_{-\mathrm{FABP}}{ }^{-/}$hartweefsel $(+60 \%)$, suggereert dat $\mathrm{H}-\mathrm{FABP}^{-/}$ cardiomyocyten voor hun energievoorziening meer gebruik maken van koolhydraten.

Het proefschrift wordt afgesloten met een algemene discussie (Hoofdstuk 7). De belangrijkste bevindingen worden besproken en er worden aanbevelingen gedaan voor vervolgonderzoek. 
Publications 
Schaap FG, Specht B, van der Vusse GJ, Börchers T, and Glatz JFC: One-step purification of rat heart-type fatty acid-binding protein expressed in Escherichia coli. J Chromatogr B Biomed Appl 679:61-7 (1996)

Glatz JFC, van Nieuwenhoven FA, Luiken JJFP, Schaap FG, and van der Vusse GJ: Role of membrane-associated and cytoplasmic fatty acid-binding proteins in cellular fatty acid metabolism. Prostaglandins Leukot Essent Fatty Acids 57:373-8 (1997)

Schaap FG, Hamers L, van der Vusse GJ, and Glatz JFC: Molecular cloning of fatty acid-transport protein cDNA from rat. Biochim Biophys Acta 1354:29-34 (1997)

Schaap FG, van der Vusse GJ, and Glatz JFC: Fatty acid-binding proteins in the heart. Mol Cell Biochem 180:43-51 (1998)

Luiken JJFP, Schaap FG, van Nieuwenhoven FA, van der Vusse GJ, and Glatz JFC: Cellular fatty acid transport in heart and skeletal muscle as facilitated by proteins. Lipids, in press (1999)

Schaap FG, Binas B, Danneberg H, van der Vusse GJ, and Glatz JFC: Impaired long-chain fatty acid utilization by cardiac myocytes isolated from mice lacking the H-FABP gene. Circ Res, under revision

Schaap FG, van der Vusse GJ, and Glatz JFC: Evolution of the family of intracellular lipid binding proteins in vertebrates. submitted for publication 
Schaap FG, van der Vusse GJ, and Glatz JFC: One-step purification of rat heart-type fatty acid-binding protein expressed in E. coli. Eur $J$ Physiol - Pflügers Archiv 430:R148 (1995)

Presented at the $1^{\text {st }}$ FEPS Congress (Maastricht, The Netherlands, 1995)

Schaap FG, Hamers L, van der Vusse GJ, and Glatz JFC: Molecular cloning of fatty acid-transport protein (FATP) cDNA from rat. Abstracts of the $3^{\text {rd }}$ International Conference on Lipid Binding Proteins (1997)

Presented at the $3^{\text {rd }}$ International Conference on Lipid Binding Proteins (Minneapolis, USA, 1997)

Schaap FG, van der Vusse GJ, and Glatz JFC: Evolutionary relationships of cytoplasmic fatty acid-binding proteins in vertebrates. Abstracts of the $3^{\text {rd }}$ International Conference on Lipid Binding Proteins (1997)

Presented at the $3^{\text {rd }}$ International Conference on Lipid Binding Proteins (Minneapolis, USA, 1997)

Schaap FG, Danneberg H, Binas B, van der Vusse GJ, and Glatz JFC: Impaired uptake and oxidation of long-chain fatty acids by cardiac myocytes of mice lacking heart-type fatty acid-binding protein (H-FABP). Chem Phys Lipids 94:159 (1998) Presented at the $39^{\text {th }}$ ICBL (Davos, Switzerland, 1998)

Glatz JFC, Schaap FG, Binas B, Danneberg H, Luiken JJFP, Bonen A, and van der Vusse GJ: Significance of fatty acid-binding proteins for myocardial metabolism in health and disease. Jpn Circ J 63:S105 (1999)

Presented at the $63^{\text {rd }}$ annual scientific meeting of the Japanese Circulation Society (Tokyo, Japan, 1999)

Schaap FG, Binas B, Danneberg H, van der Vusse GJ, and Glatz JFC: Impaired longchain fatty acid utilization by cardiac myocytes from mice lacking the heart-type FABP gene. J Mol Cell Cardiol, in press (1999)

Presented at the $20^{\text {th }}$ ISHR conference (Maastricht, The Netherlands, 1999) 


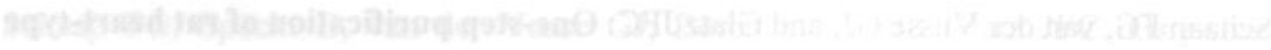

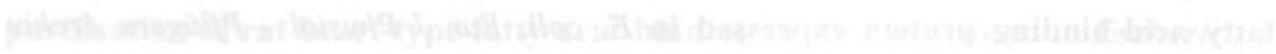




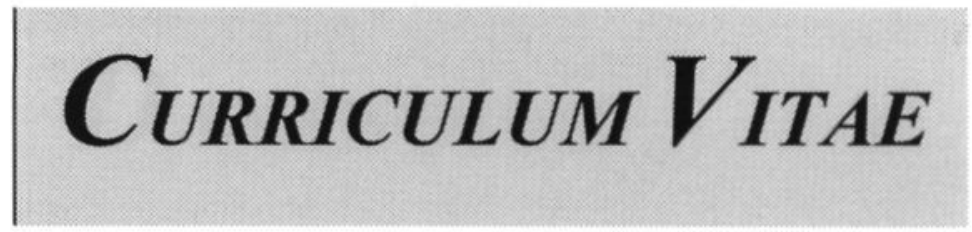




\section{Curriculum vitae}

The author of this thesis was born on the $11^{\text {th }}$ of June, 1968, in Zaandam, The Netherlands. He obtained a B.Sc. degree in Biochemistry at the Technical College of Alkmaar (1985-1989), and received a M.Sc. degree in Biochemistry and Molecular Biology at the Free University of Amsterdam (1989-1992). Following fulfilment of his military service (1992-1993), he worked as research scientist at the Department of Biochemistry and Molecular Biology, Free University of Amsterdam, studying structure-function relationships of $18 \mathrm{~S}$ ribosomal RNA in Saccharomyces cerevisiae (1993-1994). His Ph.D. study (1994-1998) was then undertaken at the Department of Physiology, Maastricht University, and involved the study of the physiological role of cytoplasmic fatty acid-binding protein (FABP) for the cardiac myocyte. During his thesis work, a short visit was paid to the laboratory of Professor A. Bonen, Waterloo University, Canada, to learn a technique for isolating giant sarcolemmal vesicles. His experimental work was presented at both focused FABP meetings and at international conferences. At present, he is working as post-doc at the Department of Gastroenterology, Academic Medical Center, Amsterdam, where he is involved in studying the molecular mechanisms underlying biliary cholesterol secretion. 
DANKWOORD 
Wetenschappelijk onderzoek en deadlines lijken wel even onlosmakelijk met elkaar verbonden als biotine en avidine. Met de hete adem van het tijdsduiveltje én de drukker in mijn nek, begin ik dan ook aan de laatste bladzijden van mijn proefschrift. Op voorhand wil ik een ieder bedanken die, direct of indirect, heeft bijgedragen aan de totstandkoming van mijn proefschrift.

Beste Jan, als dagelijks begeleider stond jouw deur altijd wijd open om de meest recente resultaten te vernemen of nieuwe onderzoeksstrategiën te bespreken, en was je altijd bereid om direct naar het lab te komen om contraherende myocyten, gelletjes, of 'piekjes' te komen bekijken. Jouw grote betrokkenheid bij het onderzoek en grote enthousiasme voor alle bevindingen (zowel positieve als negatieve resultaten) heeft zeer inspirerend gewerkt. De vrijheid die je me geboden hebt om nieuwe onderzoeksrichtingen in te slaan, heb ik erg op prijs gesteld. Met veel genoegen denk ik nog terug aan de bijzondere treinreis naar de FABP mini-workshop te Genève, en aan onze experimentele samenwerking bij de laatste serie knock-out muizen waarbij je op een goede dag -enigszins verbouwereerd- constateerde dat het betrokken exemplaar 'blijkbaar een mannetje' was.

Beste Ger, van jou heb ik geleerd om kritisch te kijken naar eigen resultaten en de daaruit voortkomende conclusies eenduidig te formuleren, en om de kern van een wetenschappelijk probleem bloot te leggen. Met plezier denk ik terug aan onze gesprekken over evolutie, Ötzi, films, et cetera, en aan de 'kroegentocht' in Minneapolis (helaas werkte je aldaar ondernomen bemiddelingspoging enigszins averechts).

Jan en Ger, beiden wil ik jullie ook bedanken voor de snelheid waarmee teksten ('kunnen jullie dit nog even nakijken vóór morgen?') en de laatste maanden, een Heel-Fors Aantal Bladzijden Proefschrift, becommentarieerd werden. Dit was een klassiek voorbeeld van een gefacilieerd proces, waardoor ik in staat was alles nog voor de zomervakantie af te ronden.

I would like to thank the members of the review committee (Prof. Ramaekers, Prof. Bonen, Prof. Reneman, Prof. Spener, and Prof. Zwaal) for reading my thesis.

Dear Arend, thank you for your hospitality during my stay at your laboratory. I hope I will be able to use the vesicle technique in future research.

Toen ik zo'n 5 jaar geleden in Maastricht begon aan mijn promotieonderzoek kwam ik terecht op kamer 3.166. Christine, Henriëtte en Sylvia: dankzij jullie heb ik de AIO-cursus Zwangerschapsfysiologieop de kamer kunnen volgen! Het eens-zo-felomstreden streepjes-systeem heeft nog heel wat gezellige kamer-uitjes (lekker heet eten) voortgebracht. Bedankt voor jullie gezelligheid (en dat ik al jullie telefoontjes mocht aannemen/beantwoorden). Christine en Henriëtte, succes met de afronding van jullie eigen werk. Wat ooit begon als een 'vrouwenkamer' kreeg gaandeweg een internationaler karakter (Anne [nice movie-and-terrace parties], Lilian [eindelijk nog een Westerling op de kamer], Xavier [great climbing-sessions!]), veranderde tijdens de evolutionaire berekeningen in een soort van computer-centrum (Danny en Frans: 
bedankt voor het ongelimiteerde gebruik van jullie snelle PCs), en werd uiteindelijk een mannenkamer waar de aandelenkoersen nauwlettend gevolgd werden. Alle kamergenoten wil ik bedanken voor de ontspannen atmosfeer op de kamer.

Mr. Frans, als wandelende vraagbaak wist je bijna altijd antwoord op de meest uiteenlopende vragen en heb je me veel nieuwe technieken bijgebracht. Bedankt! (ook voor de introductie in Excel, hetgeen toch wel efficiënter bleek te werken dan eigengeschreven rekenprogrammaatjes.) Misschien moeten we over 5 jaar nog eens een follow-up studie houden, om te kijken of je geen schadelijke gevolgen hebt overgehouden aan de legendarische fiets-klassieker Annadal-Randwyck.

Joost 'Hypertroof', als Sneaker-van-het-eerste-uur hebben we heel wat interessante werkbesprekingen gevoerd in De Poshoorn, alwaar ook vele nieuwe projectjes geïnitieerd werden. Bedankt voor je hulp bij het opstarten van de muis cardiomyocyt isolatie procedure, en het mij bijbrengen van de techniek om 'gigantische' sarcolemmale vesicles te isoleren. In Waterloo bleek je tevens over organisatorisch talent te beschikken door vóóraf een 14-dagen-durend stap-schema voor mij samen te stellen.

Frans en Joost, beiden wil ik jullie ook bedanken dat jullie mijn paranimfen willen zijn. Met een wandelende vraagbaak én een body-guard aan mijn zijde kan er weinig meer fout gaan tijdens de verdediging (Joost, voor de zekerheid zal ik het kostuumverhuurbedrijf vragen extra versteviging aan te brengen ter hoogte van de biceps).

De HLO-stagiaires Karel van Dort (het screenen van de cDNA bank verliep moeizaam, maar uiteindelijk zijn we er toch in geslaagd het rat FATP cDNA te cloneren) en Lars Hamers (de mogelijke binding van vetzuren door het $C$-terminale extracellulaire domein van FATP blijft intrigeren) wil ik bedanken voor hun inzet voor mijn onderzoek.

Vele mensen hebben hun experimentele steentje bijgedragen aan de proeven die in mijn proefschrift beschreven zijn: ELISA-specialist Maurice (welk exotisch H-FABP ga je nu bepalen?), 'Northern' Peter, Theo, Mr. Will (How's life?) en Yvonne. Ik ben jullie allen (ook degenen die ik wellicht vergeten ben te vermelden) zeer erkentelijk voor jullie hulp. Paul Bomans en Peter Frederik bedankt voor het uitvoeren van de EM-studies. Het zijn prachtige plaatjes geworden!

Christel, Danny, Joep (FAT: de verademing van de Barbaar?), Karin (ik zal een seintje geven als Gummo-2 in première gaat) en Roy succes met jullie eigen onderzoek. De collega's van de avond-, nacht-, weekend- en feestdagenploeg (Ellen en Martijn), bedankt voor jullie morele steun tijdens de schrijffase van dit proefschrift en succes met jullie eigen boekje. Antoine (plasmide isolatie lukt beter met Bizet op 10), Michael (als ik weer een kratje bier nodig heb, kunnen we dan misschien weer een weddenschap afsluiten?) en alle anderen die hebben bijgedragen aan de prettige sfeer op de diverse labs: het ga jullie goed! 
Met de afronding van mijn promotieonderzoek komt er tevens een einde aan mijn Maastrichtse periode. Buiten het werk om zijn er vele vrienden geweest die deze periode tot een fantastische tijd hebben gemaakt, en die hielpen de wetenschappelijke beslommeringen zo nu en dan te relativeren. Ook jullie hebben een belangrijke bijdrage geleverd aan dit proefschrift. Bedankt voor jullie vriendschap!

Tot slot nog een woord van dank aan mijn vader en moeder. Lieve ouders, bedankt voor jullie onvoorwaardelijke steun tijdens mijn promotieonderzoek en tijdens de laatste hectische fase. Jullie begrip, als ik na twee dagen 'nietsdoen' het gevoel kreeg op hete kolen te zitten en dan weer snel naar Maastricht terug 'moest' om te gaan werken, is erg waardevol geweest. Bedankt dat jullie altijd voor me klaar stonden en voor het vertrouwen dat jullie me hebben gegeven!

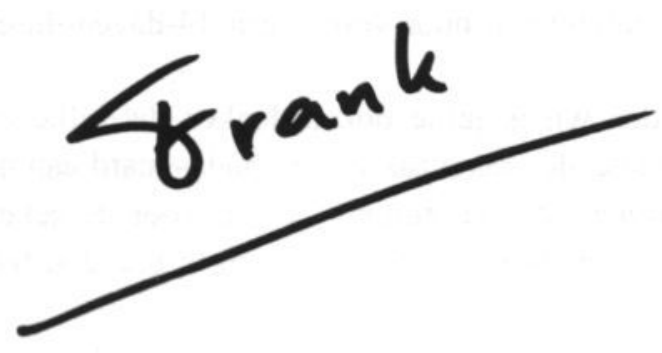



ISBN 90-9012786-0 